\title{
MOSCAS-DAS-FRUTAS (DIPTERA: TEPHRITIDAE) EM POMARES DE GOIABA NO NORTE DE MINAS GERAIS: BIODIVERSIDADE, PARASITÓIDES E CONTROLE BIOLÓGICO.
}

\section{Clarice Diniz Alvarenga Corsato}

Tese apresentada à Escola Superior de Agricultura “Luiz de Queiroz”, Universidade de São Paulo, para obtenção do título de Doutor em Ciências, Área de Concentração: Entomologia.

P I R A C I C A B A

Estado de São Paulo - Brasil

Janeiro - 2004 


\title{
MOSCAS-DAS-FRUTAS (DIPTERA: TEPHRITIDAE) EM POMARES DE GOIABA NO NORTE DE MINAS GERAIS: BIODIVERSIDADE, PARASITÓIDES E CONTROLE BIOLÓGICO.
}

\author{
Clarice Diniz Alvarenga Corsato
}

Engenheiro Agrônomo

Orientador: Prof. Dr. ROBERTO ANTONIO ZUCCHI

Tese apresentada à Escola Superior de Agricultura "Luiz de Queiroz", Universidade de São Paulo, para obtenção do título de Doutor em Ciências, Área de Concentração: Entomologia.

P I R A C I C A B A

Estado de São Paulo - Brasil

Janeiro - 2004 


\section{Dados Internacionais de Catalogação na Publicação (CIP)}

DIVISÃO DE BIBLIOTECA E DOCUMENTAÇÃO - ESALQ/USP

\section{Corsato, Clarice Diniz Alvarenga}

Moscas-das-frutas (Díptera : Tephritidae) em pomares de goiaba no norte de Minas Gerais : biodiversidade, parasitóides e controle biológico / Clarice Diniz Alvarenga Corsato. - - Piracicaba, 2004.

$83 \mathrm{p}$.

Tese (doutorado) - - Escola Superior de Agricultura Luiz de Queiroz, 2004. Bibliografia.

1. Controle biológico (fitossanidade) 2. Goiaba 3. Infestação 4. Moscas-das-frutas 5. Parasitismo I. Título

CDD 634.421

\section{"Permitida a cópia total ou parcial deste documento, desde que citada a fonte - $\mathrm{O}$ autor"}


Aos meus pais: Adejar e Maria Amélia

A quem devo tudo que sou

Agradeço e ofereço.

Ao meu marido: Carlos

Por ter assumido os papéis de pai e mãe

E aos meus queridos filhos: Sofia e Tiago

Pela alegria sempre estampada nos seus olhinhos

Dedico. 


\section{AGRADECIMENTOS}

A Deus, por me dar forças e sabedoria para realizar este trabalho.

Ao Prof. Dr. Roberto Antonio Zucchi, pela orientação, pela oportunidade de trabalhar com este grupo de insetos e por seus exemplos de profissionalismo e dedicação.

Ao Dr. Antônio Souza do Nascimento (EMBRAPA/CNPMF), uma das pessoas que mais acreditou no meu potencial e ampliou minha visão de ciência, além do valioso auxílio prestado durante a elaboração e execução desta pesquisa.

À FAPEMIG - Fundação de Amparo à Pesquisa do Estado de Minas Gerais, pela bolsa concedida.

À UNIMONTES - Universidade Estadual de Montes Claros, por me conceder a oportunidade de realizar meus estudos de Pós-Graduação e o espaço físico para a execução deste trabalho.

A todos os professores do Departamento de Entomologia da ESALQ, pelos ensinamentos transmitidos, em especial ao Prof. Dr. Sinval Silveira Neto, pelos incentivos e auxílio na interpretação dos resultados.

Ao meu marido, Carlos, por não me deixar esmorecer nas dificuldades e agüentar bravamente uma esposa, mãe, profissional e doutoranda muitas vezes preocupada e dividida. 
Aos Eng. Agrônomos Helbert Danilo e Renata Medrado, que quando estagiários do Laboratório de Entomologia (UNIMONTES), deram valiosa colaboração nesta pesquisa.

Aos estudantes, Delmácio, Elisângela, Márcio, Lorena e Neiva, que muito auxiliaram na execução dos trabalhos e à Eng. Agrônoma Eliane Souza Brito, pela dedicação na criação dos insetos. Definitivamente a ajuda dessas pessoas foi de fundamental importância.

Ao Prof. MSc. Carlos Augusto Matrangolo, pela ajuda dedicada e por resolver meus problemas durante minha ausência no laboratório.

Aos produtores: Sr. Waldir e Sr. Antônio Araújo, por permitirem os trabalhos de coletas de frutos em suas propriedades.

Ao Dr. Júlio M. Walder (CENA/USP), pelo fornecimento de pupários de C. capitata e parasitóides e à bióloga Lia (Técnica - Cena) pela presteza no fornecimento deste material.

Aos amigos taxonomistas, por identificarem ou confirmarem a identificação do material coletado: Elton L. Araújo, Jorge A. Guimarães e Miguel de Souza Filho.

A todos os colegas da ESALQ (Entomologia), principalmente aqueles com quem formamos equipe, fizemos disciplina ou simplesmente convivemos, em especial à Teresinha, Ranyse e Cláudia, com quem tive a dádiva de desenvolver uma amizade sólida.

Aos colegas da UNIMONTES, professores e funcionários, que direta ou indiretamente me acompanharam nesta importante etapa da minha vida profissional. 


\section{SUMÁRIO}

\begin{tabular}{|c|c|c|}
\hline & & ágin \\
\hline $\mathrm{DEC}$ & $\mathrm{O}$ & vii \\
\hline SUM & IARY & $\mathrm{x}$ \\
\hline 1 & INTRODUÇÃO.... & 1 \\
\hline 2 & REVISÃO DE LITERATURA... & 3 \\
\hline 2.1 & Moscas-da-frutas........ & 3 \\
\hline 2.1.1 & Aspectos gerais...... & 3 \\
\hline 2.1.2 & Moscas-das-frutas no semi-árido....... & 4 \\
\hline 2.1.3 & Moscas-das-frutas em goiaba.... & 6 \\
\hline 2.1.4 & Análise faunística de moscas-das-frutas.... & 7 \\
\hline 2.1.5 & Flutuação populacional.................. & 8 \\
\hline 2.1.6 & 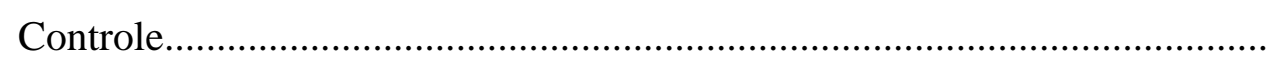 & 11 \\
\hline 2.2 & Inimigos naturais................ & 11 \\
\hline 2.2.1 & Aspectos gerais. & 11 \\
\hline 2.2.2 & Levantamento de espécies, parasitismo e fatores que afetam o nível de & \\
\hline
\end{tabular}

2.2.3 Parasitismo por Diachasmimorpha longicaudata......................................... 15

3 MATERIAL E MÉTODOS.................................................................. 18

3.1 Caracterização da área de estudo................................................................... 18

3.2 Levantamento das espécies de moscas-das-frutas e de seus parasitóides em

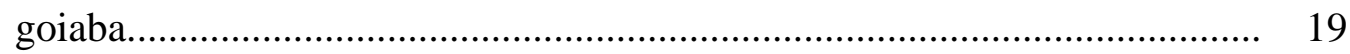

3.3 Identificação das moscas-das-frutas e dos parasitóides................................... 20

3.4 Análise faunística....................................................................................... 21 
3.5 Flutuação de populações nativas de tefritídeos em pomares de goiaba......... 21

3.6 Índice de infestação de moscas-das-frutas em goiaba................................. 22

3.7 Liberação e recaptura (capacidade de sobrevivência) do parasitóide exótico Diachasmimorpha longicaudata em goiaba no norte de Minas Gerais

$4 \quad$ RESULTADOS E DISCUSSÃO

4.1 Moscas-das-frutas em pomares de goiaba............................................... 25

4.1.1 Espécies de moscas-das-frutas........................................................... 25

4.1.2 Análise faunística das espécies de Anastrepha.......................................... 34

4.1.3 Flutuação das populações de tefritídeos em pomares de goiaba................... 36

4.2 Índices de infestação de moscas-das-frutas em goiaba............................... 45

4.3 Parasitóides de larvas/pupas de moscas-das-frutas em goiaba...................... 51

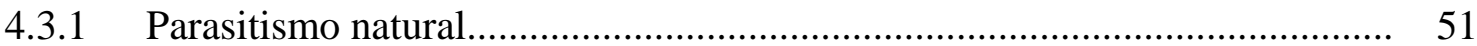

4.3.2 Liberação e recaptura (capacidade de sobrevivência) do parasitóide exótico Diachasmimorpha longicaudata................................................ 54

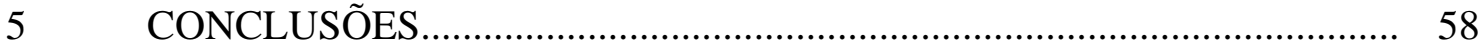

REFERÊNCIAS BIBLIOGRÁFICAS............................................................ 60

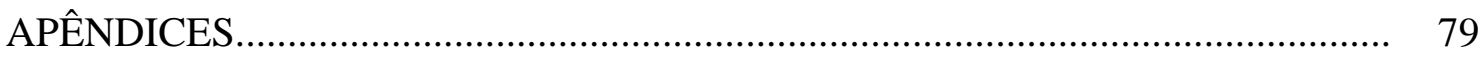




\title{
MOSCAS-DA-FRUTAS (DIPTERA: TEPHRITIDAE) EM POMARES DE GOIABA NO NORTE DE MINAS GERAIS: BIODIVERSIDADE, PARASITÓIDES E CONTROLE BIOLÓGICO
}

\author{
Autora: CLARICE DINIZ ALVARENGA CORSATO \\ Orientador: Prof. Dr. ROBERTO ANTONIO ZUCCHI
}

\section{RESUMO}

A incidência de moscas-das-frutas é um fator de preocupação todos os anos nos perímetros irrigados do norte de Minas Gerais, principalmente em pomares de goiaba, acarretando aumentos nos custos e perdas na produção. Para se estabelecer um programa de controle de moscas-das-frutas, torna-se necessário o prévio conhecimento dos aspectos ecológicos dos tefritídeos e seus parasitóides. Portanto, o presente trabalho teve por objetivo conhecer a biodiversidade de moscas-das-frutas e de seus parasitóides em dois pomares comerciais de goiaba da região, os índices de infestação das moscas-dasfrutas e a capacidade de Diachasmimorpha longicaudata parasitar moscas-das-frutas em goiaba no norte de Minas Gerais. Após três anos de coletas, em armadilhas tipo McPhail e em frutos, foram coletados 48.482 tefritídeos, sendo 45.012 exemplares de Anastrepha e 3.470 de Ceratitis capitata. Foram capturadas 18 espécies de Anastrepha, sendo que, A. turpiniae, A. manihoti, A. leptozona e A. barbiellinii estão sendo registradas pela primeira vez no norte de Minas Gerais. A. zenildae e A. fraterculus representaram mais de $90 \%$ de todas as moscas coletadas em armadilhas, sendo associadas às classes “super” de dominância, freqüência, abundância e constância. Somente C. capitata, A. 
zenildae, A. fraterculus, A. sororcula, A. obliqua e A. turpiniae emergiram das amostras de frutos. Destas, A. zenildae (58,8\%), A. fraterculus (13,5\%) e C. capitata (20,7\%) corresponderam a 93\% do total de fêmeas coletadas, sendo as responsáveis pelos altos níveis de infestação do pomar de Jaíba. Em Nova Porteirinha, somente três espécies de Anastrepha foram relacionadas aos frutos: A. fraterculus (50,3\%), A. zenildae (37,8\%) e A. obliqua (3,2\%), além de $C$. capitata ( $8,6 \%$ do total de fêmeas). Nos dois pomares, as maiores infestações ocorreram de março a julho/2003, influenciadas principalmente pela disponibilidade de frutos maduros. Ocorreu interação de A. zenildae e A. fraterculus na exploração da goiaba no pomar de Nova Porteirinha. Foi discutida a relação entre percentagem de infestação e intensidade de infestação. O parasitismo natural de moscasdas-frutas em goiabas nos pomares comerciais do norte de Minas Gerais foi muito baixo. Dos 283 parasitóides obtidos, somente o braconídeo Doryctobracon areolatus e três espécimes do eucoilíneo Aganaspis pelleranoi foram registrados. Houve correlação positiva entre o número de adultos de opiíneos e os de Anastrepha spp. Foram recuperados 37 espécimes de D. longicaudata (24 em Jaíba e 13 em Nova Porteirinha), demonstrando que a espécie fechou o ciclo nas condições locais. Assim, D. longicaudata possui chances de se estabelecer na região, sem comprometer as relações tritróficas préexistentes. 


\title{
FRUIT FLIES (DIPTERA: TEPHRITIDAE) IN GUAVA ORCHARDS IN THE NORTH OF MINAS GERAIS STATE: BIODIVERSITY, PARASITOIDS AND BIOLOGICAL CONTROL
}

\author{
Author: CLARICE DINIZ ALVARENGA CORSATO \\ Adviser: Prof. Dr. ROBERTO ANTONIO ZUCCHI
}

\section{SUMMARY}

The occurrence of fruit flies is a factor of concern every year in the irrigated areas in the north of Minas Gerais State, mainly in guava orchards, because they cause increases in the costs and losses in the production. To establish a fruit fly program control, it is necessary the previous knowledge of the ecological aspects of the tephritids and its parasitoids. Therefore, the objective of this work was to know the biodiversity of fruit flies and its parasitoids in two commercial guava orchards, the fruit flies infestation levels and the capacity of Diachasmimorpha longicaudata to parasitize fruit flies in guava in the north of Minas Gerais State. After three years of samplings, with McPhail type traps and on fruits, a total of 48,482 tephritids, was collected being 45,012 specimens of Anastrepha and 3,470 of Ceratitis capitata. Eighteen species of Anastrepha were captured; A. turpiniae, A. manihoti, A. leptozona and A. barbiellinii were registered for the first time in the north of Minas Gerais State. A. zenildae and $A$. fraterculus represented $90 \%$ of all fruit flies collected in traps and were placed in the category "super" of dominancy, frequency, abundance and constancy. Only $C$. capitata, A. zenildae, A. fraterculus, A. sororcula, A. obliqua and A. turpiniae emerged 
from fruits. From these, A. zenildae (58,8\%), A. fraterculus (13,5\%) and C. capitata (20,7\%) corresponded to $93 \%$ of the total females collected, and they caused high infestation levels in the orchard located in Jaiba. In Nova Porteirinha, three species of Anastrepha were associated to A. fraterculus (50,3\%), A. zenildae (37,8\%) and A. obliqua (3,2\%), besides $C$. capitata ( $8.6 \%$ of the total females). In the two orchards, the highest infestation occurred from March to July/2003, influenced mainly by the availability of mature fruits. Interaction of A. zenildae and A. fraterculus occurred in the exploration of guava in the orchard located in Nova Porteirinha. The relationship between infestation percentage and infestation intensity was discussed. The natural parasitism of fruit flies in commercial guava orchards in the north of Minas Gerais State was very low. Of the 283 parasitoids collected, the braconid Doryctobracon areolatus and three specimens of the eucoiline Aganaspis pelleranoi were recorded. There was a positive correlation between the number of adults of braconids and the number of Anastrepha spp. It was recovered 37 specimens of D. longicaudata (24 in Jaiba and 13 in Nova Porteirinha), which revealed that this species completed the cycle under local conditions. Therefore, there is a great success in establishment of $D$. longicaudata in this region without damaging the preexisting tritrophic relations. 


\section{INTRODUÇÃO}

O Norte do Estado de Minas Gerais é uma região que tem se destacado consideravelmente, com um grande crescimento na exploração da fruticultura. A construção de um grande projeto de irrigação e as condições de solo e clima têm favorecido esse aumento da fruticultura na região. Com a ampliação das áreas cultivadas, há o aumento das pragas, inclusive moscas-das-frutas. Esse fenômeno ocorre pelos processos naturais de dispersão, característico de cada espécie, ou também pelo transporte involuntário de frutos infestados de uma região para outra (Morgante, 1991).

A incidência de moscas-das-frutas é um sério problema todos os anos nos perímetros irrigados do norte de Minas Gerais, principalmente em pomares de goiaba, acarretando aumentos nos custos de produção, em razão das freqüentes aplicações de inseticidas e perdas na produção. Além disso, os impactos negativos sobre a entomofauna benéfica com a aplicação de agrotóxicos são significativamente ampliados, pois afetam negativamente as cadeias alimentares e são prejudiciais à saúde humana e ao ecossistema como um todo.

As moscas-das-frutas, além de causarem danos diretos às frutas, constituem-se num dos maiores entraves fitossanitários para a exportação de frutas frescas, visto que os países importadores adotam rígidas medidas quarentenárias. Assim, devido às consideráveis perdas econômicas causadas à fruticultura, o controle dessa praga é de fundamental importância. Em programas de manejo integrado de moscas-das-frutas, o controle biológico assume uma importância cada vez maior. Primeiro, por ser um dos pilares de sustentação de qualquer programa de MIP e segundo, por constituir-se numa das poucas alternativas para o futuro, pois há uma exigência global por alimentos 
isentos de resíduos de agrotóxicos (Aguiar-Menezes \& Menezes, 1997; Campanhola, 1998).

Alguns esforços para aplicar estratégias de controle biológico clássico ou aumentativo têm sido realizados no Brasil (Carvalho et al., 1999). Diachasmimorpha longicaudata (Ashmead), um parasitóide exótico, originário da região indo-filipina, foi recentemente introduzido no Brasil a partir da Flórida e, tem sido liberado massalmente em áreas-pilotos em algumas regiões do País, para controlar populações de Anastrepha spp. (Nascimento et al., 1998).

Para que se estabeleça qualquer programa de controle de moscas-das-frutas, torna-se necessário o prévio conhecimento dos aspectos ecológicos das populações dos tefritídeos e seus parasitóides. Portanto, o presente trabalho visou conhecer a biodiversidade de moscas-das-frutas e de seus parasitóides em dois pomares comerciais de goiaba da região, os índices de infestação das moscas-das-frutas e a capacidade de $D$. longicaudata parasitar moscas-das-frutas em goiaba no norte de Minas Gerais. 


\section{REVISÃO DE LITERATURA}

\subsection{Moscas-das-frutas}

\subsubsection{Aspectos gerais}

Os insetos pertencentes à família Tephritidae são vulgarmente conhecidos como moscas-das-frutas por que suas larvas se desenvolvem especialmente no interior dos frutos, alimentando-se, em geral, de sua polpa. Constitui um importante grupo de pragas da fruticultura mundial, pois se não forem adotadas medidas de controle, podem causar perdas consideráveis na produção de frutas (Morgante, 1991).

A família Tephritidae apresenta ampla distribuição geográfica, com predominância na região Neotropical, apresentando 4.352 espécies agrupadas em 481 gêneros (Norrbom, 2003), dos quais somente cinco são de importância econômica: Anastrepha, Ceratitis, Bactrocera, Rhagoletis e Toxotrypana (White \& Elson-Harris, 1994). No gênero Toxotrypana, a única espécie de importância econômica, T. curvicauda (mosca-da-papaia), não ocorre no Brasil. O gênero Bactrocera está representado por uma única espécie, B. carambolae (mosca-da-carambola), recentemente introduzida e restrita ao Oiapoque (AP) (Zucchi, 2000a). As quatro espécies de Rhagoletis registradas no Brasil têm pouca importância agrícola, pois são referidas como pragas esporádicas na região Sul (Zucchi, 2000a).

O gênero Ceratitis possui uma única espécie no Brasil, a mosca-do-mediterrâneo, C. capitata, que juntamente com sete espécies de Anastrepha - A. fraterculus (Wied.), A. sororcula Zucchi, A. zenildae Zucchi, A. striata Schiner, A. pseudoparallela (Loew), A. grandis (Macquart) e A. obliqua (Macquart) -, representam as moscas-das-frutas mais 
importantes do ponto de vista econômico. Entretanto, dependendo da área considerada, outras espécies podem vir a ser importantes em razão dos frutos que atacam e de suas abundâncias relativas (Zucchi, 2000a).

Com base nos caracteres morfológicos dos adultos, 18 grupos de espécies, incluindo 166 espécies, têm sido reconhecidos no gênero Anastrepha (outras 32 espécies não se enquadram em nenhum grupo) (Norrbom et al., 1999). Portanto, o gênero Anastrepha reúne 198 espécies, das quais 94 ocorrem no Brasil (Zucchi, 2000a,b). Entretanto, somente para 56\% das espécies de Anastrepha registradas no Brasil são conhecidos os hospedeiros (Zucchi, 2000b). As espécies de Anastrepha ocorrem em todos Estados brasileiros, embora não haja registros publicados para alguns deles (Malavasi et al., 2000).

O Brasil é um dos países onde há mais estudos sobre o levantamento das espécies de moscas-das-frutas e seus hospedeiros (Aluja, 1999). Entretanto, na região semi-árida, apesar do seu potencial para a fruticultura, são poucos os levantamentos de moscas-dasfrutas realizados (Canal, 1997), principalmente em áreas de produção comercial de frutas. Além disso, os poucos trabalhos são de levantamentos em armadilhas e coletas esporádicas de frutos e, conseqüentemente, pouco se conhece a respeito dos hospedeiros e índices de infestação no semi-árido brasileiro.

\subsubsection{Moscas-das-frutas no semi-árido}

No Estado de Minas Gerais, estão registradas 26 espécies de Anastrepha e pelo menos 20 ocorrem na região semi-árida do Norte do Estado (Alvarenga et al., 2000). No levantamento de hospedeiros, apenas oito espécies de Anastrepha foram encontradas, sendo ainda incipiente a relação moscas-das-frutas/hospedeiros na região (Canal, 1997).

Nascimento (1990), durante seus trabalhos de tratamento pós-colheita de manga, relatou a ocorrência de seis espécies de moscas-das-frutas em Mossoró e Assu, RN. Nessa região, semi-árido nordestino, o pico populacional das espécies de Anastrepha coincidiu com o início da estação chuvosa (fevereiro/março), apresentando, de modo geral, densidade populacional baixa. Em Nova Soure, região semi-árida na Bahia, foram 
encontradas sete espécies de Anastrepha, com uma freqüência de 97,03\% de Anastrepha sororcula. Em Buritizeiros, norte de Minas Gerais, A. obliqua foi a espécie mais freqüente (82,39\%), num total de oito espécies coletadas (Nascimento, 1990).

Araújo et al. (1996) coletaram 3.614 exemplares de Anastrepha pertencentes a oito espécies, em armadilhas tipo McPhail, em Mossoró e Assu, RN. Ceratitis capitata não havia sido constatada no Estado até 1993. Atualmente, é a espécie mais polífaga, infestando vários frutos, destacando-se a acerola, com infestações superiores a 200 pupários/kg de fruto (Araújo, 2002). Já foram detectadas 15 espécies de moscas-dasfrutas no Rio Grande do Norte (Araújo et al., 2000; Araújo, 2002).

Em levantamento de moscas-das-frutas na região de Teresina (PI), realizado durante três anos, foram coletados 922 tefritídeos, pertencentes a 15 espécies de Anastrepha, não sendo coletado nenhum espécime de C. capitata (Menezes et al., 2000).

No Ceará, foram encontradas cinco espécies de Anastrepha (A. dissimilis, A. fraterculus, A. sororcula, A. obliqua e A. zenildae) e C. capitata em levantamentos com armadilhas e inspeção de plantas (Sales \& Gonçalves, 2000).

Em levantamentos para estudo de dinâmica, flutuação e manejo de moscas-dasfrutas realizados em áreas agrícolas no Submédio do Vale do São Francisco e nas áreas urbanas de Petrolina (PE) e Juazeiro (BA), de julho/1989 a março/1997, Haji \& Miranda (2000) constataram a ocorrência de tefritídeos em 13 espécies de frutos e em armadilhas tipo McPhail, num total de 10 espécies de Anastrepha e C. capitata. A baixa pluviosidade (média anual inferior a $700 \mathrm{~mm}$ ) e o reduzido número de hospedeiros determinaram a baixa densidade populacional de tefritídeos na região (Haji et al., 1991). Entretanto, considerando-se que a área cultivada e a diversidade de fruteiras aumentam a cada ano nesta região, acredita-se que a densidade populacional das espécies de importância econômica tende a aumentar (Nascimento \& Carvalho, 2000). 


\subsubsection{Moscas-das-frutas em goiaba}

As espécies de Myrtaceae são hospedeiras importantes de moscas-das-frutas. Aproximadamente 25 espécies dos gêneros Psidium, Eugenia e Syzygium são atacadas por espécies do grupo fraterculus (Hernández-Ortiz, 2000).

No Brasil, a goiaba é atacada principalmente por A. fraterculus, sendo um dos hospedeiros mais infestados por esta espécie (Malavasi \& Morgante, 1980). A goiaba foi o hospedeiro que mais afetou a população de $A$. fraterculus no Recôncavo Baiano (Nascimento et al., 1982). Entretanto, em regiões semi-áridas do Brasil, A. zenildae no norte de Minas Gerais (Canal et al., 1998a) e na região de Mossoró/Assu (Araújo \& Zucchi, 2003) e A. sororcula em Nova Soure, BA (Nascimento, 1990) foram predominantes em pomares de goiaba.

Durante aproximadamente duas décadas, a goiaba foi o único hospedeiro registrado para A. zenildae. Com base em levantamentos recentes, A. zenildae está associada com outros 10 hospedeiros, sendo oito dos cerrados de Goiás (Veloso, 1997). Atualmente são conhecidas seis famílias de plantas hospedeiras de A. zenildae no Brasil, sendo que oito das 14 espécies são da família Myrtaceae (Zucchi, 2000b).

Em levantamentos realizados no semi-árido do Rio Grande do Norte, A. zenildae foi a espécie mais coletada (Araújo et al., 1996; Araújo \& Zucchi, 2003). Da mesma forma, na região norte do Estado de Minas Gerais, também semi-árida, entre 20 espécies coletadas, A. zenildae foi a predominante e dentre as 55 espécies de frutos amostrados, a goiaba foi a mais preferida por essa espécie (Canal et al., 1998a,b).

Na realidade, com o estabelecimento de pomares irrigados, A. zenildae tornou-se a espécie predominante na região norte de Minas Gerais, pois as goiabeiras frutificam praticamente o ano todo e, conseqüentemente, a goiaba tornou-se o principal hospedeiro disponível para essa espécie (Canal et al., 1998b). Como constatado para a região do semi-árido do Nordeste (Araújo et al., 1996), a região norte de Minas Gerais, igualmente área de caatinga, também oferece condições propícias para o aumento populacional de A. zenildae. Portanto, com base em estudos realizados no norte de Minas Gerais (Canal et al., 1998b), as regiões secas com plantações de goiabas apresentam as condições 
favoráveis para que A. zenildae seja predominante numa área e, portanto, atinja o nível de dano econômico.

\subsubsection{Análise faunística de moscas-das-frutas}

A diversidade de uma comunidade deve ser estudada por meio de modelos matemáticos, mas, de acordo com as condições, podem ser empregados diversos índices estatísticos não paramétricos como os referidos por Silveira Neto (1976) e Southwood (1995).

No Brasil, existem poucos estudos sobre análise faunística, entretanto todos apresentam resultados semelhantes aos trabalhos realizados em outros países (Uramoto, 2002). Nascimento et al. (1983) elaboraram análise faunística das espécies de Anastrepha no Recôncavo Baiano e, dentre as 20 espécies coletadas, somente $A$. fraterculus, A. obliqua e A. sororcula foram dominantes.

Arrigoni (1984) observou que das 14 espécies de Anastrepha coletadas em três municípios do Estado de São Paulo, $A$. fraterculus e $C$. capitata foram as espécies mais freqüentes, constantes, abundantes e dominantes.

Silva (1993), por meio de coleta de frutos hospedeiros, caracterizou quatro locais de dois municípios do Amazonas, delimitando-os com relação às espécies de Anastrepha. As principais espécies foram A. obliqua, A. fraterculus, e A. bahiensis Lima, sendo A. obliqua a espécie predominante.

Martins et al. (1996) calcularam os índices de diversidade, freqüência e dominância para as espécies de moscas-das-frutas, coletadas em armadilhas, em três locais do norte do Espírito Santo. Concluiram que houve diferença nos valores dos índices entre os pomares estudados, sendo A. fraterculus e C. capitata as principais espécies.

Kovaleski (1997), em levantamento e análise das espécies de moscas-das-frutas em Vacaria, RS, coletou 16 espécies de Anastrepha, sendo que apenas duas foram consideradas dominantes. A. fraterculus foi predominante, contribuindo com mais de 80\% do total de indivíduos capturados e resultando em valores altos do índice de 
Simpson e constância. A. fraterculus foi a espécie mais abundante, constante e freqüente em pomares de pessegueiro em Porto Alegre, RS (Garcia \& Corseuil, 1998).

Uramoto (2002) determinou a composição do gênero Anastrepha, sua distribuição e a análise quantitativa da população no campus Luiz de Queiroz/Universidade de São Paulo, Piracicaba, SP. Foram assinaladas 18 espécies e apenas A. fraterculus e A. obliqua foram dominantes. A. fraterculus foi a espécie mais freqüente, representando $80,2 \%$ do total de fêmeas capturadas e a mais constante, ocorrendo em $98,04 \%$ das amostras.

Canal et al. (1998a) realizaram estudos em quatro municípios de Minas Gerais ao longo de dois anos e coletaram 20 espécies de Anastrepha. Somente A. obliqua e A. zenildae foram dominantes.

Visando caracterizar os ecossistemas de árvores frutíferas da região Oeste de Santa Catarina em relação às espécies de Tephritidae, Garcia et al. (2003) elaboraram uma análise faunística em pomares de quatro municípios. Coletaram 20 espécies de moscas-das-frutas, pertencentes a sete gêneros e verificaram diferença na diversidade entre os municípios. A. fraterculus foi a espécie predominante na região.

\subsubsection{Flutuação populacional}

As flutuações populacionais de adultos em pomares comerciais estão relacionadas a duas variáveis: disponibilidade de frutos hospedeiros e condições climáticas (Aluja, 1994). Dentre os fatores abióticos, destacam-se a temperatura, a umidade relativa, a precipitação pluviométrica e as condições físico-químicas do solo (Christenson \& Foote, 1960; Bateman, 1972).

A umidade e a temperatura podem ser determinantes na população de tefritídeos (Bateman, 1972). A temperatura pode influir direta ou indiretamente por meio de efeitos sobre as taxas de desenvolvimento, mortalidade e fecundidade.

Segundo Vargas et al. (1993), a abundância de Ceratitis em Kawai, Havaí, parece estar relacionada negativamente com pluviosidade, ou seja, em áreas mais secas o número de indivíduos coletados em armadilhas foi maior. Entretanto, a falta de umidade 
no solo pode provocar a mortalidade de um grande número de pupas e adultos recémemergidos, que têm dificuldade de atravessar solos secos (Baker et al., 1944).

Entre os fatores bióticos, estão a disponibilidade e abundância de frutos hospedeiros, a dispersão e os inimigos naturais. As variáveis climáticas também podem influir indiretamente na disponibilidade de hospedeiros (Tan \& Serit, 1994).

A disponibilidade de hospedeiros influencia a população de Anastrepha (Aluja et al., 1996), pois as maiores infestações ocorrem justamente nos períodos de maior disponibilidade e abundância de frutos hospedeiros (Puzzi \& Orlando, 1965; Malavasi \& Morgante, 1981 e Soto-Manitiu \& Jirón, 1989). Em áreas tropicais, tem-se observado que a flutuação temporal da população de adultos está relacionada principalmente à disponibilidade de plantas hospedeiras e não às variáveis climáticas. Celedonio-Hurtado et al. (1995) observaram que os picos populacionais de adultos de tefritídeos em Chiapas, México, ocorreram logo após o período de maior disponibilidade de frutos hospedeiros. Concluíram que este fator é determinante na flutuação populacional, não havendo influência da precipitação pluviométrica. Soto-Manitiu \& Hirón (1989) também constataram, na Costa Rica, que os picos populacionais de três espécies de Anastrepha associadas à manga, coincidiram com a maior produção de frutos.

No Brasil, foram obtidos resultados semelhantes. A presença de plantas hospedeiras e o estágio de maturação dos frutos são os fatores principais na flutuação populacional de moscas-das-frutas (Puzzi \& Orlando, 1965). Malavasi \& Morgante (1981) observaram que o pico populacional de A. fraterculus ocorreu próximo ao final do período de frutificação das plantas hospedeiras. Em Itaguaí, RJ, a flutuação populacional de moscas-das-frutas foi relacionada à época de maturação dos frutos hospedeiros e a ocorrência dessas moscas durante o ano todo foi favorecida pela sequiência de maturação dos frutos hospedeiros (Aguiar-Menezes \& Menezes, 1996). Fehn (1982) observou a não dependência entre a população dos tefritídeos e os fatores climáticos estudados em três municípios do Rio Grande do Sul e concluiu que a disponibilidade de hospedeiros alternativos exerce um papel fundamental sobre a flutuação e dinâmica de tefritídeos. 
Em pomares comerciais, onde predomina um único hospedeiro, a maior densidade populacional ocorre na época de maior concentração de frutos maduros (Nascimento \& Carvalho, 2000). Entretanto, mesmo ocorrendo várias espécies de tefritídeos, normalmente somente duas a três são dominantes, estando diretamente associadas aos hospedeiros primários existente no agroecossistema (Nascimento et al., 1982; Kovaleski, 1997).

As flutuações das populações de moscas-das-frutas parecem ser dependentes principalmente das condições climáticas e da disponibilidade de plantas hospedeiras (Arrigoni, 1984; Zahler, 1990; Raga et al., 1996). Em estudo da dinâmica populacional de moscas-das-frutas, Nascimento et al. (1982) verificaram que as temperaturas (média e máxima) e a umidade do ar influíram na coleta de Anastrepha, mas a temperatura mínima e a precipitação pluvial não afetaram a captura.

Os fatores climáticos (temperatura, umidade relativa, precipitação pluvial e vento) não influenciaram o tamanho da população de $C$. capitata em cafeeiros em Pindorama (SP). Entretanto, em Campinas (SP), a temperatura exerceu influência na dinâmica populacional desta espécie. Houve predominância de moscas-das-frutas na fase de maturação do café (Parra et al., 1982).

Estudos sobre dinâmica populacional de moscas-das-frutas em pomar de citros em Presidente Prudente, SP, mostrou que a flutuação populacional de Anastrepha spp. correlacionou negativamente com a precipitação pluviométrica e com as temperaturas (média e mínima) e a flutuação de C. capitata com a umidade relativa (Raga et al., 1996).

A precipitação pluvial aliada à disponibilidade de hospedeiros são fatores determinantes na população de tefritídeos, pois os meses seguintes às maiores precipitações pluviais e o período de maior frutificação da goiaba em Mossoró foram justamente os meses de maiores picos populacionais e níveis de infestação (Araújo \& Zucchi, 2003).

A população de adultos de Anastrepha pode variar de ano para ano, não obedecendo a um padrão determinado (Aluja, 1994). Por exemplo, no Rio Grande do 
Sul, o tamanho das populações e a época do aumento populacional de A. fraterculus em pomares de maçã variaram de ano para ano (Kovaleski, 1997).

Os inimigos naturais, como fator de mortalidade biótica, também afetam as populações de moscas-das-frutas, atuando durante todas as fases de desenvolvimento dos tefritídeos (Sugayama, 2000; Carvalho et al., 2000, Nascimento \& Carvalho, 2000).

\subsubsection{Controle}

O controle das moscas-das-frutas, entre outros fatores, é grandemente dificultado pela vasta gama de hospedeiros, principalmente nativos, que proporcionam condições de sobrevivência durante todo o período do ano, além de proporcionar a formação de gerações superpostas (Veloso et al., 2000).

A distribuição de uma espécie é determinada pela presença dos hospedeiros (Morgante, 1991). Entretanto, algumas espécies possuem maior potencial biótico e tornam-se dominantes na área (Canal, 1997), provocando grandes prejuízos à fruticultura local e levando o produtor a utilizar o controle químico.

Tradicionalmente, o manejo das populações de tefritídeos-pragas no Brasil depende basicamente do uso de frascos caça-moscas para o monitoramento e do uso de iscas à base de inseticida mais atraente alimentar (por exemplo, melaço, proteína hidrolisada de milho etc.) para o controle de suas populações (Morgante, 1991; Malavasi et al., 1994). Entretanto, com a mudança do perfil do consumidor, particularmente os de fruta in natura, exigindo alimentos com níveis reduzidos, ou mesmo isentos, de resíduos de agrotóxicos, aliado ao aumento da conscientização da população em geral, dos riscos ambientais que esses produtos podem causar, a pesquisa científica tem buscado alternativas ecológica, social e economicamente viáveis para o controle de insetospragas (Carvalho et al., 2000).

Assim, o controle biológico assume uma importância cada vez maior nos programas de controle de moscas-das-frutas, já que existe uma exigência global por alimentos isentos de resíduos de agrotóxicos (Campanhola, 1998). 


\subsection{Inimigos Naturais}

\subsubsection{Aspectos gerais}

Entre os inimigos naturais das moscas-das-frutas, os himenópteros parasitóides são quase que exclusivamente responsáveis pelo equilíbrio de suas populações, principalmente aqueles pertencentes à família Braconidae (Wharton, 1996). Também no Brasil, os parasitóides de moscas-das-frutas coletados com maior freqüência são os braconídeos (Canal \& Zucchi, 2000).

Os braconídeos parasitóides de moscas-das-frutas pertencem às subfamílias Opiinae (mais comuns) e Alysiinae. São endoparasitóides coinobiontes de Diptera Cyclorrhapha, ou seja, a fêmea oviposita nos ovos ou larvas de seu hospedeiro, que permanece vivo até a fase de pupa, para o completo desenvolvimento do parasitóide (Wharton, 1997). Os opiíneos parasitóides de moscas-das-frutas pertencem aos gêneros Opius, Utetes, Doryctobracon, Biosteres e Diachasmimorpha (Wharton, 1997).

O hábito generalista dos braconídeos, i.e., parasitar espécies de Anastrepha em uma ampla variedade de espécies de plantas, tem sido observado por vários autores. Os opiíneos são preferidos nos programas de controle biológico de moscas-das-frutas devido à especificidade hospedeira para a família Tephritidae (Clausen, 1940). Todas as espécies registradas nos gêneros Utetes, Doryctobracon e a maioria das espécies do gênero Diachasmimorpha são parasitóides de Tephritidae (Wharton, 1997).

Apesar de limitarem seus hospedeiros às espécies da família Tephritidae, com algumas exceções, os parasitóides possuem uma ampla gama de espécies hospedeiras, atacando moscas-das-frutas de diferentes grupos em diversos frutos hospedeiros (Canal \& Zucchi, 2000).

O parasitismo tem sido uma das interações biológicas mais comumente estudadas em ecologia de populações de insetos, principalmente a partir da década de 70, quando se tornou freqüente a experimentação de campo em Ecologia (Cappuccino, 1995). 


\subsubsection{Levantamento de espécies, parasitismo e fatores que afetam o nível de parasitismo}

No Recôncavo Baiano, Doryctobracon areolatus é responsável, em média, por 14,08\% do parasitismo das espécies de Anastrepha, variando de 1,38\% a 30,38\%, dependendo da espécie de fruto hospedeiro (Nascimento et al., 1984).

Em levantamentos de parasitóides de espécies de Anastrepha no município de Itaguaí, RJ, Aguiar-Menezes \& Menezes (1997) coletaram aproximadamente 10.000 pupários de tefritídeos, dos quais 10,4\% estavam parasitados por opiíneos.

D. areolatus é um dos parasitóides de tefritídeos mais comum e amplamente distribuído, ocorrendo desde a Argentina até o sul dos Estados Unidos (Wharton \& Marsh, 1978; Wharton \& Gilstrap, 1983).

Em levantamentos de espécies de Braconidae associadas aos tefritídeos em 21 localidades brasileiras, Leonel Junior et al. (1995) verificaram que dos 3.525 braconídeos examinados, 81,4\% pertenciam à subfamília Opiinae e D. areolatus foi a espécie mais abundante (69,9\%).

Das oito espécies de parasitóides associados às espécies de Anastrepha em Chiapas, México, quatro pertenciam à subfamília Opiinae. Diachasmimorpha longicaudata foi a mais comum e parasitou A. ludens (em Mangifera indica e Citrus sinensis), A. obliqua (em M. indica e Spondias sp.), A. serpentina (em M. indica) e A. striata (em Psidium guajava) (Aluja et al., 1990).

Em levantamentos de moscas-das-frutas e parasitóides em quatro municípios do norte de Minas Gerais, foram coletados apenas 67 parasitóides pertencentes a três espécies (opiíneos). O baixo parasitismo natural na região ocorreu em razão do pequeno número de amostras de frutos, pois, apesar de realizado durante três anos, os levantamentos foram feitos principalmente com armadilhas (Canal, 1997).

A conformação do fruto, as condições do pericarpo (dureza e espessura) e a disposição do mesocarpo em relação às sementes, devem ter influência considerável no parasitismo das moscas-das-frutas por braconídeos, por que influem na postura dos 
parasitóides (Sivinski, 1991). A rigidez da casca do fruto foi o fator determinante para o baixo nível de parasitismo encontrado em feijoa (Salles, 1996).

A eficiência de D. longicaudata, no parasitismo de larvas de moscas-das-frutas, aumenta com o tamanho do fruto, indicando que as fêmeas dessa espécie podem ser mais hábeis para localizar ou atacar larvas hospedeiras em frutos maiores (Sivinski et al., 1997). A espessura da polpa dos frutos atua como barreira ao parasitismo de larvas de moscas-das-frutas por braconídeos e condiciona um baixo parasitismo de larvas em frutos de polpa espessa (Hickel, 2002).

Dentre 10 espécies de frutos, duas (Spondias mombim e Pouroma cecropiaefolia) exibiram uma alta porcentagem de parasitismo em quatro municípios do Estado do Amazonas. Esses frutos possuem pericarpo fino e mesocarpo raso, conseqüentemente, as larvas das moscas-das-frutas foram mais facilmente localizadas e ficaram mais vulneráveis ao parasitismo (Silva, 1993). Na região de Pelotas, RS, as maiores porcentagens de parasitismo foram obtidas em duas espécies de frutos de pericarpo fino e liso: cereja-do-mato (Eugenia involucrata) com 31,3\% de parasitismo e araçá (Psidium araca) com 17,6\% (Salles, 1996).

Os parasitóides também são regulados pelos mesmos fatores bióticos e abióticos, que afetam as moscas-das-frutas. Em Veracruz (México), as porcentagens de parasitismo de Anastrepha spp. por D. areolatus declinam durante o período de frutificação das plantas hospedeiras, com a mudança da estação chuvosa para a seca (Sivinski et al., 1997).

A temperatura foi o fator climático que melhor se correlacionou com as variações na abundância relativa de $D$. longicaudata e $D$. areolatus. Provavelmente as temperaturas mais altas favorecem D. longicaudata ou, então, D. areolatus tolera temperaturas mais baixas (Sivinski et al., 1998).

As porcentagens de parasitismo de larvas de Anastrepha spp. por D. areolatus, em pitanga e carambola, em Conceição do Almeida (BA), reduziram da primeira safra (dezembro) para a segunda (abril e junho) (Matrangolo et al., 1998).

As estações quentes e chuvosas do ano são mais favoráveis ao crescimento populacional dos parasitóides, do que as estações frias e secas, ou seja, as flutuações 
populacionais dos parasitóides dependem das precipitações pluviométricas e das temperaturas médias mensais (Aguiar-Menezes, 2000).

A população da mosca hospedeira influencia a população do parasitóide (Vargas et al., 1993). As flutuações das populações dos opiíneos, entre as estações, foram significativamente correlacionadas com as variações numéricas nas populações de Anastrepha spp. Correlações positivas entre o número de adultos de opiíneos e os de moscas (Anastrepha) indicam uma relação dependente da densidade direta (AguiarMenezes 2000).

Os estudos de dispersão e o hábitat do hospedeiro mostram que a eficiência dos parasitóides de tefritídeos aumentará as estratégias do controle biológico (Purcell, 1998).

\subsubsection{Parasitismo por Diachasmimorpha longicaudata}

Mesmo quando os índices naturais de parasitismo de moscas-das-frutas são baixos, o controle biológico pode ser de grande valia no manejo integrado de moscasdas-frutas por meio de liberações inundativas de inimigos naturais (Canal \& Zucchi, 2000).

O parasitóide de larva-pupa, $D$. longicaudata, tem sido o mais freqüentemente estudado, devido à facilidade de criá-lo em laboratório. Outro ponto a favor, em trabalhos visando sua introdução, é a intensa atividade de forrageamento em frutos caídos no solo (Purcell et al., 1994). Originalmente recuperado de espécies de Bactrocera, D. longicaudata é nativo da região indo-filipina (Clausen et al., 1965) e foi introduzido na Flórida para o controle da mosca-do-caribe, estabelecendo-se rapidamente (Cancino, 1992).

D. longicaudata localiza as frutíferas por meio de substâncias voláteis produzidas pelos frutos maduros e deteriorados (Greany et al., 1977; Messing \& Jang, 1992). As larvas do último ínstar nos frutos são localizadas pela vibração produzida pelo hospedeiro quando se movimenta ou se alimenta (Lawrence, 1981). Geralmente as larvas do parasitóide eclodem antes da pupação do hospedeiro, com a muda para o 
segundo ínstar ocorrendo dentro do pupário. O desenvolvimento é completado no interior da pupa da mosca (Lawrence, 1981).

Na Flórida, com a introdução de $D$. longicaudata, as populações de A. suspensa foram reduzidas a 40\% (Baranowski, 1993). Esta espécie representa 95\% do parasitismo da mosca-do-caribe no sul da Flórida (Sivinski, 1991).

Recentemente, a EMBRAPA Mandioca e Fruticultura introduziu este parasitóide no Brasil (Carvalho et al., 1995) e já existem colônias estabelecidas nos laboratórios da EMBRAPA, em Cruz das Almas, BA (Carvalho et al., 2000) e no Centro de Energia Nuclear na Agricultura (CENA), em Piracicaba, SP (Walder et al., 1997).

Na região do Recôncavo Baiano, onde foram feitas liberações inoculativas, $D$. longicaudata parece já estar adaptado e estabelecido, o que vem confirmar a relativa facilidade de adaptação deste agente de controle biológico aos meios naturais onde é liberado (Carvalho et al., 1997).

Entretanto, a decisão sobre introduzir um inimigo natural deve levar em conta aspectos biológicos, econômicos e operacionais. Levantamentos prévios de inimigos naturais nativos e da mortalidade que eles causam e estudos sobre a biologia da espécie, que se pretende liberar e de seu comportamento frente às condições que serão encontradas no campo, podem dar uma indicação da probabilidade de sucesso de uma espécie introduzida (van Driesche \& Bellows, 1996).

Um sério problema dos estudos de controle biológico de moscas-das-frutas é a dificuldade em estimar os níveis de parasitismo. A remoção do fruto do campo durante a amostragem diminui o período em que as larvas são suscetíveis ao ataque. O resultado é um parasitismo subestimado (Sivinski et al., 1996).

O estágio de maturação do fruto pode influenciar o parasitismo de moscas-dasfrutas. Haramoto \& Bess (1970) suspeitaram que o baixo número de $D$. longicaudata observado em goiabas colhidas das árvores foi devido às amostragens de frutos insuficientemente maduros, pois observaram fêmeas do parasitóide atacando larvas em frutos no chão. Foram recuperados um número muito maior de $D$. longicaudata e $D$. tryoni de armadilhas instaladas próximo ao solo, quando os frutos de goiaba foram derrubados das árvores (Messing et al., 1994). Após testar a eficácia de D. longicaudata 
sobre Bactrocera dorsalis em goiabas, coletadas somente da planta para maximizar o número de larvas recuperadas, Purcell et al. (1994) observaram que a taxa de parasitismo não excedeu a 6\%, mesmo liberando 500.000 insetos durante um ano. Para determinar se o estágio de maturação dos frutos de goiaba amostrados influenciou a densidade, a abundância e o parasitismo de $B$. dorsalis, aqueles autores dividiram os frutos em categorias (verde, colhido na árvore, frutos já escuros, com deformações de apodrecimento e colhidos no solo após algum tempo da queda). Concluíram que quanto mais tempo o fruto permaneceu no campo (de oito a nove dias), maior foi a porcentagem de parasitismo por $D$. longicaudata.

O aumento significativo no parasitismo de D. longicaudata em A. suspensa foi obtido, quando os frutos foram deixados no campo por vários dias, i.e., de 14\% quando os frutos foram removidos do campo para $80 \%$, quando os frutos foram mantidos no campo sobre vermiculita (Sivinski et al., 1996).

Em razão das restrições fisiológicas de $D$. longicaudata, como baixa tolerância a climas frios (Eitam, 1998), a chance de estabelecimento dessa espécie para o controle de A. fraterculus no sul do Brasil é reduzida (Sugayama, 2000). Todavia, as fêmeas do parasitóide atacam as larvas das moscas em pelo menos um dos seus hospedeiros silvestres, a guabiroba (Campomanesia xanthocarpa) e, provavelmente, se liberadas durante o período de queda desses frutos, aumentariam significativamente a mortalidade de larvas de A. fraterculus (Sugayama, 2000). 


\section{MATERIAL E MÉTODOS}

\subsection{Caracterização da área de estudo}

O presente estudo foi conduzido em dois municípios do norte do Estado de Minas Gerais: Nova Porteirinha e Jaíba (Mocambinho), localizados na região semi-árida do Estado, com ecossistema conhecido como caatinga.

O semi-árido corresponde a uma das seis grandes zonas climáticas do Brasil. Caracteriza-se basicamente pelo regime de chuvas, definido pela escassez, irregularidade e concentração das precipitações pluviométricas num curto período de cerca de três meses, durante o qual ocorrem sob a forma de fortes aguaceiros, de pequena duração; tem a caatinga como vegetação predominante e apresenta temperaturas elevadas. Abrange as áreas com precipitação média anual de 800 mm e situa-se, majoritariamente, na região Nordeste, estendendo-se até o norte de Minas Gerais, ou seja, até o que foi legalmente definido como pertencente ao Polígono das Secas (Companhia de Desenvolvimento do Vale do São Francisco - Codevasf, 2003).

As condições climáticas da região estão representadas por temperaturas médias que variam de 21 a $25^{\circ} \mathrm{C}$, com uma temperatura média mínima oscilando de 14 a $19^{\circ} \mathrm{C}$ e máximas de 26 a $31^{\circ} \mathrm{C}$; a precipitação total anual varia de 700 a $1200 \mathrm{~mm}$, sendo que o período chuvoso estende-se de outubro a abril e o seco de maio a setembro; a umidade relativa da região oscila entre 60 e $70 \%$ (Antunes, 1994).

Foram escolhidos dois pomares comerciais de goiaba 'Paluma', um localizado no Projeto de Irrigação do Jaíba, em Jaíba (implantado em 1993) e o outro no Projeto de Irrigação do Gorutuba, em Nova Porteirinha (implantado em 1996), distantes 150 km 
um do outro. Em ambos os locais, não houve pulverizações para o controle de moscasdas-frutas e a área plantada é de 0,5 ha (200 plantas aproximadamente).

A cultivar Paluma caracteriza-se por produzir frutos grandes, destinados ao consumo "in natura” e principalmente à indústria (Manica, 2000).

\subsection{Levantamento das espécies de moscas-das-frutas e de seus parasitóides em goiaba}

Os levantamentos das espécies de Anastrepha foram realizados por meio da utilização de frascos caça-moscas do tipo McPhail e da coleta sistemática de frutos nos dois pomares.

Os levantamentos em frascos caça-moscas e em frutos foram realizados em duas épocas. A primeira iniciou-se em maio/1999 (coleta de frutos) e em julho/1999 (coleta em frascos caça-mosca) e foi realizada até abril/2001; a segunda, com início em maio/2002, compreendeu 13 meses para a coleta em frascos caça-moscas (até maio/ 2003) e 16 meses para a coleta de frutos (até agosto/2003).

Em cada um dos locais de coleta foi colocado um frasco caça-moscas na primeira época e dez na segunda, contendo $200 \mathrm{ml}$ de uma solução a 5\% de proteína hidrolisada de milho.

As armadilhas foram revisadas a cada sete dias, procedendo-se à coleta dos insetos, limpeza e substituição do atrativo. Os insetos coletados foram transportados até o Laboratório de Entomologia da Universidade Estadual de Montes Claros (Unimontes), onde as moscas-das-frutas foram sexadas e contadas. Os representantes do gênero Anastrepha foram acondicionados em álcool 70\% para posterior identificação.

A fim de se conhecer as espécies de moscas-das-frutas associadas à goiaba da região e os seus parasitóides, os frutos (maduros ou em amadurecimento) foram amostrados semanalmente. O método de coleta foi aleatório, em qualquer altura da copa das árvores, além dos recém-caídos no solo, que ainda estavam em boas condições de conservação e sem orifícios de saída das larvas. O tamanho das amostras foi variável, dependendo da disponibilidade de frutos no campo. 
As amostras, devidamente rotuladas (data, local, coletor), foram acondicionadas em bandejas plásticas e transportadas até o Laboratório de Entomologia da Unimontes. Os frutos foram contados, pesados e acondicionados em recipientes plásticos (um fruto por recipiente), contendo vermiculita umedecida e fechados com tecido "voil" e elástico. As amostras foram mantidas sob condições controladas de temperatura $\left(27 \pm 1^{\circ} \mathrm{C}\right)$.

Após sete a 15 dias, foi realizado o peneiramento da vermiculita, bem como o exame cuidadoso da polpa. As larvas e os pupários obtidos foram contados e transferidos para frascos de vidro contendo vermiculita e fechados com "voil”, rotulados (data, loca e coletor), onde ocorreu a emergência de moscas e/ou parasitóides. Foi colocado um pedaço de algodão umedecido sobre o "voil” como fonte de água aos insetos que emergiram e após algumas horas, foram mortos e fixados em álcool 70\% para posterior identificação.

Os espécimes de Anastrepha foram sexados e contados e os de Ceratitis capitata foram descartados após a contagem. Os espécimes de Anastrepha (machos e fêmeas) foram mantidos em frascos com álcool 70\%.

A percentagem de parasitismo (I\%) foi determinada pela fórmula:

$\mathrm{I} \%=(\mathrm{P} / \mathrm{TA}) \times 100$

onde:

P: $\quad$ número total de parasitóides emergidos

TA: total de adultos emergidos (moscas + parasitóides)

\subsection{Identificação das moscas-das-frutas e dos parasitóides}

A identificação das espécies de Anastrepha e parasitóides (Braconidae) foi realizada na Escola Superior de Agricultura "Luiz de Queiroz" (ESALQ) (Setor de Entomologia). Para as espécies de Anastrepha, a identificação foi baseada nas fêmeas, observando-se o acúleo (Zucchi, 1978), usando-se as chaves elaboradas por Canal (1997), Souza Filho (1999), Zucchi (2000a) e Uramoto (2002). Foi elaborada uma chave 
para a identificação das espécies de Anastrepha registradas nos pomares de goiaba da região norte de Minas Gerais.

As identificações dos parasitóides braconídeos foram baseadas na forma da mandíbula e do clípeo, na asa e no propódeo (Canal, 1993). As identificações dos parasitóides Figitidae foram realizadas pelo Dr. Jorge Anderson Guimarães, Embrapa, Centro Nacional de Pesquisa em Agroindústria Tropical, Fortaleza, CE.

Os espécimes estão depositados no Departamento de Ciências Agrárias da UNIMONTES e na coleção do Setor de Entomologia da ESALQ/USP.

\subsection{Análise faunística}

Para a análise faunística das espécies de Anastrepha, utilizou-se o programa denominado ANAFAU (Moraes et al., 2003), que permite caracterizar uma comunidade pelos índices de freqüência, abundância, dominância e constância, e também selecionar as espécies predominantes, além dos índices de equitabilidade e diversidade. A definição de classes extremas (super) foi baseada na classificação hierárquica de classes, seguindo a metodologia de Silveira Neto (1976).

$\mathrm{O}$ índice de diversidade $\left(\mathrm{H}^{`}\right)$ foi de Shannon-Weaver, $\mathrm{H}^{`}=$ \} De. $\mathrm{Ri}{ }^{*} \mathrm{LN}(\mathrm{De}$. Ri), que permite calcular a sua variância e o intervalo de confiança, bem como calcular o índice de equitabilidade (homogeneidade na ocorrência das espécies), calculado pela divisão do $\mathrm{H}^{`}$ pelo $\mathrm{H}^{`}$ max, que é alcançado quando todas as populações têm a mesma densidade relativa (Poole, 1974).

\subsection{Flutuação de populações nativas de tefritídeos em pomares de goiaba}

Os levantamentos das espécies de Anastrepha para o estudo da flutuação populacional foram realizados por meio da utilização de armadilhas do tipo McPhail.

As flutuações populacionais foram baseadas no número total de espécimes coletados por mês, determinado pela soma de seus números obtidos em cada coleta, 
realizada semanalmente, durante o levantamento das espécies de moscas e parasitóides (item 3.2).

Para relacionar as flutuações anuais das populações dos tefritídeos com os fatores climáticos (temperatura, precipitação pluviométrica e umidade relativa), foi realizada uma análise de regressão linear Stepwise forward (tolerância $1.0 \mathrm{e}^{-11}$ ), utilizando-se o programa Systat-9 for Windows. Segundo Clark et al. (1967), os fatores climáticos, especialmente a temperatura, podem limitar o número de ovos deixados pelas fêmeas de um inseto, por restringir a própria produção de ovos, a oviposição ou a longevidade das fêmeas. Os dados climáticos foram fornecidos pela Estação Climatológica do Centro Tecnológico do Norte de Minas, da Epamig, localizado em Nova Porteirinha, MG.

\section{6 Índice de infestação de moscas-das-frutas em goiaba}

Foram coletadas semanalmente, goiabas maduras, da planta e do solo, rotuladas e levadas ao Laboratório de Entomologia da Unimontes, onde foram acondicionadas em caixas plásticas com vermiculita. Os frutos foram contados e pesados por amostra e as caixas, contendo apenas um fruto, foram mantidas sob condições controladas de temperatura $\left(27 \pm 1^{\circ} \mathrm{C}\right)$.

Após sete a dez dias, foram retiradas as larvas e/ou pupários por meio do exame cuidadoso da polpa e da vermiculita, e, em seguida, foram transferidas para frascos de vidro contendo vermiculita, onde ocorreu a emergência das moscas e/ou parasitóides.

As coletas para a determinação dos índices de infestação foram realizadas nos dois pomares, durante 16 meses (maio/2002 a agosto/2003). No pomar de Nova Porteirinha, as coletas iniciaram-se em julho/2002, pois as plantas foram podadas e só começaram a produzir a partir desta data.

As infestações e os índices de infestação de moscas-das-frutas em goiabas foram determinados como se segue:

Índice de infestação de mosca $=($ frutos atacados/frutos totais) $\times 100$

Intensidade de infestação (I.I.) = (número de pupários/massa)

Massa $\rightarrow$ peso total dos frutos infestados (kg) 


\subsection{Liberação e recaptura (capacidade de sobrevivência) do parasitóide exótico Diachasmimorpha longicaudata em goiaba no norte de Minas Gerais}

Os exemplares de $D$. longicaudata para as liberações foram criados em larvas de C. capitata. A criação do hospedeiro foi iniciada com pupários provenientes do Laboratório de Radioentomologia do CENA/ESALQ/USP, Piracicaba, SP.

Os parasitóides foram mantidos no Laboratório de Criação de Insetos da Unimontes, em Janaúba, MG, em condições controladas (26 $\pm 2^{\circ} \mathrm{C}, 65 \pm 10 \%$ de UR e fotofase de 14h), utilizando-se larvas de terceiro estádio de C. capitata como hospedeiro. Foram utilizadas placas de Petri, fechadas com tecido fino tipo “voil”, contendo de 1.600 a 1.700 larvas de C. capitata. As placas de Petri com as larvas foram apoiadas no exterior de uma gaiola retangular telada $(15 \mathrm{~cm} \mathrm{x} 12 \mathrm{~cm})$, contendo entre 400 e 600 casais do parasitóide sexualmente maduros, de forma que a face telada (aberta) ficasse em contato com a tela da gaiola. Aos parasitóides, foi oferecida dieta artificial e água. Cada placa foi exposta durante uma hora ao parasitismo de D. longicaudata. As larvas parasitadas foram, em seguida, acondicionadas em frascos com vermiculita, fechados com “voil”" e presos com elástico, de onde emergiram adultos do parasitóide a partir do $14^{0}$ dia. À medida que emergiam, os parasitóides eram transferidos para as gaiolas para se alimentarem e acasalarem.

As liberações do parasitóide foram realizadas nos dois pomares comerciais de goiaba 'Paluma'.

Inicialmente, a liberação era feita em potes plásticos contendo parasitóides aspirados das gaiolas. A coleta dos adultos do parasitóide na gaiola de criação era feita com um succionador de insetos acoplado a um aspirador de pó de uso doméstico. Para isso utilizou-se um pote plástico com capacidade de 200 a $250 \mathrm{~cm}^{3}$, de boca larga e tampa rosqueada. A esta tampa adaptou-se os tubos e mangueiras, a exemplo de um succionador comum. Efetuada a coleta, substituiu-se o aparato por uma tampa perfurada ou "voil", de modo que o mesmo pote usado para coletar os insetos fosse levado ao campo para liberação dos parasitóides. Esta técnica provocava alta mortalidade e 
também um certo estresse nos parasitóides, podendo reduzir seu potencial de ação no campo.

Com isto, optou-se em fazer as liberações das próprias gaiolas. Para isso, adaptou-se a lateral superior da gaiola em uma tampa. A armação de madeira foi retirada, liberando-se a tela, fixando em sua borda e na armação de madeira fitas de velcro, de modo que bastava retirar esta tela para liberar os parasitóides. As liberações foram realizadas sob a copa das árvores, caminhando-se pelo pomar com a gaiola aberta virada para as plantas, para que os parasitóides tivessem livre acesso ao exterior da gaiola.

As liberações do parasitóide em campo iniciaram-se em fevereiro/2003, com parasitóides produzidos no CENA/USP, sendo realizadas no máximo duas liberações mensais, até junho, quando então a produção no laboratório da Unimontes se estabilizou e passaram a ser realizadas semanalmente.

Foram liberados parasitóides de 5 a 6 dias de idade, pois com 9 dias de idade atingem o máximo de sua capacidade de parasitismo. O número de insetos nas três primeiras liberações foi de aproximadamente 3.000 (1.800 casais) por área. Posteriormente, esse número foi elevado para 4.000 a 6.000 (100 a $200 \mathrm{ml}$ de pupários parasitados aproximadamente) por área, variando de acordo com a disponibilidade de parasitóides no laboratório. As liberações foram realizadas durante sete meses (fevereiro a agosto/ 2003), totalizando 15 liberações.

Para se recapturar os parasitóides, sete dias após as liberações, foram coletadas goiabas e levadas ao Laboratório de Entomologia da Unimontes, seguindo-se a mesma metodologia citada anteriormente (item 3.2). O índice de parasitismo (I\%) foi calculado pela fórmula citada anteriormente (item 3.2). 


\section{RESULTADOS E DISCUSSÃO}

\subsection{Moscas-das-frutas em pomares de goiaba}

\subsubsection{Espécies de moscas-das-frutas}

Após o período de estudo, foram obtidos das armadilhas e dos frutos 48.482 tefritídeos, sendo 45.012 exemplares de Anastrepha e 3.470 de C. capitata (Tabela 1). Como as coletas foram realizadas em pomares comerciais, o número de C. capitata foi bem menor que o de Anastrepha spp. Segundo Canal et al. (1998a), C. capitata ocorre mais comumente em pomares de áreas urbanas enquanto as espécies de Anastrepha são mais comuns nas áreas rurais.

Tabela 1. Número de moscas-das-frutas coletadas em pomares comerciais de goiaba no norte de Minas Gerais. (maio/1999 a abril/2001 e maio/2002 a agosto/2003)

\begin{tabular}{lrrrrrrr}
\hline \multirow{2}{*}{ Gêneros } & \multicolumn{3}{c}{ Em Armadilhas } & \multicolumn{3}{c}{ Em Frutos } & \multirow{2}{*}{ Total Geral } \\
\cline { 2 - 6 } & Machos & Fêmeas & Total & Machos & Fêmeas & Total & \\
\hline Anastrepha & 14.822 & 24.565 & 39.387 & 2.807 & 2.818 & 5.625 & 45.012 \\
Ceratitis & 989 & 2.262 & 3.251 & 89 & 130 & 219 & 3.470 \\
Total & 15.811 & 26.827 & 42.638 & 2.896 & 2.948 & 5.844 & 48.482 \\
\hline
\end{tabular}


Foram coletadas 18 espécies de Anastrepha em armadilhas e frutos (Tabela 2), sendo que a maioria já havia sido assinalada na região (Canal, 1997; Alvarenga et al., 2000). Apenas A. turpiniae, A. manihoti, A. leptozona e A. barbiellinii estão sendo registradas pela primeira vez no norte de Minas Gerais. Duas espécies, Anastrepha n.sp.2 e Anastrepha n.sp.3, relacionadas a A. pickeli, estão em fase de descrição.

Dentre as regiões semi-áridas do Brasil, o norte de Minas Gerais apresenta a maior diversidade de moscas-das-frutas, elevando, com este trabalho, de 21 (Canal, 1997) para 25 espécies. Em outras regiões semi-áridas, como Mossoró/Assu (RN) e Petrolina/Juazeiro (PE e BA) a diversidade das espécies de moscas-das-frutas é menor, sendo registradas 11 espécies (Haji \& Miranda, 2000; Araújo \& Zucchi, 2003). Todas as espécies assinaladas para estas regiões também ocorrem na região semi-árida de Minas Gerais.

Contudo, vale salientar que as coletas foram realizadas somente nos dois pomares comerciais de goiaba, sendo que algumas espécies encontradas por Canal (1997), em levantamento de vários pomares (domésticos e comerciais) do norte de Minas não foram coletadas neste estudo, como A. bahiensis, A. barnesi, A. flavipennis, A. nigripalpis, A. zernyi e Anastrepha n.sp.1. A diversidade de moscas-das-frutas obtidas neste trabalho pode estar diretamente relacionada à presença de áreas de preservação de cerrado próximas aos dois pomares avaliados. O ecossistema de cerrado é um ambiente riquíssimo em frutos nativos e grande parte desses frutos podem atuar como repositório natural de moscas-das-frutas (Veloso, 1997; Uchoa, 1999).

Dentre as espécies de Anastrepha coletadas, A. fraterculus e A. zenildae foram as mais freqüentes e são importantes do ponto de vista econômico, pois a primeira é de importância quarentenária e a segunda, apesar de não ser quarentenária, possui o status de praga de goiaba, conforme constatado por Canal et al. (1998b) e Araújo \& Zucchi (2003). A. sororcula e A. obliqua são pragas quarentenárias e foram freqüentes também em frutos. A. turpiniae não possui importância quarentenária, entretanto ataca as goiabas.

Na segunda época (maio/2002 a agosto/2003), devido ao grande número de tefritídeos coletados em armadilhas (16.394 fêmeas), somente uma amostra (18,9\%) dos 
Tabela 2. Espécies de Anastrepha (fêmeas) e C. capitata (machos e fêmeas) coletadas em pomares comerciais de goiaba no norte de Minas Gerais. (maio/1999 a abril/2001 e maio/2002 a agosto/2003)

\begin{tabular}{|c|c|c|c|}
\hline \multirow{2}{*}{ Espécies } & \multicolumn{2}{|c|}{ Exemplares (n) } & \multirow[b]{2}{*}{ Total } \\
\hline & Armadilhas & Frutos & \\
\hline Anastrepha alveata Stone, 1942 & 6 & - & 6 \\
\hline Anastrepha barbiellinii Lima, 1938 & 1 & - & 1 \\
\hline Anastrepha daciformis Bezzi, 1909 & 1 & - & 1 \\
\hline Anastrepha dissimilis Stone, 1942 & 101 & - & 101 \\
\hline Anastrepha distincta Greene, 1934 & 1 & - & 1 \\
\hline Anastrepha fraterculus (Wiedemann, 1830) & 2.562 & 622 & 3.184 \\
\hline Anastrepha leptozona Hendel, 1914 & 1 & - & 1 \\
\hline Anastrepha manihoti Lima, 1934 & 4 & - & 4 \\
\hline Anastrepha montei Lima, 1934 & 14 & - & 14 \\
\hline Anastrepha obliqua (Macquart, 1835) & 155 & 66 & 221 \\
\hline Anastrepha pickeli Lima, 1934 & 102 & - & 102 \\
\hline Anastrepha serpentina (Wiedemann, 1830) & 1 & - & 1 \\
\hline Anastrepha sororcula Zucchi, 1979 & 266 & 89 & 355 \\
\hline Anastrepha undosa Stone, 1942 & 2 & - & 2 \\
\hline Anastrepha zenildae Zucchi, 1979 & 8.030 & 2.028 & 10.058 \\
\hline Anastrepha turpiniae Stone, 1942 & 6 & 13 & 19 \\
\hline Anastrepha n.sp.2 & 5 & - & 5 \\
\hline Anastrepha n.sp.3 & 15 & - & 15 \\
\hline Total & 11.273 & 2.818 & 14.091 \\
\hline Anastrepha spp. (não identificadas) & 13.292 & - & 13.292 \\
\hline Ceratitis capitata (Wiedemann, 1824) & 3.251 & 219 & 3.470 \\
\hline
\end{tabular}


espécimes de Anastrepha foram identificados, totalizando 3.102 fêmeas. Foram coletados 3.251 espécimes de C. capitata (machos e fêmeas) em armadilhas, durante todo o período de coleta (Tabela 2).

Foram amostradas 5.285 goiabas, de maio/1999 a abril/2001 e de maio/2002 a agosto/2003. Dos frutos amostrados, coletaram-se 10.650 pupários, porém foram obtidos apenas 6.161 adultos (moscas-das-frutas e parasitóides), com uma viabilidade pupal de 57,9\%. Dos adultos emergidos, 5.625 foram espécies de Anastrepha (2.807 machos e 2.818 fêmeas) e apenas 219 espécimes foram de C. capitata (89 machos e 130 fêmeas) (Tabela 3).

Tabela 3. Moscas-das-frutas coletadas em goiaba no norte de Minas Gerais. (maio/1999 a abril/2001 e maio/2002 a agosto/2003)

\begin{tabular}{cccccccc}
\hline \multirow{2}{*}{ Gêneros } & \multicolumn{3}{c}{ Jaíba } & \multicolumn{3}{c}{ Nova Porteirinha } & \multirow{2}{*}{ Total } \\
\cline { 2 - 6 } & Machos & Fêmeas & Total & Machos & Fêmeas & Total & \\
\hline Anastrepha spp. & 1968 & 1960 & 3928 & 839 & 858 & 1697 & 5625 \\
Ceratitis capitata & 71 & 101 & 172 & 18 & 29 & 47 & 219 \\
Total & 2039 & 2061 & 4100 & 857 & 892 & 1744 & 5844 \\
\hline
\end{tabular}

Em Jaíba, o número de C. capitata foi maior que o encontrado em Nova Porteirinha, pois neste pomar existia uma área com plantio de mamão com "meleira" e infestada de mosca-do-mediterrâneo Segundo Nascimento et al. (2000), mamoeiros infectados por "meleira” são altamente suscetíveis às moscas-das-frutas, pois a redução do BITC no fruto permite a oviposição e desenvolvimento das larvas. Isto colaborou para que houvesse uma infestação de C. capitata em goiaba, mesmo em pomar comercial, pois, segundo Canal (1997), no norte de Minas Gerais essa espécie se concentra nas frutíferas das áreas urbanas. Entretanto, C. capitata possui elevado poder de colonização. Até pouco tempo, não havia sido detectada em áreas de produção do semi-árido nordestino, ficando restrita somente às áreas urbanas (Araújo et al., 2000; Nascimento et al., 2001). Entretanto, à partir da década de 90, a população de $C$. 
capitata aumentou consideravelmente nas áreas de produção de fruteiras do nordeste brasileiro. A expansão de áreas plantadas com goiaba, acerola e café determinaram este aumento (Nascimento et al., 2001). Segundo Araújo (2002), em menos de dez anos após sua constatação na região de Mossoró, RN, ocorre em altas populações, mas restrita a focos isolados, ou seja, em alguns pomares de frutíferas exóticas, como acerola e kunquat.

Foram coletadas cinco espécies de Anastrepha (Tabela 4), sendo que somente $A$. zenildae e A. sororcula já haviam sido associadas à goiaba na região (Canal et al., 1998b). A. turpiniae está sendo registrada pela primeira vez no norte de Minas Gerais. A. fraterculus e A. obliqua já haviam sido coletadas em pomares de goiaba, porém somente em frascos caça-moscas (Canal et al., 1998b).

Araújo \& Zucchi (2003), durante estudos de determinação de níveis de infestação de espécies de Anastrepha em goiaba, obtiveram somente A. zenildae e A. sororcula dos frutos, com predominância da primeira espécie. Estudos em outras regiões do Brasil demonstraram que a goiaba foi o hospedeiro com a maior diversidade de espécies de moscas-das-frutas (Malavasi et al., 1980; Silva et al., 1996; Veloso, 1997; Souza Filho, 1999; Uchôa-Fernandes et al., 2002; Uramoto, 2002). Segundo Zucchi (2000b e 2001), dez espécies de Anastrepha e C. capitata estão associadas à goiaba no Brasil.

Tabela 4. Espécies de Anastrepha coletadas em goiaba no norte de Minas Gerais (maio/1999 a abril/2001 e maio/2002 a agosto/2003)

\begin{tabular}{lrr}
\hline Espécies de Anastrepha & Total & $\%$ \\
\hline A. zenildae & 2028 & 71,97 \\
A. fraterculus & 622 & 22,07 \\
A. sororcula & 89 & 3,16 \\
A. obliqua & 66 & 2,34 \\
A. turpiniae & 13 & 0,46
\end{tabular}


Entre as espécies de Anastrepha, A. zenildae foi a mais freqüente (Tabela 4). Ao contrário de outros trabalhos realizados em áreas de semi-árido (Nascimento, 1990; Canal et al., 1998b; Araújo \& Zucchi, 2003), a goiaba foi também bastante infestada por A. fraterculus, totalizando 22,07\% das fêmeas de Anastrepha obtidas de frutos. Segundo Malavasi \& Morgante (1980), no Brasil a goiaba é um dos hospedeiros mais atacados por A. fraterculus. No Recôncavo Baiano, a goiaba foi o hospedeiro que mais afetou a população desta espécie (Nascimento et al., 1982).

Em pomares comerciais, onde predomina um único hospedeiro, mesmo ocorrendo várias espécies de tefritídeos, normalmente somente duas a três são dominantes (Nascimento et al., 1982; Kovaleski, 1997). Nos dois pomares avaliados, as espécies predominantes foram A. zenildae e A. fraterculus (em armadilhas e frutos), somando 94\% dos indivíduos coletados (Tabelas 2 e 4).

A população de adultos de Anastrepha pode variar de ano para ano, não obedecendo a um padrão determinado (Aluja, 1994). Em Nova Porteirinha, as populações de A. zenildae e de $A$. fraterculus variaram entre os períodos avaliados (Tabela 5). Em 1999/2001, 65,1\% dos espécimes de Anastrepha coletados foram de $A$. zenildae, enquanto $A$. fraterculus totalizou $27,2 \%$. Na segunda época de avaliação, houve um decréscimo da população de $A$. zenildae (para 41,4\%) e um aumento significativo de $A$. fraterculus $(55,1 \%)$ (Tabela 5). Até pouco tempo, A. fraterculus ocorria em pequenas proporções em pomares de goiaba da região (5,5\% das fêmeas coletadas de armadilhas) e não estava relacionado aos frutos de goiaba (Canal et al., 1998b). Essas duas espécies foram predominantes neste pomar, somando mais de 90\% dos indivíduos coletados nas duas épocas.

Observa-se que a dinâmica populacional nos dois locais foi diferente para as espécies predominantes. No pomar de Jaíba, as proporções de cada espécie se mantiveram entre os anos avaliados, enquanto em Nova Porteirinha houve uma inversão, com uma tendência no aumento de A. fraterculus (Tabela 5). Segundo Canal (1997) e Aluja (1994), a predominância das espécies de moscas-das-frutas varia de local para local e também de ano para ano, portanto, a importância econômica de uma espécie depende da região (local) onde ocorre (Aluja, 1994; Hernandez-Ortiz \& Aluja, 1993). 
Tabela 5. Espécies de Anastrepha coletadas em goiaba em dois pomares comerciais do norte de Minas Gerais (maio/1999 a abril/2001 e maio/2002 a agosto/2003)

\begin{tabular}{|c|c|c|c|c|c|c|}
\hline \multirow{2}{*}{$\begin{array}{c}\text { Espécies de } \\
\text { Anastrepha }\end{array}$} & \multicolumn{3}{|c|}{ Jaíba } & \multicolumn{3}{|c|}{ Nova Porteirinha } \\
\hline & $1999 / 2001$ & $2002 / 2003$ & Total & $1999 / 2001$ & $2002 / 2003$ & Total \\
\hline A. zenildae & $1.259(79,4)^{1}$ & $278 \quad(74,1)$ & $1.537(78,4)$ & $373(65,1)$ & $118(41,4)$ & $491(57,2)$ \\
\hline A. fraterculus & $245(15,5)$ & $64(17,1)$ & $309(15,8)$ & $156(27,2)$ & $157(55,1)$ & $313(36,5)$ \\
\hline A. sororcula & $65(4,1)$ & $18(4,8)$ & $83(4,2)$ & $6(1,1)$ & $0(0)$ & $6(0,7)$ \\
\hline A. obliqua & $10(0,6)$ & $8(2,1)$ & $18(0,9)$ & $38 \quad(6,6)$ & $10(3,5)$ & $48(5,6)$ \\
\hline A. turpiniae & $6(0,4)$ & $7(1,9)$ & $13(0,7)$ & $0 \quad(0)$ & $0(0)$ & $0 \quad(0)$ \\
\hline Total & 1.585 & 375 & 1.960 & 573 & 285 & 858 \\
\hline
\end{tabular}

Chave para as espécies de Anastrepha coletadas em armadilhas em pomares de goiaba no norte de Minas Gerais

1 Faixa costal em toda a margem anterior da asa; faixa $\mathrm{S}$ incompleta; acúleo com menos de 0,05 mm de largura; ápice denteado A. daciformis

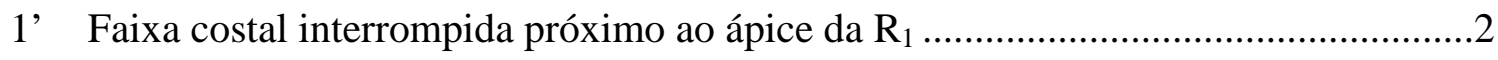

2 Mesonoto e abdome escuros com faixas amarelas; faixas das asas predominantemente marrom escura a preta; faixa V sem o ramo distal; acúleo denteado em menos da metade apical A. serpentina

2' Mesonoto e abdome predominantemente amarelados ................................................. 3

3 Mesonoto apresentando dois pares de faixas longitudinais muito finas, de coloração marrom escura; faixas costal e $\mathrm{S}$ separadas, faixa $\mathrm{V}$ unida à $\mathrm{S}$; ápice do acúleo liso e acentuadamente estreitado após a abertura do oviduto A. undosa 
3' Mesonoto sem manchas escuras em forma de faixas longitudinais.............................4

4 Metanoto e pós-escutelo totalmente amarelados ........................................................... 5

4' Metanoto e pós-escutelo escurecidos lateralmente...................................................13

5 Acúleo com menos de 0,07 mm de largura, uniformemente afilado e amplamente expandido na sua base; ápice muito curto; asa com todas as faixas separadas, ramo externo da V ausente ou não .................................................................... A. montei

5' Acúleo com mais de 0,07 mm de largura .............................................................. 6

6 Ápice do acúleo mais de duas vezes mais comprido do que a largura no fim do

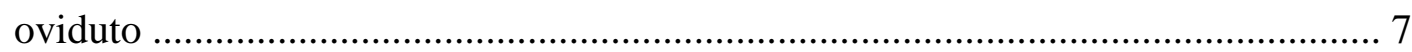

6' Ápice do acúleo em torno de 1,5 vezes mais comprido do que a largura no fim do

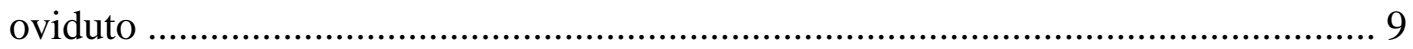

7 Dentes sobre 1/5 apical; ápice do acúleo afilando gradativamente........ A. barbiellinii

7' Dentes sobre mais da metade apical ............................................................................8

8 Asa com a nervura $\mathrm{M}$ acentuadamente curvada atingindo a faixa $\mathrm{S}$; faixa $\mathrm{V}$ incompleta, às vezes apenas com o ramo proximal .......................... leptozona

8' Asa com a nervura $\mathrm{M}$ não atingindo a faixa $\mathrm{S}$; faixa $\mathrm{V}$ completa............. A. dissimilis

9 Ápice do acúleo com as laterais voltadas para baixo; faixa costal unida ou separada da S; dentes estendendo-se até o nível da abertura do oviduto .................... A. alveata

9’ Ápice do acúleo com as laterais normais ..................................................................10

10 Ápice do acúleo com constrição evidente antes da serra .......................... A. manihoti

10’ Ápice do acúleo sem constrição antes da serra ..................................................... 11

11 Dentes do acúleo não alcançando o nível do fim do oviduto; todas as faixas alares separadas Anastrepha n.sp.2

11' Dentes ultrapassando o nível do fim do oviduto ....................................................... 12

12 Acúleo com menos de $1,7 \mathrm{~mm}$........................................................................

12' Acúleo com mais de 2,0 mm ........................................... Anastrepha n.sp.3

13 Acúleo com dentes restritos à sua parte apical, sem constrição antes da serra; acúleo com mais de 2,0 mm; faixa costal unida à $\mathrm{S}$

A. distincta 
13’ Acúleo com constrição antes da serra, dentes até a metade apical ou além ............14

14 Ápice do acúleo com uma nítida constrição antes da serra ...................................... 15

14' Ápice do acúleo com uma leve constrição antes da serra ....................................... 16

15 Ápice do acúleo com menos de 0,20 mm de comprimento..................... A. sororcula

15' Ápice do acúleo com mais de 0,22 mm de comprimento.................... A. fraterculus

16 Ápice do acúleo com menos de 0,25 mm de comprimento; dentes agudos; faixa costal unida à S ................................................................................... obliqua

16' Ápice do acúleo com mais de 0,25 mm de comprimento ...................................... 17

17 Ápice do acúleo com os dentes sobre 2/3 apical ..................................... A. zenildae

17' Ápice do acúleo com os dentes ultrapassando a $1 / 2$ apical ..................... A. turpiniae 


\subsubsection{Análise faunística das espécies de Anastrepha}

Foram coletadas 18 espécies de Anastrepha nos dois pomares durante 160 semanas. Os índices faunísticos foram calculados considerando-se somente as fêmeas coletadas e identificadas (11.273) (Tabela 2), pois as espécies de Anastrepha só podem ser identificadas através das fêmeas. A análise faunística foi feita para os dois pomares em conjunto e encontra-se na Tabela 6.

A. fraterculus, A. obliqua, A. sororcula e A. zenildae foram as espécies mais importantes, pois foram associadas aos índices máximos (classe super) de dominância, abundância, freqüência e constância. Dentre as cinco espécies coletadas que utilizam a goiaba como hospedeiro (Tabela 4), A. turpiniae apresentou os menores índices (dominante, comum, freqüente e acidental). A. zenildae foi a mais freqüente correspondendo a 71,2\% do total de fêmeas capturadas, seguida por A. fraterculus (22,7\%), A. sororcula (2,4\%) e A. obliqua $(1,4 \%)$. As demais espécies apresentaram freqüência menor que $1 \%$ (Tabela 6) e dentre elas, somente A. dissimilis, A. pickeli e Anastrepha n.sp.3 foram acessórias. Todas as outras 12 espécies foram acidentais, ou seja, ocorreram esporadicamente nos pomares. A. barbiellinii, A. daciformis, A. distincta, A. leptozona e A. serpentina foram espécies raras, sendo obtidas em apenas uma coleta cada uma.

Embora diversas espécies de Anastrepha estejam presentes nos pomares, apenas duas (A. zenildae e A. fraterculus) representaram mais de $90 \%$ de todas as moscas coletadas em armadilhas. Os altos índices encontrados para as duas espécies mais freqüentes confirmam o status de praga nestes pomares, pois, das espécies que relacionaram aos frutos de goiaba (Tabela 4), A. zenildae e A. fraterculus contribuíram com a maior porcentagem de infestação. A alta dominância de apenas uma ou duas espécies também foi verificada em estudos similares conduzidos no Brasil (Nascimento \& Zucchi, 1981; Nascimento et al., 1983; Kovaleski, 1997; Veloso, 1997; Canal et al., 1998a; Garcia \& Corseuil, 1998; Uramoto, 2002; Garcia et al., 2003). 
Tabela 6. Análise faunística das espécies de Anastrepha coletadas em armadilhas tipo McPhail em dois pomares de goiaba no norte do Estado de Minas Gerais (julho/1999 a abril/2001 e maio/2002 a maio/2003)

\begin{tabular}{lccccc}
\hline \multicolumn{1}{c}{ Espécies } & $\mathrm{N}^{0}$ de coletas & Dominância & Abundância & Freqüência & Constância \\
\hline A. alveata & 5 & $\mathrm{D}$ & $\mathrm{C}$ & $\mathrm{F}$ & $\mathrm{Z}$ \\
A. barbiellinii & 1 & $\mathrm{ND}$ & $\mathrm{r}$ & $\mathrm{PF}$ & $\mathrm{Z}$ \\
A. daciformis & 1 & $\mathrm{ND}$ & $\mathrm{r}$ & $\mathrm{PF}$ & $\mathrm{Z}$ \\
A. dissimilis & 28 & $\mathrm{SD}$ & $\mathrm{sa}$ & $\mathrm{SF}$ & $\mathrm{Y}$ \\
A. distincta & 1 & $\mathrm{ND}$ & $\mathrm{r}$ & $\mathrm{PF}$ & $\mathrm{Z}$ \\
A. fraterculus & 135 & $\mathrm{SD}$ & $\mathrm{sa}$ & $\mathrm{SF}$ & $\mathrm{W}$ \\
A. leptozona & 1 & $\mathrm{ND}$ & $\mathrm{r}$ & $\mathrm{PF}$ & $\mathrm{Z}$ \\
A. manihoti & 3 & $\mathrm{ND}$ & $\mathrm{C}$ & $\mathrm{F}$ & $\mathrm{Z}$ \\
A. montei & 7 & $\mathrm{D}$ & $\mathrm{ma}$ & $\mathrm{MF}$ & $\mathrm{Z}$ \\
A. obliqua & 63 & $\mathrm{SD}$ & $\mathrm{sa}$ & $\mathrm{SF}$ & $\mathrm{W}$ \\
A. pickeli & 43 & $\mathrm{SD}$ & $\mathrm{sa}$ & $\mathrm{SF}$ & $\mathrm{Y}$ \\
A. serpentina & 1 & $\mathrm{ND}$ & $\mathrm{r}$ & $\mathrm{PF}$ & $\mathrm{Z}$ \\
A. sororcula & 64 & $\mathrm{SD}$ & $\mathrm{sa}$ & $\mathrm{SF}$ & $\mathrm{W}$ \\
A. undosa & 2 & $\mathrm{ND}$ & $\mathrm{c}$ & $\mathrm{F}$ & $\mathrm{Z}$ \\
A. zenildae & 153 & $\mathrm{SD}$ & $\mathrm{sa}$ & $\mathrm{SF}$ & $\mathrm{W}$ \\
A. turpiniae & 6 & $\mathrm{D}$ & $\mathrm{c}$ & $\mathrm{F}$ & $\mathrm{Z}$ \\
Anastrepha $\mathrm{n} . \mathrm{sp} .2$ & 5 & $\mathrm{ND}$ & $\mathrm{c}$ & $\mathrm{F}$ & $\mathrm{Z}$ \\
Anastrepha $\mathrm{n} . \mathrm{sp} .3$ & 13 & $\mathrm{D}$ & $\mathrm{ma}$ & $\mathrm{MF}$ & $\mathrm{Y}$ \\
\hline In & & & & & \\
\hline
\end{tabular}

Índice de diversidade $\mathrm{H}=0,8476$

Intervalo de confiança $(\mathrm{P}=0,005)=(0,847402 ; 0,847777)$

Dominância: SD: super dominante; D: dominante; ND: não dominante.

Abundância: as: super abundante; ma: muito abundante; c: comum; r: rara.

Freqüência: SF: super freqüente; MF: muito freqüente; F: freqüente; PF: pouco freqüente.

Constância: w: constante; y: acessória; z: acidental. 


\subsubsection{Flutuação das populações de tefritídeos em pomares de goiaba}

Foram capturados 39.387 espécimes de Anastrepha em armadilhas tipo McPhail (24.565 fêmeas e 14.822 machos), durante o período de coleta, nos dois pomares (Tabela 1). Os níveis populacionais mantiveram-se relativamente altos em todo o período de coleta, exceto em julho, outubro, novembro e dezembro/1999, quando o número máximo coletado não passou de 45 espécimes por mês (1,5 moscas/armadilha/dia) (Figura 1). Em todos os meses de coleta foram capturados adultos de Anastrepha, mas em novembro somente um espécime foi coletado. Na segunda época de coleta, quando foram instaladas dez armadilhas em cada pomar, totalizando 20 armadilhas, a população atingiu um pico máximo em abril/2003, quando foram coletados aproximadamente 53\% (14.367 moscas) do total de adultos capturados. Um outro aumento populacional, embora menor, foi observado em novembro/2002. Da mesma forma, em todos os meses foram coletados adultos nas armadilhas, mas em agosto houve o menor nível populacional (Figura 1).

As duas espécies mais freqüentes foram A. zenildae e A. fraterculus, representando aproximadamente 94\% de todas as fêmeas coletadas e identificadas. Essas duas espécies ocorreram durante quase todo o período de coleta em pelo menos um dos

pomares. A. zenildae só não foi coletada em julho e novembro/1999 e pelo menos um espécime foi coletado nos outros meses de coleta (Figura 2).

Considerando-se as flutuações em número das duas espécies nos dois locais, pôde-se observar que a população de $A$. zenildae manteve-se maior do que a de $A$. fraterculus ao longo de todo o período, exceto de agosto a outubro/1999, quando ocorreu discreta elevação no nível populacional de A. fraterculus, mantendo-se em níveis mais baixos que A. zenildae nos demais meses (Figura 2).

A flutuação populacional de A. zenildae apresentou o mesmo padrão observado para o total de fêmeas capturadas, em conseqüência de sua significativa contribuição proporcional (71,2\%) (Figuras 1 e 2). 

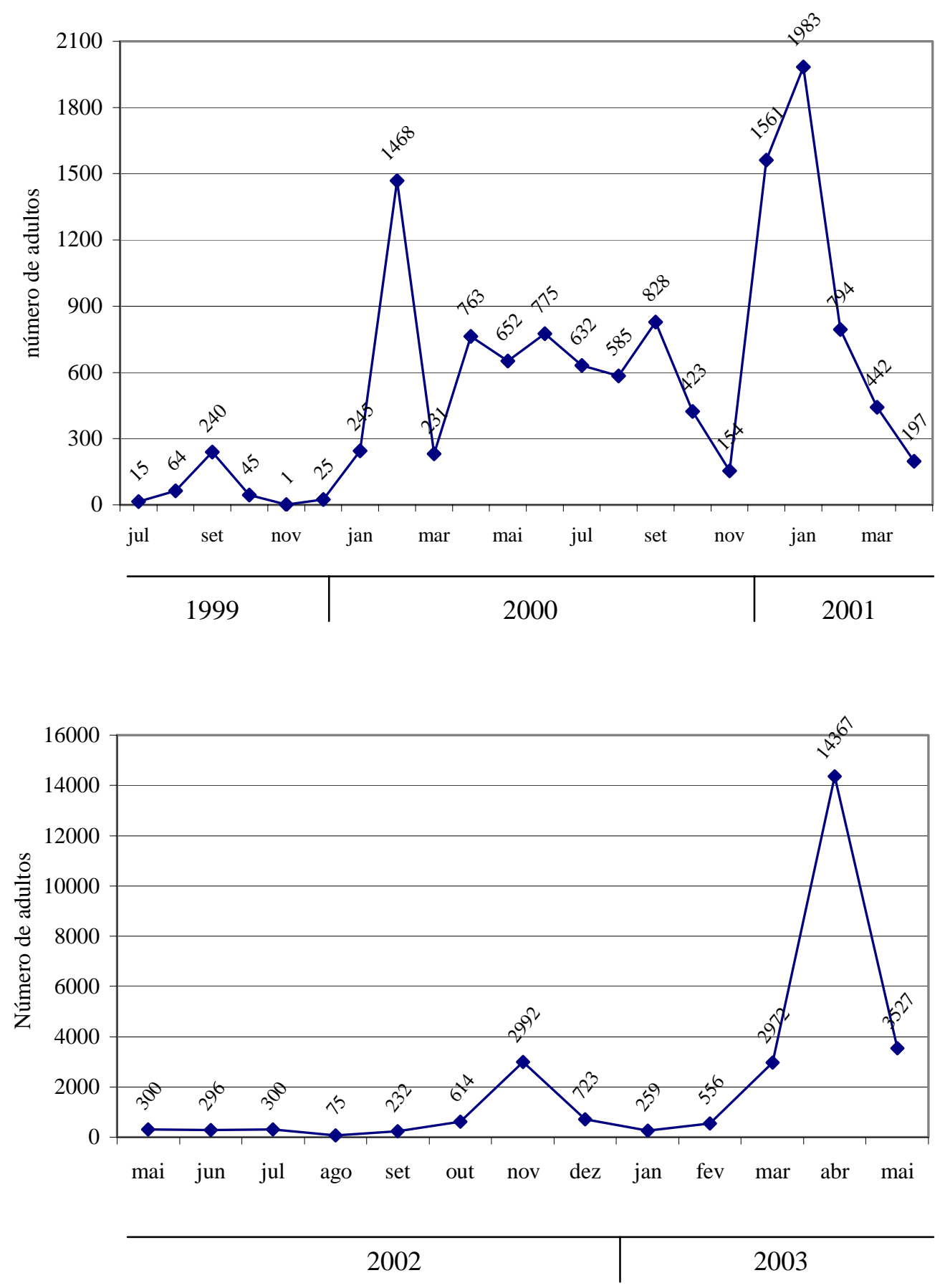

Figura 1 - Flutuação populacional de adultos de Anastrepha spp. capturados em armadilhas tipo McPhail no norte de Minas Gerais, julho/1999 a abril/2001 e maio/2002 a maio/2003 
$\rightarrow$ A. fraterculus $\rightarrow$ A. zenildae
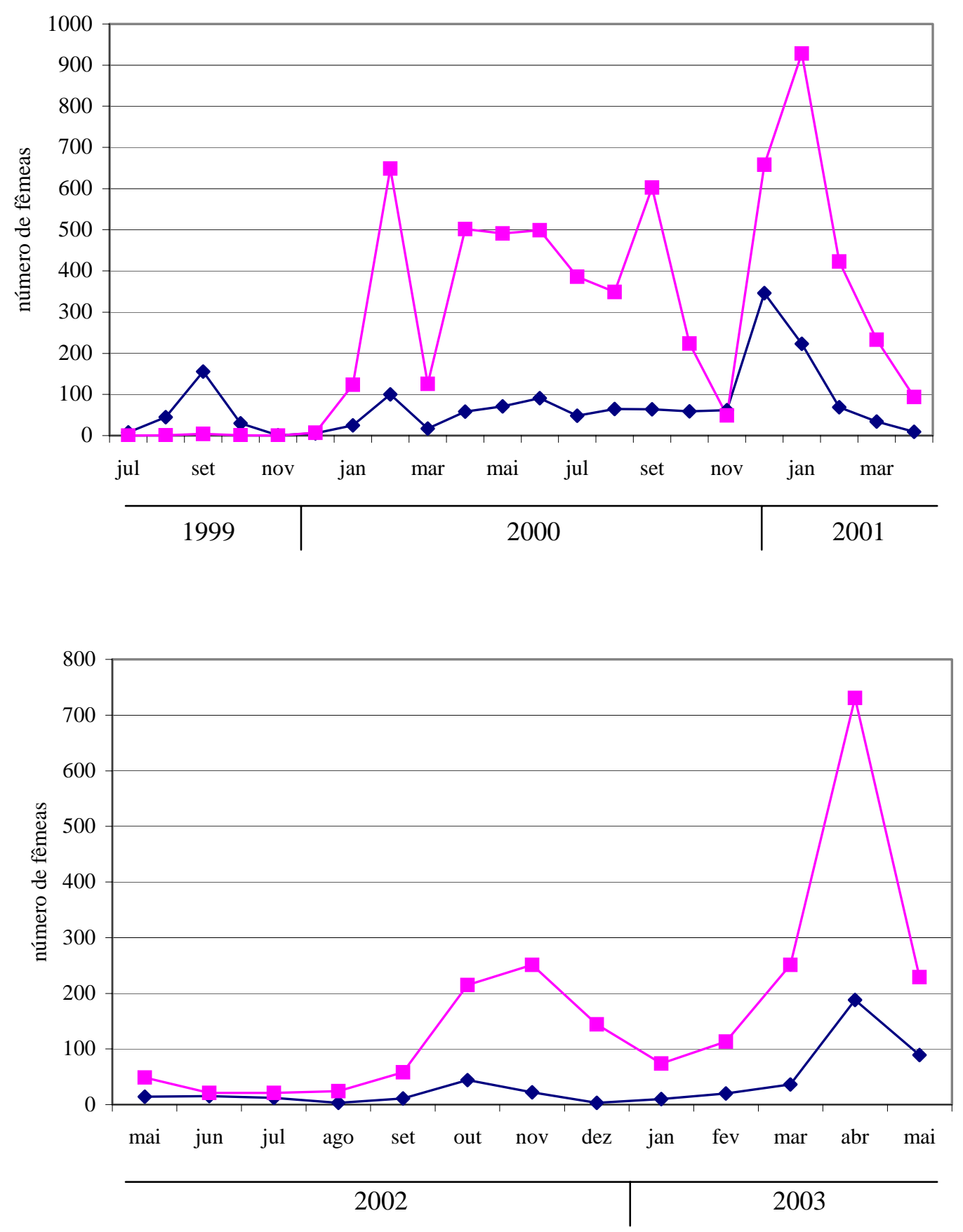

Figura 2 - Flutuação populacional de fêmeas de A. fraterculus e A. zenildae capturadas em armadilhas tipo McPhail em Jaíba e Nova Porteirinha, MG, julho/1999 a abril/2001 e maio/2002 a maio/2003 
Analisando-se a flutuação populacional das duas espécies em cada local de coleta (Figura 3), observa-se que em Nova Porteirinha as populações de $A$. fraterculus e $A$. zenildae se alternaram durante todo o período de coleta. Os aumentos populacionais ocorreram na mesma época, porém sempre com uma das espécies predominando, o que pode ser atribuído à competição entre essas duas espécies pelo mesmo nicho (hospedeiro) neste local. Entretanto, este fato não ocorreu no pomar de Jaíba, no qual, em praticamente todo o período de coleta, $A$. zenildae predominou sobre $A$. fraterculus (Figura 4).

A análise por espécie permite verificar, no caso de A. fraterculus (Figura 5), que houve uma alternância nos picos populacionais desta espécie entre os dois pomares avaliados. Quando a população atingia um pico em um dos locais, no outro ela era reduzida, sempre no mesmo período de coleta. No período entre dezembro/2000 e janeiro/2001, mesmo havendo um pico populacional nos dois locais, a população de $A$. fraterculus foi maior em Nova Porteirinha, obedecendo a ordem de alternância das flutuações. Observa-se que A. zenildae foi mais abundante no pomar de Jaíba em quase todo o período de coleta, apesar de em alguns períodos haver uma queda na população (Figura 6). Somente em dois momentos a população desta espécie foi maior no pomar de Nova Porteirinha (abril/maio de 2000 e agosto a dezembro/2002).

A predominância das espécies de moscas-das-frutas variou de local para local e também de ano para ano, o que vem confirmar que a importância econômica de uma espécie pode ser maior segundo a região (local) onde ocorre e também a época do ano (Aluja, 1994; Canal, 1997).

As flutuações populacionais nos dois locais e das espécies mais freqüentes não correlacionaram com nenhum parâmetro climático analisado. Provavelmente as maiores capturas tenham ocorrido em razão da maior disponibilidade de frutos. Apesar de haver frutos durante todo o período de coleta, pois os pomares eram irrigados, a época do ano em que os dois pomares apresentavam a maior produção, ou seja, o pico de frutos maduros, era de março a maio. Neste período também foi capturado um grande número de tefritídeos em armadilhas. Entretanto, mesmo não sendo observada correlação, os picos de coleta ocorreram nos meses de janeiro e fevereiro, exatamente 


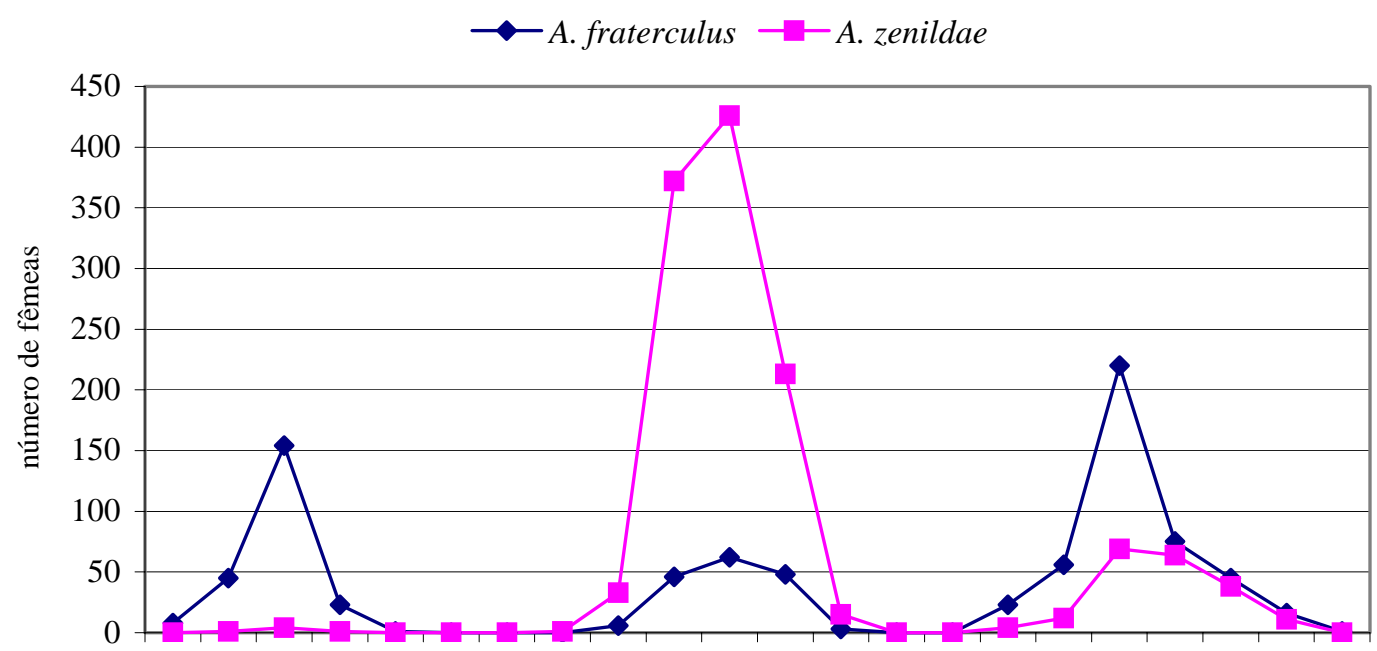

jul ago set out nov dez jan fev mar abr mai jun jul ago set out nov dez jan fev mar abr

\begin{tabular}{l|l|l}
\hline 1999 & 2000 & 2001
\end{tabular}

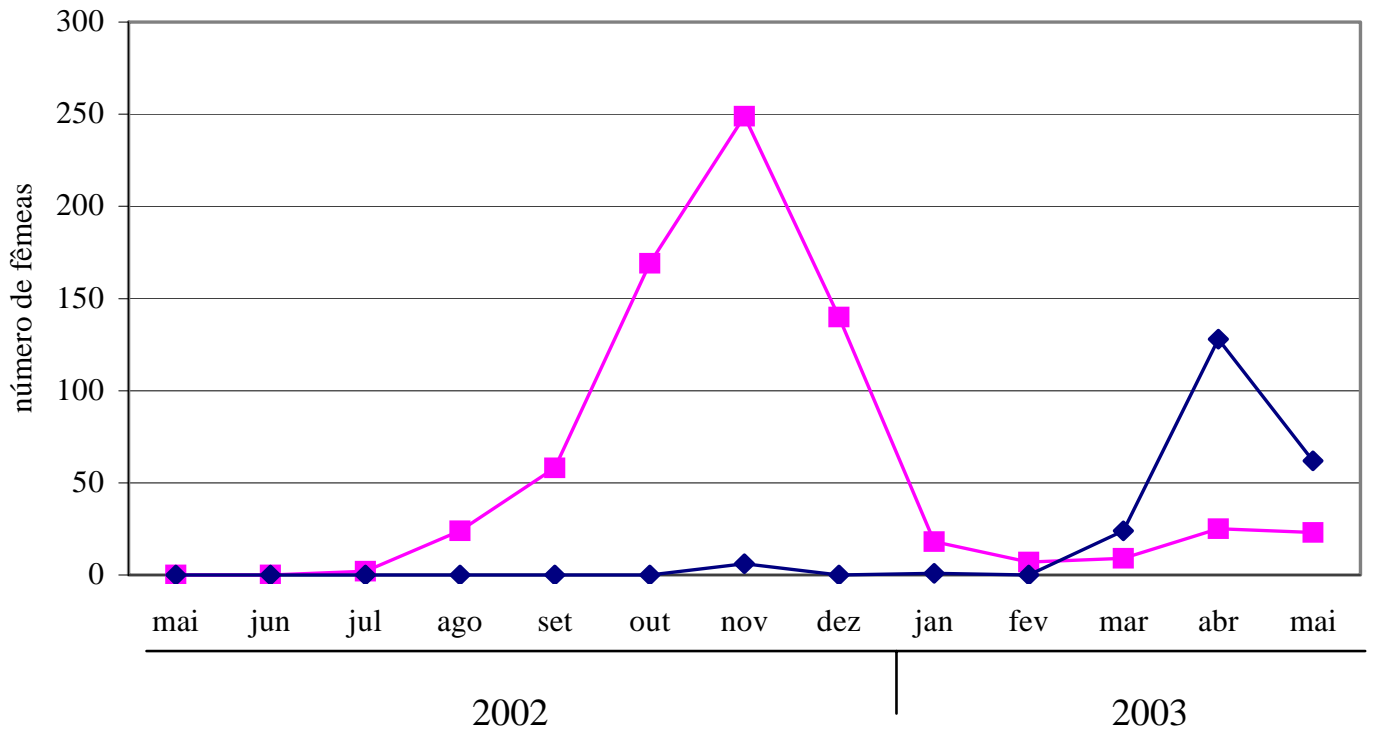

Figura 3 - Flutuação populacional de fêmeas de A. fraterculus e A. zenildae capturadas em armadilhas tipo McPhail em Nova Porteirinha, MG, julho/1999 a abril/2001 e maio/2002 a maio/2003 

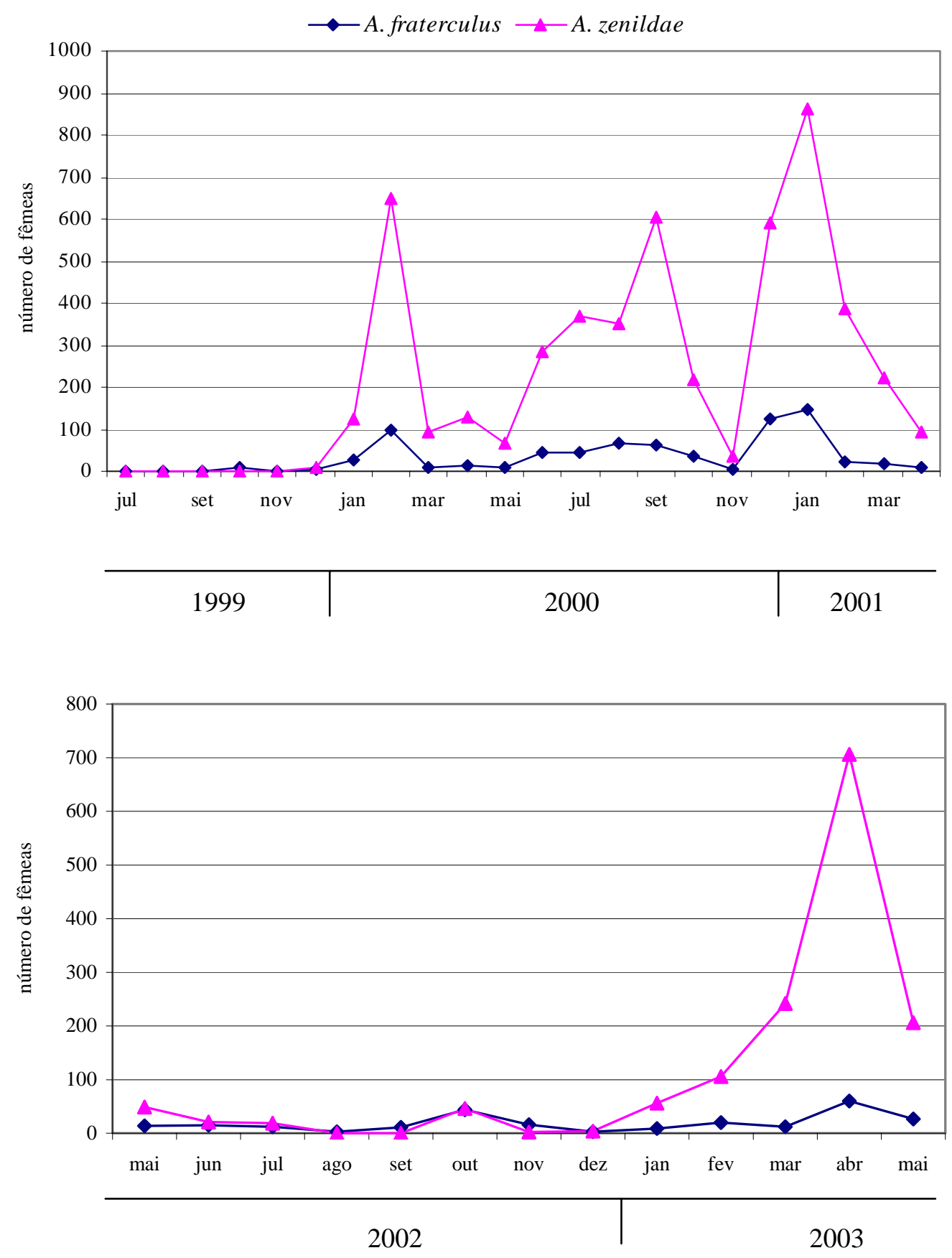

Figura 4 - Flutuação populacional de fêmeas de A. fraterculus e A. zenildae capturadas em armadilhas tipo McPhail em Jaíba, MG, julho/1999 a abril/2001 e maio/2002 a maio/2003 
após o período chuvoso. Portanto, os fatores climáticos podem ter exercido uma certa influência sobre as populações nativas de moscas-das-frutas no norte de Minas Gerais, mesmo que seja a nível microclimático como observado por Parra et al. (1982). Segundo Aluja (1994), a precipitação pluvial é um dos principais fatores relacionados com a flutuação populacional das moscas-das-frutas.

Zahler (1991) estudou a flutuação populacional de moscas-das-frutas em dois pomares comerciais de mangueira no Distrito Federal. Observou que os maiores valores de captura foram durante a época de frutificação e que não existiu correlação entre os fatores climáticos e as populações de mosca. Entretanto, em outro trabalho na mesma região, concluiu que as populações de tefritídeos foram afetadas pela presença de frutos maduros e por condições climáticas, especialmente temperatura e umidade relativa (Zahler, 1990). Fato semelhante foi observado por vários autores (Rossi et al., 1988; Salles, 1995; Aguiar-Menezes \& Menezes, 1996; Canal et al., 1998a; Veloso, 1997; Ronchi-Teles, 2000; Uramoto, 2002). 

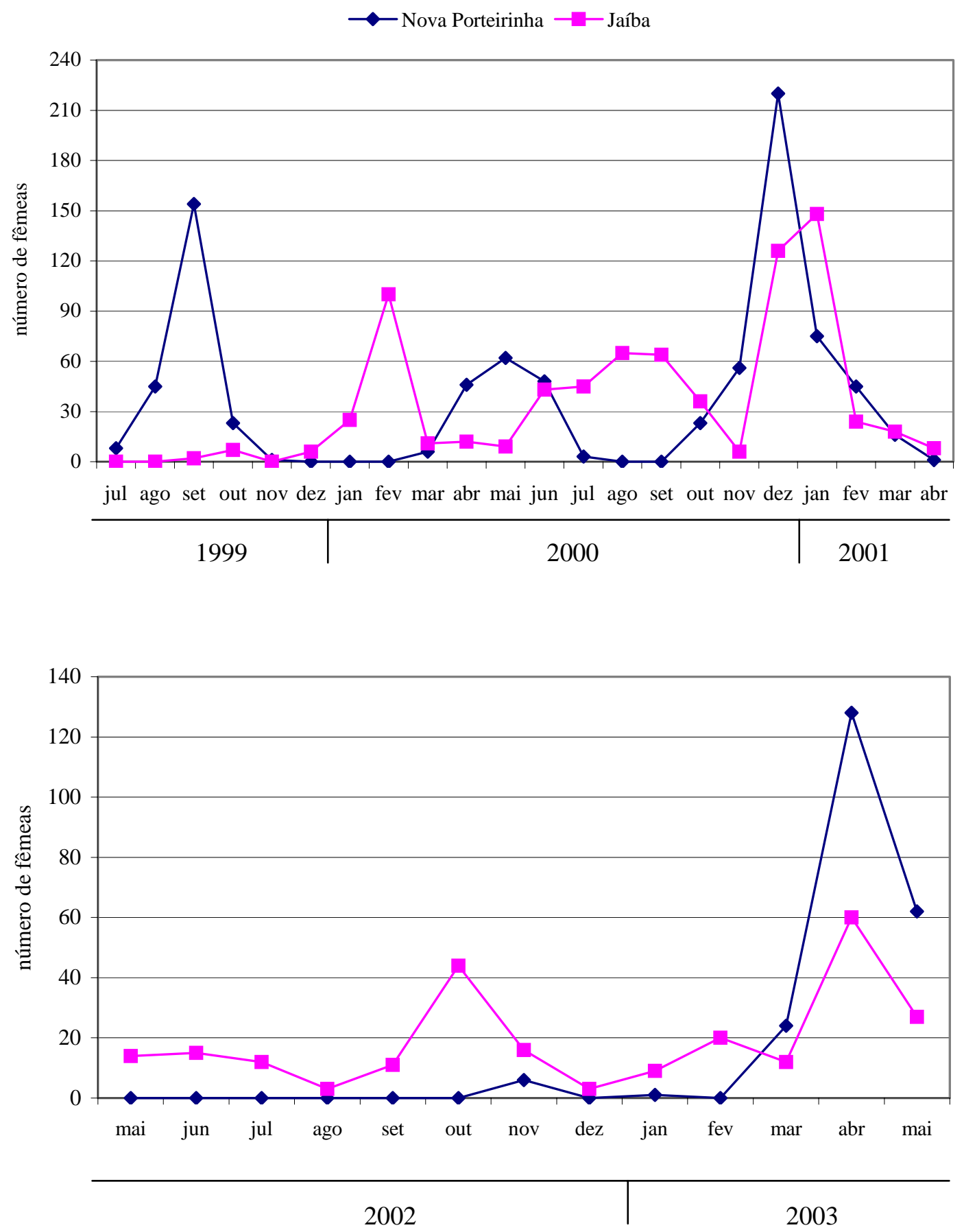

Figura 5 - Flutuação populacional de fêmeas de A. fraterculus capturadas em armadilhas tipo McPhail em Nova Porteirinha e Jaíba, MG, julho/1999 a abril/2001 e maio/2002 a maio/2003 

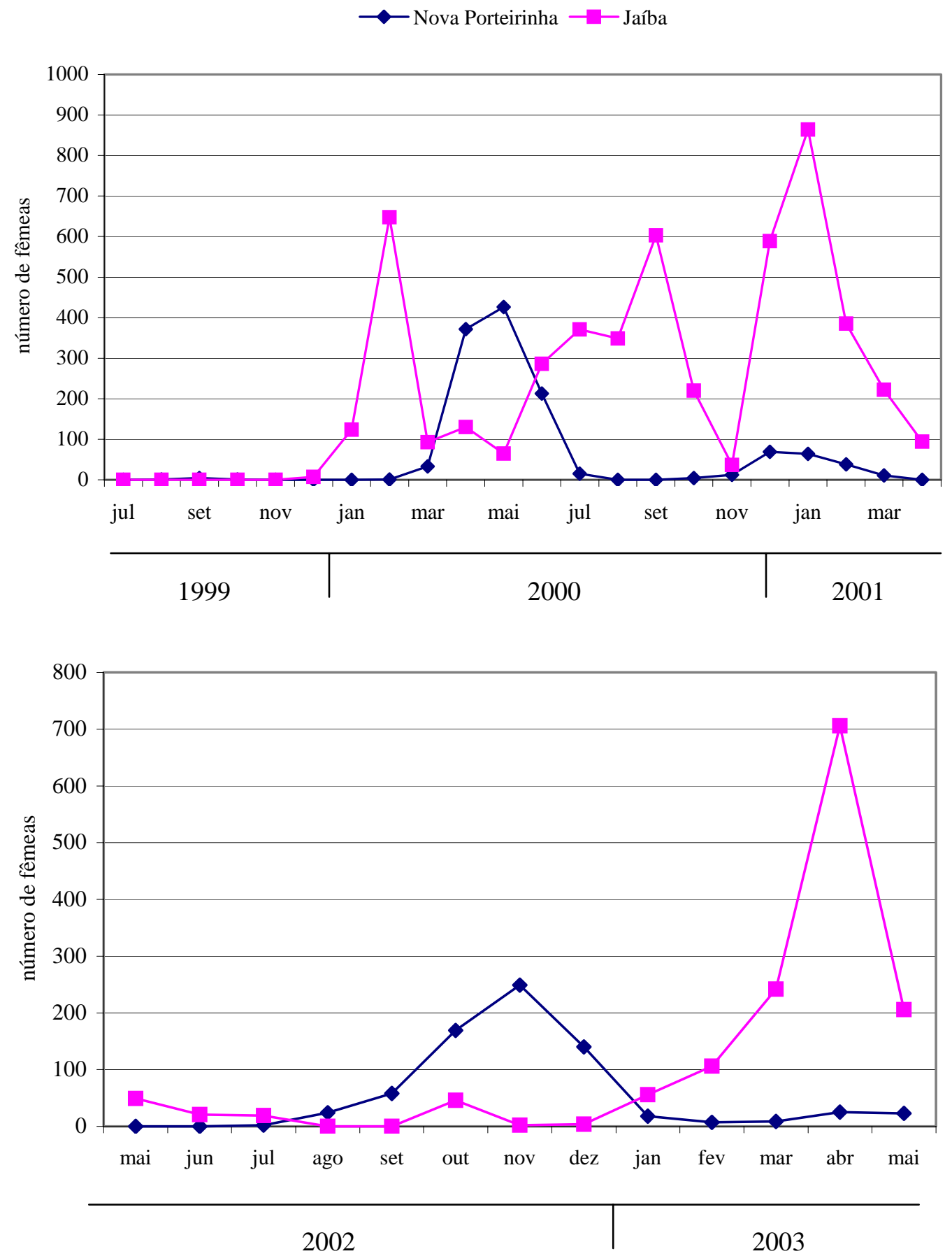

Figura 6 - Flutuação populacional de fêmeas de A. zenildae capturadas em armadilhas tipo McPhail em Nova Porteirinha e Jaíba, MG, julho/1999 a abril/2001 e maio/2002 a maio/2003 


\section{2 Î́ndices de infestação de moscas-das-frutas em goiaba}

Durante todo o período de coleta de frutos (nas duas épocas), C. capitata e 18 espécies de Anastrepha spp. foram capturadas nas armadilhas (Tabela 2), com predominância de A. zenildae seguida de A. fraterculus. Além de C. capitata, apenas cinco espécies de Anastrepha foram obtidas de frutos: A. zenildae (71,97\%), A. fraterculus (22,07\%), A. sororcula (3,16\%), A. obliqua (2,34\%) e A. turpiniae (0,46\%) (Tabela 4). Em trabalho realizado anteriormente na região, Canal et al. (1998b) obtiveram A. zenildae e A. sororcula de goiabas e coletaram A. fraterculus e A. obliqua somente em armadilhas. Informações semelhantes foram obtidas por Araújo \& Zucchi (2003), durante estudos de determinação de índices de infestação de moscas-das-frutas em goiaba, em Mossoró, RN, região também semi-árida.

Para a determinação dos índices de infestação e intensidade de infestação foram utilizados os dados de coleta de frutos de maio/2002 a agosto/2003.

No pomar de Jaíba foram coletados frutos durante todo o período e verificado frutos infestados em todos os meses de coleta. No pomar de Nova Porteirinha, a coleta de frutos iniciou-se em julho/2002, pois o pomar havia sido podado. Neste local somente em fevereiro/2003 não foram encontrados frutos infestados.

Tabela 7. Número de goiabas coletadas e infestadas, porcentagem de infestação e intensidade de infestação de moscas-das-frutas em dois pomares comerciais no norte de Minas Gerais (maio/2002 a agosto/2003)

\begin{tabular}{lccccccc}
\hline \multirow{2}{*}{ Local } & \multicolumn{2}{c}{ Frutos (n) } & \multicolumn{2}{c}{ Infestação } & \multicolumn{2}{c}{ Adultos (n) } & \\
\cline { 2 - 7 } & Coletados & Infestados & $\%$ & I.I. & Anastrepha & Ceratitis & Total \\
\hline Jaíba & 1412 & 506 & 35,8 & 28,0 & 763 & 166 & 929 \\
Nova Porteirinha & 1317 & 339 & 25,7 & 21,4 & 556 & 43 & 599 \\
\hline
\end{tabular}

A infestação de moscas-das-frutas em goiaba foi maior em Jaíba (Tabela 7), com média de 35,84\% de frutos infestados, variando de 10,53\% (agosto/2003) a 73,03\% 
(junho/2003). Entretanto, mesmo a infestação sendo alta, nem sempre a intensidade de infestação acompanha estes valores, ou seja, a porcentagem de frutos infestados não mede a intensidade de infestação destes frutos. Por exemplo, no mês de maior intensidade de infestação (dezembro/2002), a porcentagem de frutos infestados foi de 15,38\% (Figura 7). No entanto, um fruto infestado é um fruto perdido, mesmo que tenha somente uma larva. Logo, a intensidade de infestação não quantifica a perda na produção. Porém, se observar que quanto maior o número de larvas maior a população de adultos que emergirá na próxima geração, aí sim este índice é importante, pois, mede a intensidade daquela infestação, a qual poderá prejudicar o fruto a ser produzido posteriormente.

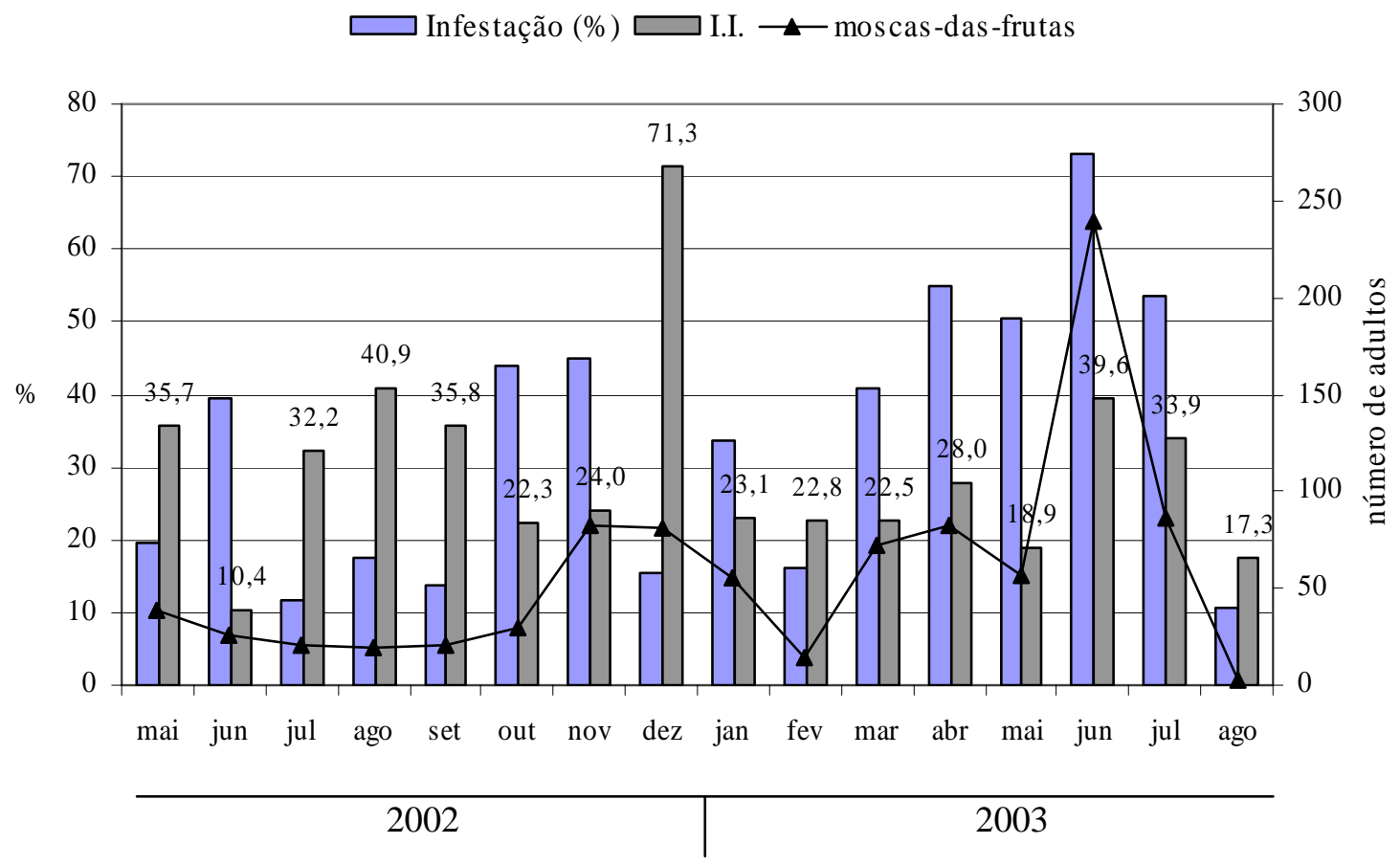

Figura 7 - Índice de infestação (\% frutos infestados), intensidade de infestação (I.I.) e número de moscas-das-frutas em goiaba Psidium guajava no pomar de Jaíba, MG, maio/2002 a agosto/2003 
Vários fatores podem influenciar o nível de infestação das moscas-das-frutas nos pomares (Nascimento et al., 1982; Parra et al., 1982). Segundo Araújo \& Zucchi (2003), nas regiões semi-áridas, tudo indica que a precipitação pluvial aliada à disponibilidade de hospedeiros são os fatores preponderantes, pois os meses seguintes às maiores precipitações pluviais e o período de maior frutificação da goiaba em Mossoró, RN, foram justamente os meses de maiores picos populacionais e níveis de infestação. Em pomares comerciais, onde predomina um único hospedeiro, a maior densidade populacional ocorre na época de maior concentração de frutos maduros (Nascimento \& Carvalho, 2000). No período de março a junho/2003, houve a maior produção de goiabas no pomar. Apesar do número de frutos amostrados ser praticamente o mesmo durante os meses de coleta, o tamanho dos frutos, e conseqüentemente o peso, variou bastante.

Foram coletados 929 tefritídeos (C. capitata e Anastrepha spp.) (Tabela 7) durante os 16 meses de coleta no pomar de Jaíba. Das seis espécies de moscas-das-frutas obtidas da goiaba, A. zenildae (58,8\%), A. fraterculus (13,5\%) e C. capitata (20,7\%) predominaram, correspondendo a $93 \%$ do total de fêmeas coletadas. Portanto, pode-se afirmar que estas três espécies são as responsáveis pelos altos níveis de infestação do pomar. C. capitata foi a segunda espécie que mais contribuiu nos índices de infestação da goiaba. Em levantamentos realizados na região, esta espécie estava restrita aos pomares domésticos principalmente de áreas urabanas (Canal, 1997). Entretanto, pelo fato do pomar de Jaíba localizar-se ao lado de um plantio de 0,5 ha de mamão infectado por "meleira”, houve uma infestação significativa de C. capitata nas goiabas, decorrente da elevada população desta praga na área.

Os índices de infestação foram maiores de março a julho/2003 com um pico em junho (73\%) (Figura 7), coincidindo com o pico de A. zenildae obtidas de frutos (Figura 8). Estes resultados estão próximos aos observados no pomar de goiaba de Mossoró (Araújo \& Zucchi, 2003), RN, onde as mais altas infestações de frutos ocorreram de maio a julho, período com os maiores índices populacionais e com predominância de $A$. zenildae (86,9\%). 
Em Nova Porteirinha, 25,7\% dos frutos coletados estavam infestados, com uma intensidade de 21,4 (Tabela 7). As maiores infestações foram observadas em março, abril, junho e julho/2003 (40\%), sendo em março a infestação mais intensa $(36,93)$ (Figura 9). Em fevereiro/2003, nenhum fruto coletado estava infestado, ou seja, não houve perda na produção. Entretanto foram coletados poucos frutos em relação aos outros meses de coleta. As menores infestações foram observadas de julho a setembro/2002. Estes frutos foram produzidos logo após uma poda e provavelmente o nível populacional de moscas-das-frutas estava baixo pela falta de frutos hospedeiros no pomar.

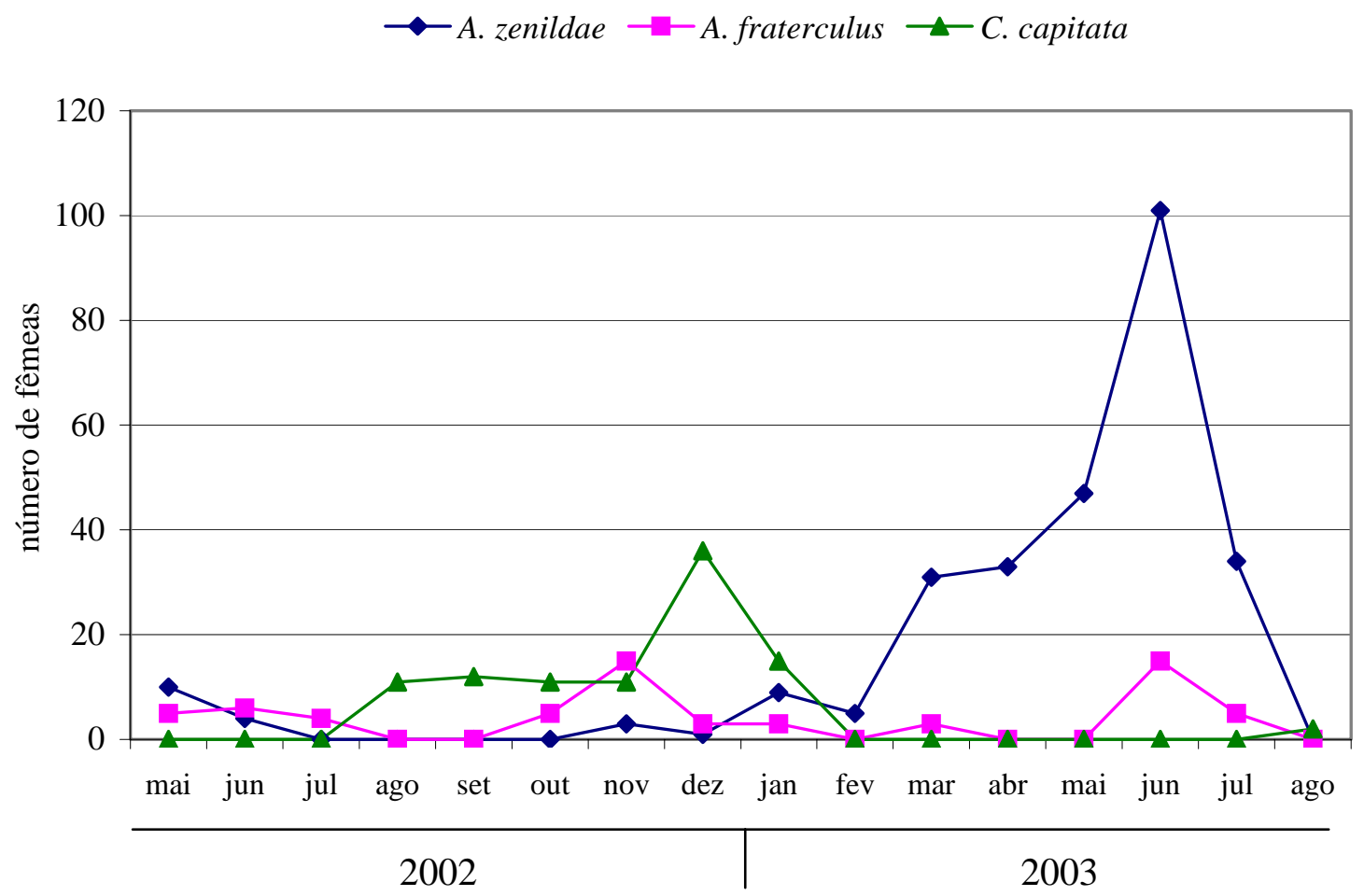

Figura 8 - Número de fêmeas de A. zenildae, A. fraterculus e C. capitata obtidas de goiabas Psidium guajava em Jaíba, MG, maio/2002 a agosto/2003

Durante o período de coleta de frutos no pomar de Nova Porteirinha (14 meses), foram obtidos 599 adultos (Anastrepha spp. e C. capitata) (Tabela 7). Somente três 
espécies de Anastrepha foram relacionadas aos frutos neste pomar: A. fraterculus (50,3\%), A. zenildae (37,8\%) e A. obliqua (3,2\%), além de 43 espécimes de C. capitata (8,6\% do total de fêmeas).

Neste pomar, foram obtidos resultados semelhantes ao de Jaíba com relação às espécies de Anastrepha. Aproximadamente 88\% das fêmeas de tefritídeos coletadas pertenciam às espécies $A$. fraterculus e A. zenildae, sendo, portanto também as responsáveis pelos altos índices de infestação neste local.

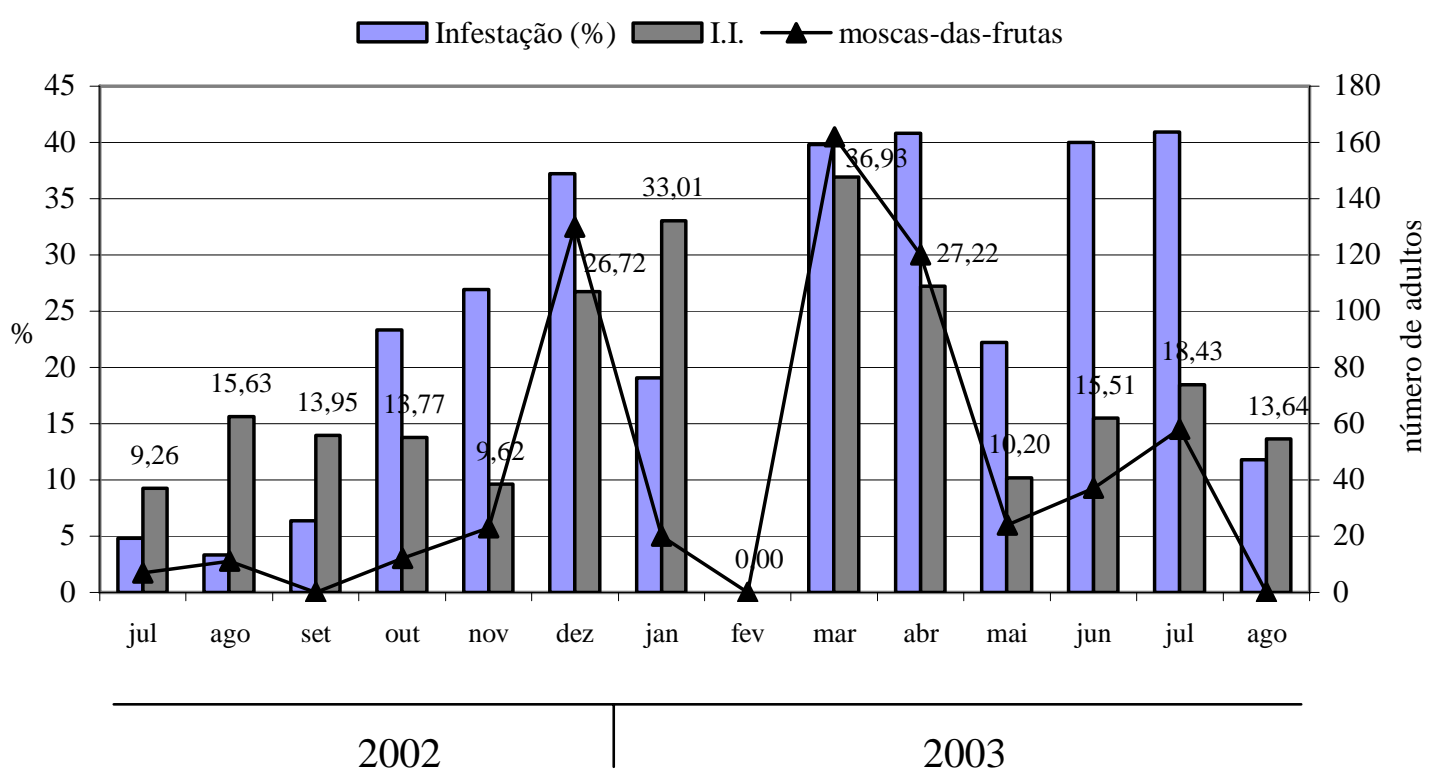

Figura 9 - Índice de infestação (\% frutos infestados), intensidade de infestação (I.I.) e número de moscas-das-frutas em goiaba Psidium guajava no pomar de Nova Porteirinha, MG, maio/2002 a agosto/2003

Constatou-se que os altos índices de infestação ocorridos em dezembro/2002 e março/abril/2003 foram conseqüência de picos populacionais de $A$. fraterculus e $A$. zenildae separadamente, com predominância da primeira, ou seja, em cada período uma espécie foi responsável pelo dano (Figuras 10 e 11), obedecendo a alternância observada na flutuação populacional (em armadilhas) entre essas espécies (Figura 4). Araújo \& Zucchi (2003) observaram uma interação de A. zenildae e A. sororcula na exploração da 


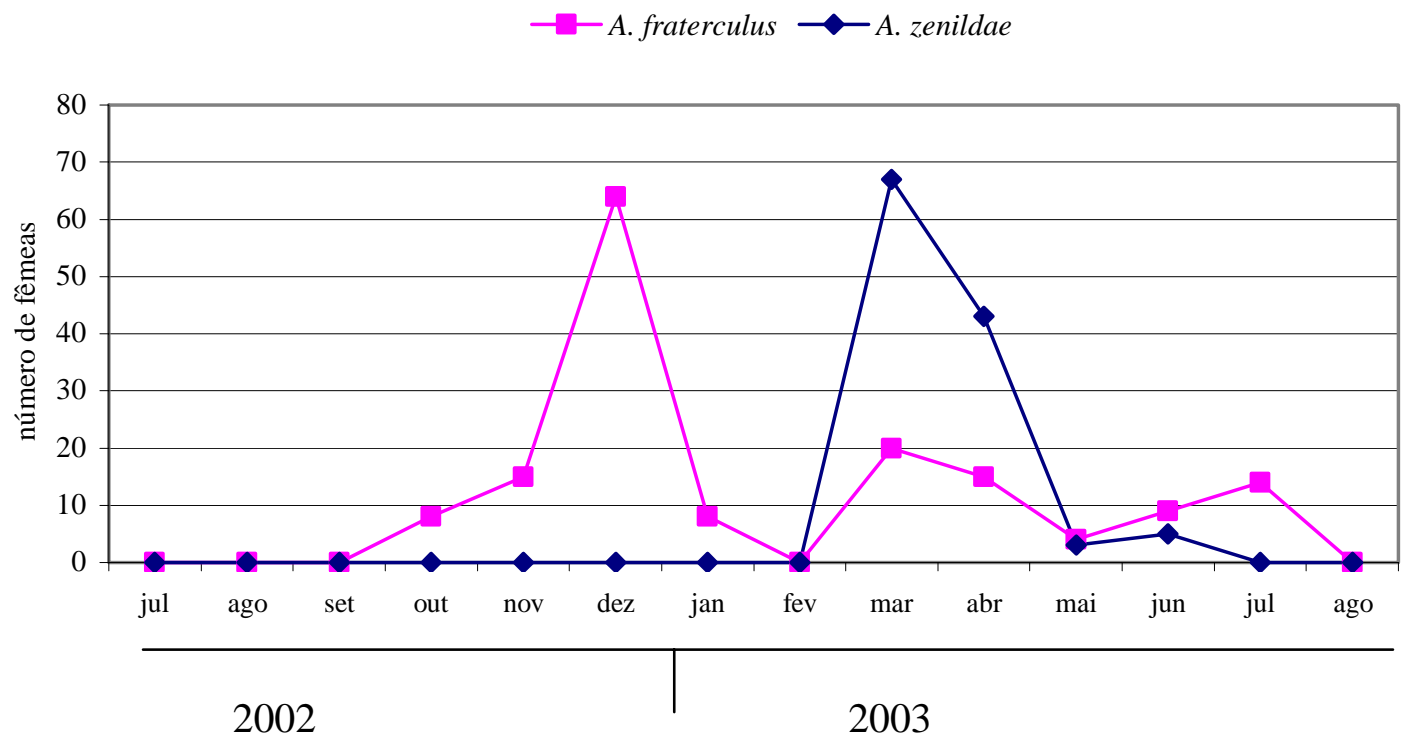

Figura 10 - Número de fêmeas de A. zenildae e A. fraterculus obtidas de goiabas Psidium guajava em Nova Porteirinha, MG, maio/2002 a agosto/2003

goiaba em Mossoró, RN, sendo que A. zenildae é predominante e a primeira a infestar o pomar. Ao contrário de outros estudos realizados em regiões semi-áridas (Nascimento, 1990; Canal et al., 1998b; Araújo \& Zucchi, 2003), A. fraterculus foi a espécie que mais contribuiu para os altos índices de infestação em Nova Porteirinha.

É importante considerar que as flutuações das populações de Anastrepha spp. são dependentes principalmente da disponibilidade de plantas hospedeiras e condições climáticas, conforme salientado por vários autores (Puzzi \& Orlando, 1965; Bateman, 1972; Fehn, 1982; Zahler, 1991; Aguiar-Menezes \& Menezes, 1996; Canal, 1997 e Araújo, 2002).

Todavia, verificou-se que, nos dois pomares, os índices de infestação e a intensidade de infestação, bem como as flutuações populacionais, não correlacionaram com nenhum parâmetro climático (temperaturas média, máxima e mínima, umidade relativa, precipitação pluvial e velocidade do vento). Segundo Aluja (1994), os parâmetros climáticos, principalmente a precipitação pluvial, são um dos fatores abióticos que mais interferem sobre as populações das moscas-das-frutas e, portanto, 
sobre seus níveis de infestação. Araújo (2002), estudando a influência de fatores bióticos e abióticos, constatou que as precipitações pluviais altas e temperaturas baixas foram os fatores que mais contribuíram para o aumento do nível de infestação de espécies de Anastrepha em goiaba, em Mossoró, RN.

Analisando-se a flutuação populacional, os índices de infestação e a intensidade de infestação dos tefritídeos nos dois pomares de goiaba, é possível concluir que as populações de $A$. zenildae e $A$. fraterculus, foram influenciadas principalmente pela disponibilidade do fruto hospedeiro. A influência da precipitação pluvial sobre as populações de moscas-das-frutas e, conseqüentemente na infestação, na região pode ter ocorrido principalmente de forma indireta, ou seja, a precipitação proporcionou condições favoráveis para a frutificação e, com isso, ocorreu o aumento da população das moscas-das-frutas, como observado por Araújo (2002). Como os pomares eram irrigados, constatou-se a presença de frutos o ano inteiro, mesmo assim os maiores picos populacionais ocorreram após o período chuvoso. O pico de produção nos dois pomares foi de março a junho, período em que se constatou a maior disponibilidade de frutos maduros. As chuvas na região normalmente ocorrem de setembro a maio, com as maiores precipitações de novembro a janeiro (Antunes, 1994). Entretanto, o clima deve ter alguma incidência nessas flutuações, mesmo que seja a nível microclimático, influenciando as atividades comportamentais dos indivíduos da população, como observado por Parra et al. (1982).

\subsection{Parasitóides de larvas/pupas de moscas-das-frutas em goiaba}

\subsubsection{Parasitismo natural}

Com relação ao parasitismo natural de moscas-das-frutas em goiaba no norte de Minas Gerais, dos 5.291 frutos coletados, somente em 96 foram obtidos parasitóides, a maioria pertencente à família Braconidae, subfamília Opiinae. Dos 10.650 pupários de moscas obtidos nos frutos, emergiram apenas 283 parasitóides, pertencente principalmente a Doryctobracon areolatus. Também foram obtidos 3 espécimes de 
Aganaspis pelleranoi (Figitidae, Eucoilinae). O parasitismo natural de moscas-das-frutas em goiabas nos pomares comerciais do norte de Minas Gerais foi muito baixo, como observado por Canal (1997), que coletou somente quatro espécimes de D. areolatus em frutos de goiaba. Segundo Bateman (1972), a maioria dos parasitóides de moscas-dasfrutas ocorre em baixas densidades em condições naturais e dessa forma raramente interfere nos níveis de infestações das moscas-das-frutas em pomares comerciais.

Dos braconídeos parasitóides de moscas-das-frutas, $D$. areolatus é o que possui a mais ampla distribuição geográfica na América Latina, tendo sido registrado do México à Argentina (Ovruski et al., 2000). No Brasil, esse parasitóide ocorre de norte à sul (Canal \& Zucchi, 2000), predominando em várias regiões (Leonel Jr. et al., 1996; Veloso, 1997; Matrangolo et al., 1998; Uchoa-Fernandes, 1999; Aguiar-Menezes, 2000).

Não houve correlação entre o número mensal de adultos de parasitóides e nenhum fator climático estudado (temperatura média, precipitação, umidade relativa e velocidade do vento). Todavia, analisando os dados obtidos no presente estudo, verificou-se que as flutuações em número nas populações dos opiíneos foram significativamente correlacionadas com as variações numéricas nas populações de Anastrepha spp. ( $\mathrm{r}=$ 0,74 em 1999/2001 e $\mathrm{r}=0$ 0,82 em 2002/2003; $\mathrm{P} \geq 0$ 0,05) (Figura 11). Correlações positivas entre o número de adultos de opiíneos e os de moscas do gênero Anastrepha indicam uma relação dependente da densidade direta, como foi observado também por Aguiar-Menezes (2000). Não foi verificada nenhuma associação de parasitóide com C. capitata.

O parasitismo natural na primeira época de coleta foi de 4,88\%, variando de 2,63 a 21,43\%. Na segunda época de coleta, o parasitismo variou de 2,5 a 100\%, com média de 4,28\%. Em algumas coletas não houve emergência de moscas, emergindo pelo menos um parasitóide, o que contribuiu para o índice de 100\% de parasitismo em alguns meses. Não houve emergência de parasitóides em alguns meses (Figura 11). 

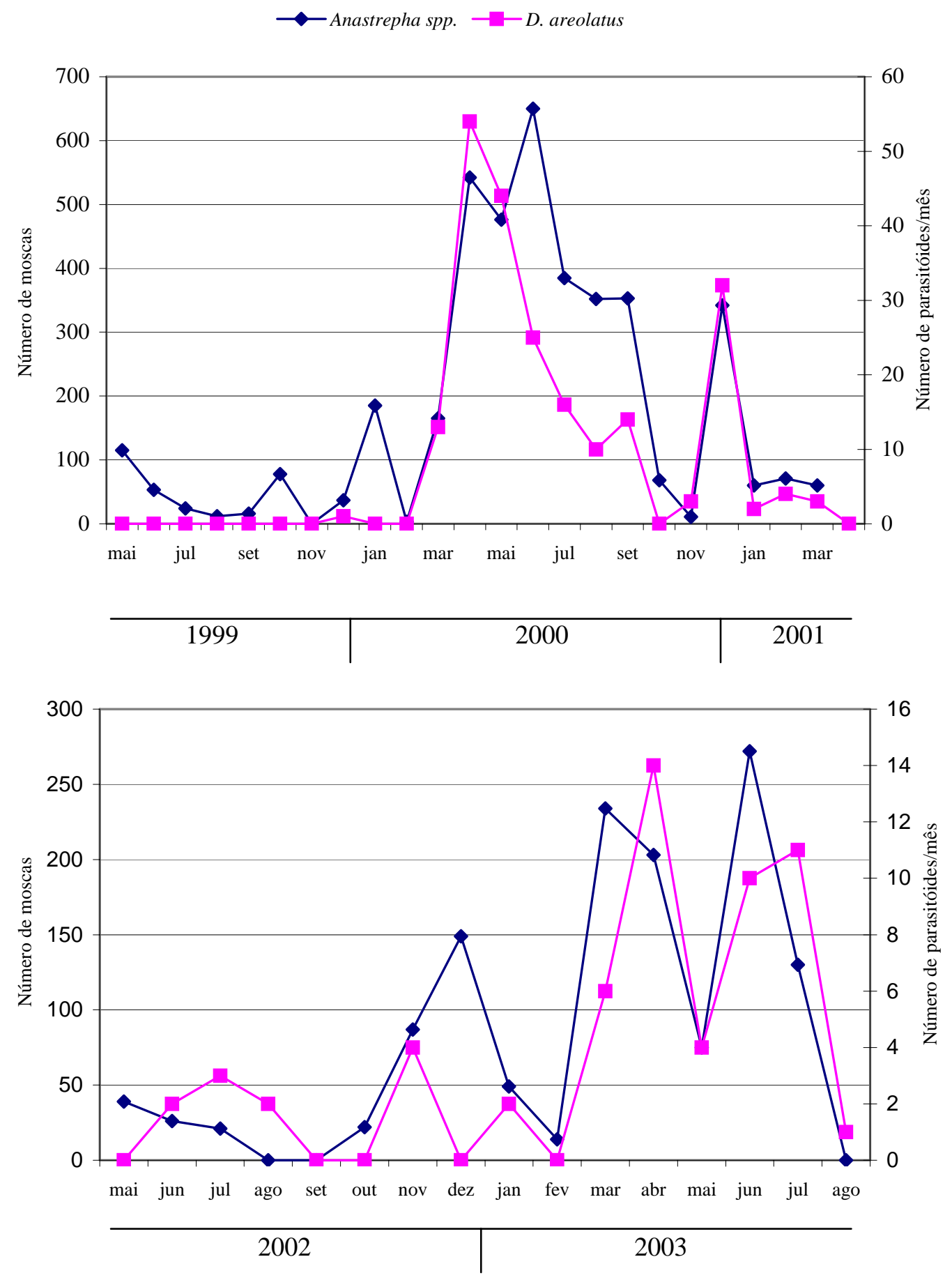

Figura 11 - Flutuação populacional de Doryctobracon areolatus e de seus hospedeiros em dois pomares comerciais de goiaba no norte de Minas Gerais, maio/1999 a abril/2001 e maio/2002 a agosto/2003 


\subsubsection{Liberação e recaptura (capacidade de sobrevivência) do parasitóide exótico Diachasmimorpha longicaudata}

O objetivo das liberações de $D$. longicaudata em campo foi conhecer a capacidade do parasitóide em atacar larvas de moscas-das-frutas no ecossistema semiárido do norte de Minas Gerais em pomares comerciais de goiabas.

Em fevereiro/2003, realizou-se a primeira liberação do parasitóide $D$. longicaudata no pomar de Jaíba e no pomar de Nova Porteirinha. Inicialmente liberaram-se aproximadamente 1.800 casais em cada pomar. Posteriormente realizaramse liberações sucessivas totalizando aproximadamente 34.000 casais por pomar em 15 liberações.

Foram recuperados 37 espécimes de D. longicaudata (24 em Jaíba e 13 em Nova Porteirinha) durante o período de liberação (Tabela 8). Apesar do baixo número de indivíduos de $D$. longicaudata recuperados, o resultado demonstrou que a espécie fechou o ciclo nas condições locais. Liberações realizadas no Recôncavo da Bahia e no Submédio do São Francisco (cerca de 60.000 indivíduos), resultaram em recuperação efetiva do D. longicaudata (Carvalho et al., 1998 e Nascimento et al., 1998).

Tabela 8. Número de casais de D. longicaudata liberados e número de parasitóides obtidos em goiabas infestadas por moscas-das-frutas, durante o período de liberação em Nova Porteirinha e Jaíba, MG, fevereiro a agosto/2003

\begin{tabular}{lcccc}
\hline \multirow{2}{*}{ Locais } & \multirow{2}{*}{$\mathrm{N}^{\mathrm{o}}$ de casais } & \multicolumn{2}{c}{ Parasitóides } & \multirow{2}{*}{ Total } \\
\cline { 3 - 4 } & & D. longicaudata & D. areolatus & 31 \\
\hline Nova Porteirinha & 34.250 & 13 & 18 & 52 \\
Jaíba & 34.650 & 24 & 28 & 83 \\
Total & 68.900 & 37 & 46 & 83 \\
\hline
\end{tabular}

Constatou-se que não houve competição pelo nicho entre as espécies, pois não foi observada redução na população de parasitóides nativos devido à ação do parasitóide 
exótico (Figura 12). Nos dois pomares, D. areolatus predominou sobre $D$. longicaudata após as liberações, observando-se um aumento no número do parasitóide nativo após o início das liberações do exótico. É importante ressaltar que esta espécie poderá se estabelecer na região com base na hipótese de Sivinski et al. (1998). Segundo estes autores, $D$. longicaudata e $D$. areolatus são capazes de co-existirem abundantemente em LaBelle (Flórida), pois $D$. areolatus apresenta maior capacidade de localizar o hábitat de seu hospedeiro (planta) e $D$. longicaudata apresenta maior capacidade de explorar o hospedeiro (larva). Dessa forma, baseando-se nos resultados obtidos no presente estudo, D. longicaudata possui grandes chances de se estabelecer, sem comprometer as relações tritróficas pré-existentes.

O fato de ter ocorrido baixa taxa de parasitismo natural, como já citado (item 4.3.1), deve ser considerado como uma vantagem do ponto de vista do manejo, pois pode-se considerar apenas a possibilidade de ações de controle biológico inundativo, já que o parasitóide exótico conseguiu completar o ciclo nestas condições e não afetou a população do nativo.

As coletas de frutos neste trabalho foram feitas na planta e no solo, de acordo com a disponibilidade e não obedecendo a nenhum critério. Procurou-se também coletar frutos bem maduros, porém em algumas coletas isto não foi possível pela não disponibilidade destes no campo. Estes fatos podem ter sido os responsáveis pelo pequeno número de parasitóides recuperados dos frutos. Segundo Sivinski et al. (1996), a remoção do fruto do campo durante a amostragem diminui o período em que as larvas são suscetíveis ao ataque, resultando em um parasitismo subestimado. Haramoto \& Bess (1970) consideraram que o baixo número de $D$. longicaudata coletado em goiabas colhidas das plantas foi devido às amostragens de frutos insuficientemente maduros, pois observaram fêmeas do parasitóide atacando larvas de frutos no solo. AguiarMenezes \& Menezes (2002) observaram que a diversidade de espécies de parasitóides aumentou quando os frutos permaneceram de quatro a mais dias no campo. 
$D$. longicaudata $\square$ D. areolatus

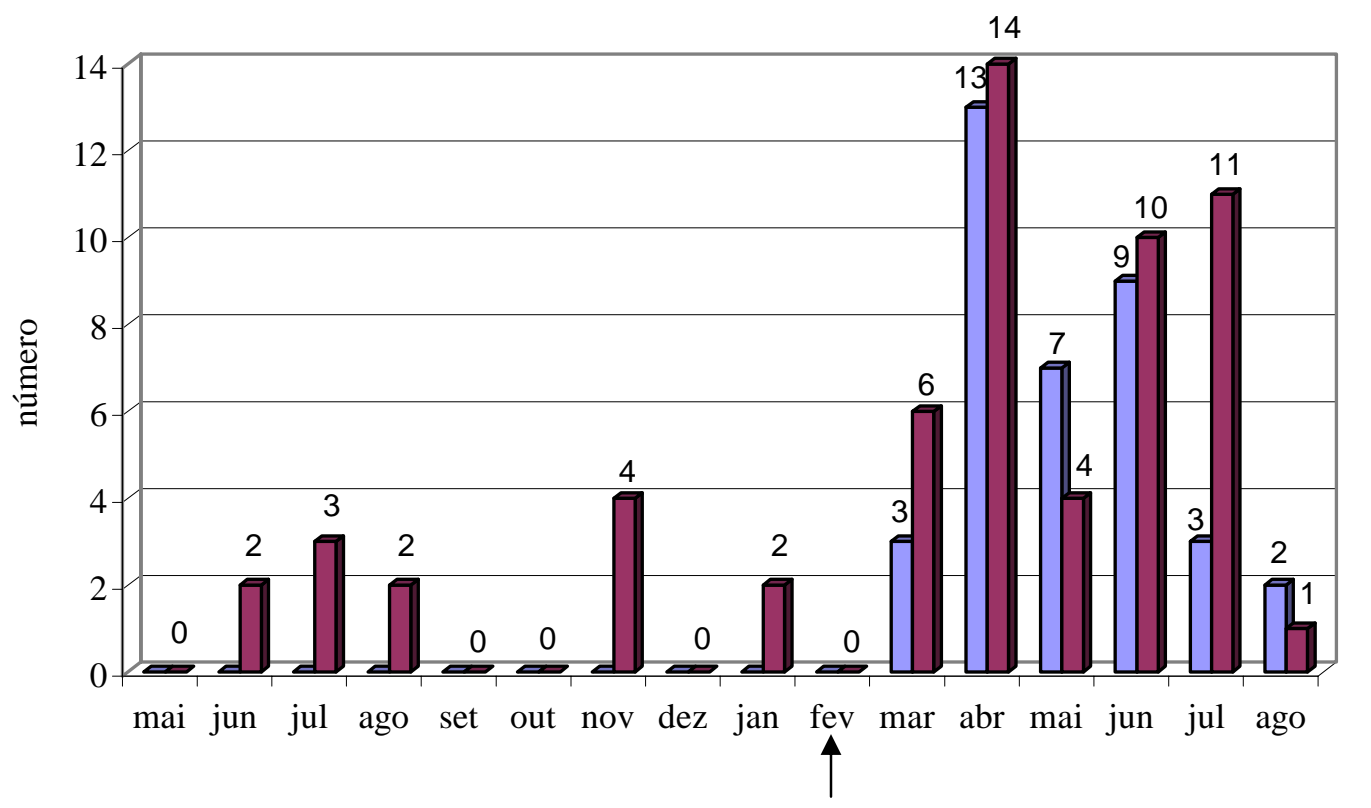

início da liberação do parasitóide exótico

Figura 12 - Número de parasitóides (nativo e exótico) obtidos de goiaba em dois pomares comerciais no norte de Minas Gerais (maio/2002 a agosto/2003)

Os pontos favoráveis da introdução de $D$. longicaudata na região são a alta atividade de exploração dos recursos disponíveis em uma área pelas fêmeas (Sivinski et al., 1998), a intensa atividade de forrageamento em frutos no solo (Purcell et al., 1994) e a facilidade de criação em laboratório.

Silva (1993) observou que das 10 espécies de frutos coletados no Estado do Amazonas, em duas espécies, as larvas das moscas tiveram alta porcentagem de parasitismo. Em razão das frutas terem casca fina e polpa rasa, as larvas das moscas-dasfrutas são mais facilmente localizadas e ficam mais vulneráveis ao parasitismo. A capacidade de fêmeas de $D$. longicaudata em localizar e parasitar larvas de $A$. fraterculus em hospedeiros silvestres foi avaliada por Sugayama (2000). Constatou que liberações inundativas do parasitóide exótico concentradas durante períodos de frutificação da gabiroba seriam eficientes na diminuição da população da praga. Portanto, é plausível supor que fêmeas de $D$. longicaudata liberadas em hospedeiros 
silvestres de áreas vizinhas aos pomares comerciais do norte de Minas Gerais, aumentariam significativamente a mortalidade de larvas de moscas-das-frutas. Isso indica o potencial do umbu, da serigüela e do juá como fontes naturais de multiplicação do parasitóide exótico, permitindo assim a manutenção da população de parasitóides ao longo do ano, já que essas espécies estão largamente distribuídas em toda a região, além de produzir frutos em grande quantidade e em diferentes épocas do ano.

O fato de um parasitóide atacar a espécie que se deseja controlar, em laboratório, não significa que ele atacará a praga em condição natural (Lewis et al., 1990). As liberações massais de $D$. longicaudata na região produtora de maçãs do Brasil (Sugayama, 2000) mostraram que a chance do parasitóide se estabelecer é baixa por restrições fisiológicas da espécie, por exemplo, tolerância a clima frios (Eitam, 1998). Entretanto, a região norte de Minas Gerais apresenta clima seco e quente e os pomares comerciais recebem irrigação durante todo o período seco do ano. Esta espécie adaptouse bem em todos os locais em que foi introduzida (Wharton et al., 1981; Wong et al., 1984; Jirón \& Mexzon, 1989; Aluja et al., 1990; Eskafi, 1990; Baranowsky et al., 1993; Carvalho et al., 1995).

Demonstrou-se neste estudo que $D$. longicaudata se desenvolveu satisfatoriamente em A. zenildae e A. fraterculus, mesmo usando C. capitata como hospedeiro alternativo em laboratório. O ideal é que mais estudos com relação à adaptação deste parasitóide sejam desenvolvidos em cada região, considerando-se os fatores locais. É importante salientar também que, para empregar adequadamente $D$. longicaudata em programas de manejo de moscas-das-frutas, é necessário obter dados mais conclusivos sobre os impactos desses inimigos naturais sobre as populações de tefritídeos-pragas, os quais somente serão obtidos por meio do monitoramento das flutuações populacionais dessas pragas e de seus parasitóides durante os períodos de sucessivas liberações. 


\section{CONCLUSÕES}

Um total de 18 espécies de Anasterpha, além de Ceratitis capitata, ocorre em pomares comerciais de goiaba na região norte de Minas Gerais.

Anastrepha zenildae, A. fraterculus, A. sororcula, A. obliqua, A. turpiniae e Ceratitis capitata são espécies que utilizam a goiaba como hospedeiro na região.

A. zenildae e $A$. fraterculus são espécies dominantes e responsáveis pelos maiores índices de infestação em goiaba.

A. turpiniae, A. manihot, A. leptozona e A. barbiellinii são registradas pela primeira vez no norte de Minas Gerais.

A disponibilidade de frutos maduros é o fator responsável pela determinação do tamanho das populações das espécies mais abundantes de moscas-das-frutas e, conseqüentemente, das maiores infestações.

Doryctobracon areolatus é o único braconídeo parasitóide de espécies de Anastrepha em goiaba no norte de Minas Gerais, em condições naturais.

O parasitismo natural de moscas-das-frutas em goiaba na região norte de Minas Gerais é baixo e dependente da densidade direta de seus hospedeiros. 
Diachasmimorpha longicaudata parasita larvas de moscas-das-frutas em goiaba na região semi-árida de Minas Gerais. 


\section{REFERÊNCIAS BIBLIOGRÁFICAS}

AGUIAR-MENEZES, E.L. Aspectos ecológicos de populações de parasitóides Braconidae (Hymenoptera) de Anastrepha spp. Schiner, 1868 (Diptera: Tephritidae) no município de Seropédica, RJ. Rio de Janeiro, 2000. 138p. Tese (Doutorado) Universidade Federal Rural do Rio de Janeiro.

AGUIAR-MENEZES, E.L.; MENEZES, E.B. Flutuação populacional das moscas-dasfrutas e sua relação com a disponibilidade hospedeira em Itaguaí, RJ. Anais da Sociedade Entomológica do Brasil, v.25, n.2, p.223-232, 1996.

AGUIAR-MENEZES, E.L.; MENEZES, E.B. Natural occurrence of parasitoids of Anastrepha spp. Schiner, 1868 (Diptera: Tephritidae) in differente host plants in Itaguai (RJ), Brazil. Biological Control, v.8, p.1-6, 1997.

AGUIAR-MENEZES, E.L.; MENEZES, E.B. Effect of time of permanence of host fruits in the field on natural parasitism of Anastrepha spp. (Diptera: Tephritidae). Neotropical Entomology, v.31, n.4, p.589-595, 2002.

ALUJA, M. Bionomics and management of Anastrepha. Annual Review of Entomology, v.39, p.155-178, 1994.

ALUJA, M. Fruit fly (Diptera: Tephritidae) research in Latin America: myths, realities and dreams. Anais da Sociedade Entomológica do Brasil, v.28, n.4, p.565-594, 1999. 
ALUJA, M.; CELEDONIO-HURTADO, H.; LIEDO, P.; CABRERA, M.; CASTILHO, F.; GUILLÉN, J.; RIOS, E. Seasonal population fluctuations and ecological implications for management of Anastrepha fruit flies (Diptera: Tephritidae) in commercial mango orchards in Southern Mexico. Journal of Economic Entomology, v.89, p.654-667, 1996.

ALUJA, M.; GUILLEN, J.; LIEDO, P.; CABRERA, M.; RIOS, E.; DE LA ROSA, G.; CELEDONIO, H.; MOTA, D. Fruit infesting tephritids (Dipt.: Tephritidae) and associated parasitoids in Chiapas, México. Entomophaga, v.35, n.1, p.39-48, 1990.

ALVARENGA, C.D.; CANAL, N.A.; ZUCCHI, R.A. Minas Gerais. In: MALAVASI, A.; ZUCCHI, R.A. (Ed.). Moscas-das-frutas de importância econômica no Brasil: conhecimento básico e aplicado. Ribeirão Preto: Holos, 2000. cap.39, p.265-270.

ANTUNES, F.Z. Caracterização climática. Informe Agropecuário, v.17, n.81, p.1519, 1994.

ARAUJO, E.L. Dipteros frugívoros (Tephritidae e Lonchaeidae) na região de Mossoró/Assu, Estado do Rio Grande do Norte. Piracicaba, 2002. 112p. Tese (Doutorado) - Escola Superior de Agricultura "Luiz de Queiroz”, Universidade de São Paulo.

ARAUJO, E.L.; ZUCCHI, R.A. Moscas-das-frutas (Díptera: Tephritidae) em goiaba (Psidium guajava L.), em Mossoró, RN. Arquivos do Instituto Biológico, v.70, n.1, p.73-77, 2003. 
ARAUJO, E.L.; LIMA, F.A.M.; ZUCCHI, R.A. Rio Grande do Norte. In: MALAVASI, A.; ZUCCHI, R.A. (Ed.). Moscas-das-frutas de importância econômica no Brasil: conhecimento básico e aplicado. Ribeirão Preto: Holos, 2000. cap.31, p.223-226.

ARAUJO, E.L.; ZUCCHI, R.A.; CANAL, N.A. Caracterização e ocorrência de Anastrepha zenildae Zucchi (Diptera: Tephritidae) e seus parasitóides (Hymenoptera: Braconidae) numa nova planta hospedeira, no Rio Grande do Norte. Anais da Sociedade Entomológica do Brasil, v.25, n.1, p.147-150, 1996.

ARRIGONI, E.B. Dinâmica populacional de moscas-das-frutas (Diptera - Tephritidae) em três regiões do Estado de São Paulo. Piracicaba, 1984. 165p. Tese (Doutorado) - Escola Superior de Agricultura "Luiz de Queiroz", Universidade de São Paulo.

BAKER, A.C.; STONE, W.E.; PLUMMER, C.C.; McPHAIL, M. A review of studies on the Mexican fruit fly an related Mexican species. Washington: USDA, 1944. 155p. (Miscellaneous Publication, 531).

BARANOWSKI, R.; GLENN, H.; SIVINSKI, J. Biological biocontrol of the Caribbean fruit fly (Diptera: Tephritidae). Florida Entomologist, v.76, p.245-250, 1993.

BATEMAN, M.A. The ecology of fruit flies. Annual Review of Entomology, v.17, p.493-518, 1972.

CAMPANHOLA, C. Agricultural biological diversity. Ciência e Cultura, v.50, n.1, p.10-13, 1998. 
CANAL, N.A. Espécies de parasitóides (Hymenoptera: Braconidae) de moscas-dasfrutas (Diptera: Tephritidae) em quatro locais do Estado do Amazonas. Piracicaba, 1993. 93p. Dissertação (Mestrado) - Escola Superior de Agricultura "Luiz de Queiroz”, Universidade de São Paulo.

CANAL, N.A. Levantamento, flutuação populacional e análise faunística das espécies de moscas-das-frutas (Dip., Tephritidae) em quatro municípios do norte do Estado de Minas Gerais. Piracicaba, 1997. 113p. Tese (Doutorado) - Escola Superior de Agricultura “Luiz de Queiroz”, Universidade de São Paulo.

CANAL, N.A.; ZUCCHI, R.A. Parasitóides - Braconidae. In: MALAVASI, A.; ZUCCHI, R.A. (Ed.). Moscas-das-frutas de importância econômica no Brasil: conhecimento básico e aplicado. Ribeirão Preto: Holos, 2000. cap.15, p.119-126.

CANAL, N.A.; ALVARENGA, C.D.; ZUCCHI, R.A. Análise faunística das espécies de moscas-das-frutas (Dip., Tephritidae) em quatro municípios do Norte do Estado de Minas Gerais. Scientia Agricola, v.55, n.1, p.15-24, 1998a.

CANAL, N.A.; ALVARENGA, C.D.; ZUCCHI, R.A. Níveis de infestação de goiaba por Anastrepha zenildae Zucchi, 1979 (Dip., Tephritidae), em pomares comerciais do Norte de Minas Gerais. Anais da Sociedade Entomológica do Brasil, v.27, n.4, p.657-661, 1998b.

CANCINO, J. Cria de Diachasmimorpha longicaudata, parasitoide de moscas de la fruta. Fundamentos e procedimentos. In: CURSO INTERNACIONAL SOBRE MOSCAS DE LA FRUTA, 6., Chiapas, 1992. Chiapas: Programa Moscamed. Metapa de Domingues, 1992. t.2, 409-417p. 
CAPPUCCINO, N. Novel approaches to the study of population dynamics. In: CAPPUCCINO, N.; PRICE, P.W. (Ed.). Population dynamics: new approaches and synthesis. San Diego: Academic press, 1995. p.3-16.

CARVALHO, R.S.; NASCIMENTO, A.S.; MENDONÇA, M.C. Introdução e criação de Diachasmimorpha longicaudata (Hymenoptera: Braconidae), parasitóide de moscas-das-frutas. In: CONGRESSO BRASILEIRO DE ENTOMOLOGIA, 15., Caxambu, 1995. Resumos. Caxambu: SEB, 1995. p.365.

CARVALHO, R.S.; NASCIMENTO, A.S.; MATRANGOLO, W.J.R. Inseto exótico controla moscas-das-frutas. A Lavoura, v.3, p.40-43, 1999.

CARVALHO, R.S.; NASCIMENTO, A.S.; MATRANGOLO, W.J.R. Controle Biológico. In: MALAVASI, A.; ZUCCHI, R.A. (Ed.). Moscas-das-frutas de importância econômica no Brasil: conhecimento básico e aplicado. Ribeirão Preto: Holos, 2000. cap.14, p.113-117.

CARVALHO, R.S.; MATRANGOLO, W.J.R.; NASCIMENTO, A.S.; MELO, E.D. Influência do estágio fenológico de frutos de pitanga na presença de parasitóides de moscas-das-frutas. In: CONGRESSO BRASILEIRO DE ENTOMOLOGIA, 16., Salvador, 1997. Resumos. Salvador: SEB, 1997. p.316.

CARVALHO, R.S.; NASCIMENTO, A.S.; MATRANGOLO, W.J.R.; JESUS, M.; LUNA, J.V.U. Situação atual da introdução do parasitóide exótico Diachasmimorpha longicaudata no Recôncavo Baiano. In: CONGRESSO BRASILEIRO DE ENTOMOLOGIA, 17., Rio de Janeiro, 1998. Resumos. Rio de Janeiro: SEB, 1998. p.322. 
CELEDONIO-HURTADO, H.; ALUJA, M.; LIEDO, P. Adult population fluctuation Anastrepha species (Diptera: Tephritidae) in tropical orchard habitat in Chiapas, Mexico. Environmental Entomology, v.24, p.861-869, 1995.

CHRISTENSON, L.D.; FOOTE, R.H. Biology of fruit flies. Annual Review of Entomology, v.5, p.171-192, 1960.

CLARK, L.R.; GEIER, P.W.; HUGHES, R.D.; MORRIS, H.F. The ecology of insect populations in theory and practice. London: Chapman and Hill, 1967. 232p.

CLAUSEN, C.P. Entomophagous insects. New York: McGraw-Hill, 1940. 688p.

CLAUSEN, C.P.; CLANCY, D.W.; CHOCK, Q.C. Biological control of the oriental fruti fly (Dacus dorsalis Hendel) and other fruit flies in Hawaii. Washington: USDA, ARS, 1965. 102 p. (Technical Bulletin, 1322).

COMPANHIA DE DESENVOLVIMENTO DO VALE DO SÃO FRANCISCO. Semiárido. http://www.codevasf.gov.br/semi_arido/sem_arido.htm. (08 dez. 2003).

EITAM, A. Biogeography of braconid parasitoids of the caribbean fruit fly, Anastrepha suspensa (Loew) (Diptera: Tephritidae) in Florida. Gainesville, 1998. 98p. Dissertation (PhD) - University of Florida.

ESKAFI, F. Parasitism of fruit flies Ceratitis capitata and Anastrepha spp. (Diptera: Tephritidae) in Guatemala. Entomophaga, v.35, p.355-362, 1990.

FEHN, L.M. Influência dos fatores meteorológicos na flutuação e dinâmica de população de Anastrepha spp. Pesquisa Agropecuária Brasileira, v.17, n.4, p.533544, 1982. 
GARCIA, F.R.M.; CORSEUIL, E. Flutuação populacional de Anastrepha fraterculus (Wiedemann) e Ceratitis capitata (Wiedemann) (Diptera, Tephritidae) em pomares de pessegueiro em Porto Alegre, Rio Grande do Sul. Revista Brasileira de Zoologia, v.15, n.1, p.153-158, 1998.

GARCIA, F.R.M.; CAMPOS, J.V.; CORSEUIL, E. Análise faunística de espécies de moscas-das-frutas (Diptera: Tephritidae) na região Oeste de Santa Catarina. Neotropical Entomology, v.32, n.3, p.421-426, 2003.

GREANY, P.D.; TUMLINSON, J.L.; CHAMBERS, D.L.; BOUSH, G.M. Chemically mediated host finding by Biosteres (Opius) longicaudatus, a parasitoid of tephritids fruit fly larvae. Journal of Chemical Ecology, v.3, n.2, p.189-195, 1977.

HAJI, F.N.P.; MIRANDA, I.G. Pernambuco. In: MALAVASI, A.; ZUCCHI, R.A. (Ed.). Moscas-das-frutas de importância econômica no Brasil: conhecimento básico e aplicado. Ribeirão Preto: Holos, 2000. cap.33, p.229-233.

HAJI, F.N.P.; NASCIMENTO, A.S.; CARVALHO, R.S.; COUTINHO, C.C. Ocorrência e índice de infestação de moscas-das-frutas (Tephritidae) na região do submédio São Francisco. Revista Brasileira de Fruticultura, v.13, n.4, p.205-209, 1991.

HARAMOTO, F.H.; BESS, H.A. Recent studies on the abundance of the oriental and Mediterranean fruit flies and the status of their parasites. Proceedings of the Hawaii Entomological Society, v.20, p.551-566, 1970.

HERNANDEZ-ORTIZ, V. Fitofagia y sus implicaciones evolutivas em Tephritidae. In: CURSO INTERNACIONAL SOBRE MOSCAS DE LA FRUTA, 13., Chiapas, 2000. Memórias. Chiapas: Metapa de Dominguez, 2000. p.79-88. 
HERNANDEZ-ORTIZ, V.; ALUJA, M. Listado Del gênero neotropical Anastrepha (Diptera: Tephritidae) com notas sobre su distribución y plantas hospederas. Folia Entomológica Mexicana, v.88, p.89-105, 1993.

HICKEL, E.R. Espessura da polpa como condicionante do parasitismo de mosca-dasfrutas (Diptera: Tephritidae) por Hymenoptera: Braconidae. Ciência Rural, v.32, n.6, p.1005-1009, 2002.

JIRÓN, L.F.; MEXZON, R.G. Parasitoid hymenopterans of Costa Rica: geografical distribution of the species associated with fruti flies (Dipt.: Tephritidae). Entomophaga, v.34, p.53-60, 1989.

KOVALESKI, A. Processos adaptativos na colonização da maçã (Malus domestica L.) por Anastrepha fraterculus (Wied.) (Diptera: Tephritidae) na região de Vacaria, RS. São Paulo, 1997. 122p. Tese (Doutorado) - Instituto de Biociências, Universidade de São Paulo.

LAWRENCE, P.O. Host vibration - a cue to host location by the parasite, Biosteres longicaudatus. Oecologia, v.48, p.249-251, 1981.

LEONEL JUNIOR, F.L.; ZUCCHI, R.A.; WHARTON, R.A. Distribution and tephritid hosts (Diptera) of braconid parasitoids (Hymenoptera) in Brazil. International Journal of Pest Management, v.41, n.4, p.208-213, 1995.

LEONEL JUNIOR, F.L.; ZUCCHI, R.A.; CANAL, N.A. Parasitismo de moscas-dsfrutas (Diptera: Tephritidae) por Braconidae (Hymenoptera) em duas localidades do Estado de São Paulo. Anais da Sociedade Entomológica do Brasil, v.25, n.2, p.199-206, 1996. 
LEWIS, W.J.; VET, L.E.M.; TUMLIMSON, J.H.; LENTEREN, J.C. van; PAPAJ, D.R. Variations in parasitoid foraging behavior: essential element of a sound biological control theory. Environmental Entomology, v.19, p.1183-1193, 1990.

MALAVASI, A.; MORGANTE, J.S. Biologia de "moscas-das-frutas" (Diptera: Tephritidae). II. Índices de infestação em diferentes hospedeiros e localidades. Revista Brasileira de Biologia, v.40, n.1, p.17-24, 1980.

MALAVASI, A.; MORGANTE, J.S. Adult and larval population fluctuation of Anastrepha fraterculus and its relationship to host availability. Environmental Entomology, v.10, p.275-278, 1981.

MALAVASI, A.; SUGAYAMA, R.L. Biogeografia. In: MALAVASI, A.; ZUCCHI, R.A. (Ed.). Moscas-das-frutas de importância econômica no Brasil: conhecimento básico e aplicado. Ribeirão Preto: Holos, 2000. cap.10, p.93-98.

MALAVASI, A.; MORGANTE, J.S.; ZUCCHI, R.A. Biologia de "moscas-ds-frutas" (Diptera: Tephritidae). I. Lista de hospedeiros e ocorrência. Revista Brasileira de Biologia, v.40, n.1, p.9-16, 1980.

MALAVASI, A.; NASCIMENTO, A.S.; CARVALHO, R.S. Moscas-das-frutas no MIP-Citros. In: DONADIO, L.C.; GRAVENA, S. (Coord.). Manejo integrado de pragas dos citros. Campinas: Fundação Cargill, 1994. p.211-231.

MANICA, I. Principais cultivares e melhoramento. In: MANICA, I.; ICUMA, I.M.; JUNQUEIRA, N.T.; SALVADOR, J.O.; MOREIRA, A.; MALAVOLTA, E. Fruticultura tropical 6: goiaba. Porto Alegre: Cinco Continentes Editora, 2000. p.57-84. 
MARTINS, D.S.; URAMOTO, K.; MALAVASI, A. Occurrence and distribution of fruit flies in three papaya commercial orchards in the state of Espirito Santo, Brazil. In: MEETING OF THE WORKING GROUP ON FRUIT FLIES OF THE WESTERN HEMISPHERE, 2., Viña del Mar, 1996. Abstracts. Viña del Mar: Working Group on Fruit Flies of the Western Hemisphere, 1996. p.31.

MATRANGOLO, W.J.R.; NASCIMENTO, A.S.; CARVALHO, R.S.; MELO, E.D.; JESUS, M. Parasitóides de moscas-das-frutas (Diptera: Tephritidae) associados a fruteiras tropicais. Anais da Sociedade Entomológica do Brasil, v.27, n.4, p.593603, 1998.

MENEZES, R.V.S.; NUNES, E.M.; BRANCO, R.S.C.; ZUCCHI, R.A. Piauí. In: MALAVASI, A.; ZUCCHI, R.A. (Ed.). Moscas-das-frutas de importância econômica no Brasil: conhecimento básico e aplicado. Ribeirão Preto: Holos, 2000. cap.29, p.213-215.

MESSING, R.H.; JANG, E.B. Response of the fruit fly parasitois Diachasmimorpha longicaudata (Hymenoptera: Braconidae) to host-fruit stimuli. Environmental Entomology, v.21, n.5, p.1189-1195, 1992.

MESSING, R.H.; KLUNGNESS, L.M.; PURCELL, M.F. Short range dispersal of mass-reared Diachasmimorpha longicaudata and D. tryoni, parasitoids of tephritid fruit flies. Journal of Economic Entomology, v.87, p.975-985, 1994.

MORAES, R.C.B.; HADDAD, M.L.; SILVEIRA NETO, S.; REYES, A.E.L. Software para análise faunística. In: SIMPÓSIO DE CONTROLE BIOLÓGICO, 8., São Pedro, 2003. Resumos. São Pedro: s.ed., 2003. p.195. 
MORGANTE, J.S. Moscas-das-frutas (Tephritidae): características biológicas, descrição e controle. Brasília: SENIR, 1991. 19p. (Boletim Técnico de Recomendações para os Perímetros Irrigados do Vale São Francisco, 2).

NASCIMENTO, A.S. Aspectos ecológicos e tratamento pós-colheita de moscas-dasfrutas (Tephritidae) em manga, Mangifera indica. São Paulo, 1990. 97p. Tese (Doutorado) - Instituto de Biociências, Universidade de São Paulo.

NASCIMENTO, A.S.; CARVALHO, R.S. Bahia. In: MALAVASI, A.; ZUCCHI, R.A. (Ed.). Moscas-das-frutas de importância econômica no Brasil: conhecimento básico e aplicado. Ribeirão Preto: Holos, 2000. cap.34, p.235-239.

NASCIMENTO, A.S.; ZUCCHI, R.A. Dinâmica populacional de moscas-das-frutas do gênero Anastrepha (Dip., Tephritidae) no Recôncavo Baiano. I. Levantamento das espécies. Revista Agropecuária Brasileira, v.16, n.6, p.763-767, 1981.

NASCIMENTO, A.S.; ZUCCHI, R.A.; SILVEIRA NETO, S. Dinâmica populacional das moscas-das-frutas do gênero Anastrepha (Dip., Tephritidae) no Recôncavo Baiano. III. Análise Faunística. Pesquisa Agropecuária Brasileira, v.18, n.4, p.319-328, 1983.

NASCIMENTO, A.S.; MESQUITA, A.L.M.; ZUCCHI, R.A. Parasitism of pupae of Anastrepha spp. (Dip.: Tephritidae) by Doryctobracon areolatus (Szépligeti, 1911) (Hym.: Braconidae) in citrus and tropical fruits. In: JAPAN-BRAZIL SYMPOSIUM ON SCIENCE AND TECHNOLOGY, 4. , São Paulo, 1984. Annals. São Paulo: Academia de Ciências e Tecnologia do Estado de São Paulo, SP, 1984. v.2, p.239246. 
NASCIMENTO, A.S.; ZUCCHI, R.A.; MORGANTE, J.S.; MALAVASI, A. Dinâmica populacional das moscas-das-frutas do gênero Anastrepha (Dip., Tephritidae) no Recôncavo Baiano. II - flutuação populacional. Pesquisa Agropecuária Brasileira, v.17, n.7, p.969-980, 1982.

NASCIMENTO, A.S.; CARVALHO, R.S.; MATRANGOLO, W.J.R.; LUNA, J.U.V. Situação atual do controle biológico de moscas-das-frutas com parasitóides no Brasil. Informativo SBF, v.17, n.3, p.12-15, 1998.

NASCIMENTO, A.S.; CARVALHO, R.; ALVARENGA, C.D.; ARAUJO, E.L., HAJI, F.N.P. Status of the Ceratitis capitata (Tephritidae) as a pest in the irrigated fruit crop project of the northeast of Brazil. In: MEETING OF THE WORKING GROUP ON FRUIT FLIES OF THE WESTERN HEMISPHERE, 4., Mendoza, 2001. Abstracts. Mendoza: s.ed., 2001. p.56-57.

NORRBOM, A.L. Fruit fly (Diptera: Tephritidae) classification and diversity. http://www.sel.barc.usda.gov/diptera/tephriti/Tephclas.htm. (08 dez. 2003).

NORRBOM, A.L.; ZUCCHI, R.A.; HERNÁNDEZ-ORTIZ, V. Phylogeny of the genera Anastrepha and Toxotrypana (Trypetinae: Toxotripanini) based on morphology. In: NORRBOM, A.L.; ALUJA, M. (Ed.). Fruit flies (Tephritidae): phylogeny and evolution of behavior. Boca Raton: CRC Press, 1999. cap.12, p.299342.

OVRUSKI, S.M.; ALUJA, M.; SIVINSKI, J.; WHARTON, R. Hymenopteran parasitoids on fruit-infesting Tephritidae (Diptera) in Latin América and the southern United States: Diversity, distribution, taxonomic status and their use in fruit fly biological control. Integrated Pest Management Reviews, v.5, p.81-107, 2000. 
PARRA, J.R.P.; ZUCCHI, R.A.; SILVEIRA NETO, S. Flutuação populacional e atividade diária de vôo da mosca-do-mediterrâneo em cafeeiros 'Mundo Novo'. Pesquisa Agropecuária Brasileira, v.17, n.7, p.985-992, 1982.

POOLE, R.W. An introduction to quantitative ecology. Tokyo: McGraw-Hill, 1974. 532p.

PURCELL, M.F. Contribution of biological control to integrated pest management of tephritid fruit flies in the tropics and subtropics. Integrated Pest Management Reviews, v.3, n.2, p.63-83, 1998.

PURCELL, M.F.; JACKSON, C.G.; LONG, J.P.; BATCHELOR, M.A. Influence of guava ripening on parasitism of the oriental fruit fly, Bactrocera dorsalis (Hendel) (Diptera: Tephritidae), by Diachasmimorpha longicaudata (Ashmead) (Hymenoptera: Braconidae) and other parasitoids. Biological Control, v.4, p.396403, 1994.

PUZZI, D.; ORLANDO, A. Estudos sobre a ecologia das “moscas-das-frutas" (Trypetidae) no Estado de São Paulo, visando o controle racional da praga. Arquivos do Instituto Biológico, v.32, n.1, p.9-22, 1965.

RAGA, A.; SOUZA FILHO, M.F. de; SATO, M.E.; CERÁVOLO, L.C. Dinâmica populacional de adultos de moscas-das-frutas (Diptera: Tephritidae) em pomar de citros de Presidente Prudente, SP. Arquivos do Instituto Biológico, v.63, n.2, p.2328, 1996.

RONCHI-TELES, B. Ocorrência e flutuação populacional de espécies de moscas-dasfrutas e parasitóides com ênfase para o gênero Anastrepha (Diptera: Tephritidae) na Amazônia brasileira. Manaus, 2000. 156p. Tese (Doutorado) - Instituto Nacional de Pesquisas da Amazônia, Fundação Universidade do Amazonas. 
ROSSI, M.M.; MATIOLI, J.C.; BUENO, V.H.P. Principais espécies de moscas-dasfrutas (Diptera: Tephritidae) e sua dinâmica populacional em pessegueiros na região de Caldas, sul de Minas Gerais. Revista de Agricultura, v.63, n.3, p.329-342, 1988.

SALES, F.J.M.; GONÇALVES, N.G.G. Ceará. In: MALAVASI, A.; ZUCCHI, R.A. (Ed.). Moscas-das-frutas de importância econômica no Brasil: conhecimento básico e aplicado. Ribeirão Preto: Holos, 2000. cap.30, p.217-222.

SALLES, L.A.B. Bioecologia e controle de moscas-das-frutas Sul-americana. Pelotas: EMBRAPA, CPACT, 1995. 58p.

SALLES, L.A.B. Parasitismo de Anastrepha fraterculus (Wied.) (Diptera: Tephritidae) por Hymenoptera, na região de Pelotas, RS. Pesquisa Agropecuária Brasileira, v.31, n.11, p.769-774, 1996.

SILVA, N.M. Levantamento e análise faunística de moscas-das-frutas (Diptera; Tephritidae) em quatro locais do Estado do Amazonas. Piracicaba, 1993. 152p. Tese (Doutorado) - Escola Superior de Agricultura “Luiz de Queiroz”, Universidade de São Paulo.

SILVA, N.M.; SILVEIRA NETO, S.; ZUCCHI, R.A. The natural host plants of Anastrepha in the State of Amazonas, Brazil. In: McPHERON, B.A.; STECK, G.J. (Ed.). Fruit fly pests: a world assessment of their biology and management. Delray Beach: St. Lucie Press, 1996. p.353-357.

SILVEIRA NETO, S.; NAKANO, O.; BARBIN, D.; VILA NOVA, N.A. Manual de ecologia dos insetos. São Paulo: Agronômica Ceres, 1976. 420p. 
SIVINSKI, J. The influence of host fruit morphology on parasitization rates in the Caribbean fruit fly, Anastrepha suspensa. Entomophaga, v.36, n.3, p.447-454, 1991.

SIVINSKI, J.; ALUJA, M.; LÓPEZ, M. Spatial and temporal distributions of parasitoids of Mexican Anastrepha species (Diptera: Tephritidae) within the canopies of fruit tress. Annals of the Entomological Society of America, v.90, n.5, p.604-618, 1997.

SIVINSKI, J.; ALUJA, M.; HOLLER, T.; EITAM, A. Phenological comparison of two braconid parasitoids of the Caribbean fruit fly (Diptera: Tephritidae). Environmental Entomology, v.27, n.2, p.360-365, 1998.

SIVINSKI, J.; CALKINS, C.O.; BARANOWSKI, R.; HARRIS, D.; BRAMBILA, J.; DIAZ, J.; BURNS, R.E.; HOLLER, T.; DODSON, G. Suppression of Caribbean fruit fly (Anastepha suspensa (Loew) Diptera: Tephritidae) population through augmented releases of the parasitoid Diachasmimorpha longicaudata (Asmead) (Hymenoptera: Braconidae). Biological Control, v.6, p.177-185, 1996.

SOTO-MANITIU, J.; JIRÓN, L.F. Studies on the population dynamics of the fruit flies, Anastrepha (Diptera: Tephritidae), associated with mango (Mangifera indica L.) in Costa Rica. Tropical Pest Management, v.35, p.425-427, 1989.

SOUTHWOOD, T.R.E. Ecological methods: with particular reference to the study of insect populations. London: Chapman \& Hall, 1995. 524p.

SOUZA FILHO, M.F. Biodiversidade de moscas-das-frutas (Diptera: Tephritidae) e seus parasitóides (Hymenoptera) em plantas hospedeiras no Estado de São Paulo. Piracicaba, 1999. 173p. Dissertação (Mestrado) - Escola Superior de Agricultura “Luiz de Queiroz”, Universidade de São Paulo. 
SUGAYAMA, R.L. Anastrepha fraterculus (Wiedemann) (Diptera: Tephritidae) na região produtora de maçãs do Rio Grande do Sul: Relação com seus inimigos naturais e potencial para o controle biológico. São Paulo, 2000. 117p. Tese (Doutorado) - Instituto de Biociências, Universidade de São Paulo.

TAN, K.; SERIT, M. Adult population dynamics of Bactrocera dorsalis (Diptera: Tephritidae) in relation to host phenology and weather in two villages of Penang Island, Malaysia. Environmental Entomology, v.23, p. 267-275, 1994.

UCHOA-FERNANDES, M.A. Biodiversidade de moscas frugívoras (Diptera, Tephritoidea), seus frutos hospedeiros e parasitóides (Hymenoptera) em áreas de cerrado do Estado de Mato Grosso do Sul. Piracicaba, 1999. 104p. Tese (Doutorado) - Escola Superior de Agricultura "Luiz de Queiroz”, Universidade de São Paulo.

UCHOA-FERNANDES, M.A.; OLIVEIRA, I.; MOLINA, R.M.S.; ZUCCHI, R.A. Species diversity of frugivorous flies (Diptera: Tephritoidea) from hosts in the cerrado of the State of Mato Grosso do Sul, Brazil. Neotropical Entomology, v.31, n.4, p.515-524, 2002.

URAMOTO, K. Biodiversidade de moscas-das-frutas do gênero Anastrepha (Diptera, Tephritidae) no campus Luiz de Queiroz, Piracicaba, São Paulo. Piracicaba, 2002, 85p. Dissertação (Mestrado) - Escola Superior de Agricultura "Luiz de Queiroz", Universidade de São Paulo.

VAN DRIESCHE, R.G.; BELLOWS, T.S. Biological control. New York: Chapman \& Hall, 1996. 539p. 
VARGAS, R.I.; STARK, J.D.; UCHIDA, G.K.; PURCELL, M. Opiine parasitoids (Hymenoptera: Braconidae) of oriental fruit fly (Diptera: Tephritidae) on Kauai island, Hawaii: island wide relative abundance and parasitism rates in wild and orchards guava habitats. Environmental Entomology, v.22, n.1, p.246-253, 1993.

VELOSO, V.R.S. Dinâmica populacional de Anastrepha spp. E Ceratitis capitata (Wied., 1824) (Diptera, Tephritidae) nos cerrados de Goiás. Goiana, 1997. 115p. Tese (Doutorado) - Universidade Federal de Goiás.

VELOSO, V.R.S.; FERNANDES, P.M.; ZUCCHI, R.A. Goiás. In: MALAVASI, A.; ZUCCHI, R.A. (Ed.). Moscas-das-frutas de importância econômica no Brasil: conhecimento básico e aplicado. Ribeirão Preto: Holos, 2000. cap.36, p.247-252.

WALDER, J.M.M.; COSTA, M.L.Z.; LOPES, L.A. Alguns aspectos biológicos do parasitóide Diachasmimorpha longicaudata (Ashmead) (Hymenoptera: Braconidae) criado sobre larvas de Ceratitis capitata (Wied., 1824) (Diptera: Tephritidae). In: CONGRESSO BRASILEIRO DE ENTOMOLOGIA, 15., Salvador, 1997. Resumos. Salvador: SEB, 1997. p.72.

WHARTON, R.A. Parasitoids of fruit-infesting Tephritidae - how to attack a concealed host. In: INTERNATIONAL CONGRESS OF ENTOMOLOGY, 20., Firense, 1996. Resumos. Firense: s.ed., 1996. p.665.

WHARTON, R.A. Subfamily Opiinae. In: WHARTON, R.A.; MARSH, P.M.; SHARKEY, M.J. (Ed.). Manual of the new world genera of the family Braconidae (Hymenoptera). Lawrence: Allen Press, 1997. p.379-395. 
WHARTON, R.A.; MARSH, P.M. New World Opiinae (Hymenoptera: Braconidade) parasitic on Tephritidae (Diptera). Journal of the Washington Academy of Sciences, v.68, n.4, p.147-167, 1978.

WHARTON, R.A.; GILSTRAP, F.E. Key to and status of opine braconid (Hymenoptera) parasitoids used in biological control of Ceratitis and Dacus s. $l$. (Diptera: Tephritidae). Annals of the Entomological Society of America, v.76, n.4, p.721-742, 1983.

WHARTON, R.A.; GILSTRAP, F.E.; RHODE, R.H.; FISCHEL-M, M.; HART, W.G. Hymenopterous egg-pupal and larval-pupal parasitoids of Ceratitis capitata and Anastrepha spp. (Dip.: Tephritidae) in Costa Rica. Entomophaga, v.26, p.285-290, 1981.

WHITE, I.A.; ELSON-HARRIS, M.M. Fruit flies of economic significance: their identification and bionomics. Wallingford: CAB International, 1994. 601p.

WONG, T.T.Y.; MOCHIZUKI, N.; NISHIMOTO, J.I. Seasonal abundance of parasitoids of the Mediterranean and Oriental fruit flies (Diptera: Tephritidae) in the Kula Area of Maui, Hawaii. Envoronmental Entomology, n. 13, p.140-145, 1984.

ZAHLER, P.M. Moscas-das-frutas em três pomares do Distrito Federal: levantamento de espécies e flutuação populacional. Ciência e Cultura, v.42, n.2, p.177-182, 1990.

ZAHLER, P.M. Moscas-das-frutas (Diptera, Tephritidae) em dois pomares de manga (Mangifera indica) do Distrito Federal: levantamento de espécies e flutuação populacional. Revista Ceres, v.38, n.217, p.206-216, 1991. 
ZUCCHI, R.A. Taxonomia. In: MALAVASI, A.; ZUCCHI, R.A. (Ed.). Moscas-dasfrutas de importância econômica no Brasil: conhecimento básico e aplicado. Ribeirão Preto: Holos, 2000a. cap.1, p.13-24.

ZUCCHI, R.A. Espécies de Anastrepha, sinonímias, plantas hospedeiras e parasitóides. In: MALAVASI, A.; ZUCCHI, R.A. (Ed.). Moscas-das-frutas de importância econômica no Brasil: conhecimento básico e aplicado. Ribeirão Preto: Holos, 2000b. cap.4, p.41-48.

ZUCCHI, R.A. Mosca-do-mediterrâneo, Ceratitis capitata (Diptera: Tephritidae). In: VILELA, E.F.; ZUCCHI, R.A.; CANTOR, F. (Ed.). Histórico e impacto das pragas introduzidas no Brasil. Ribeirão Preto: Holos, 2001. cap.1, p.15-22. 
APÊNDICES 
APÊNDICE 1. Quantidade e peso de goiabas coletadas e infestadas, número de pupários de moscas-das-frutas e índices de infestação no pomar de Jaíba, MG. (maio/1999 a abril/2001 e maio/2002 a agosto/2003)

\begin{tabular}{|c|c|c|c|c|c|c|c|}
\hline \multirow{2}{*}{ Mês/ano } & \multicolumn{2}{|c|}{ Frutos coletados } & \multicolumn{2}{|c|}{ Frutos infestados } & \multirow{2}{*}{ Pupários } & \multicolumn{2}{|c|}{ Índices de Infestação } \\
\hline & Número & Peso (kg) & Número & Peso (kg) & & F.I. $(\%)^{1}$ & I.I. $^{2}$ \\
\hline mai/99 & 197 & 25,12 & 40 & 5,10 & 81 & 20,30 & 15,88 \\
\hline jun/99 & 212 & 34,37 & 2 & 0,32 & 3 & 0,94 & 9,38 \\
\hline jul/99 & 33 & 4,47 & 5 & 0,68 & 7 & 15,15 & 10,29 \\
\hline ago/99 & 16 & 1,61 & 0 & 0 & 0 & 0 & 0 \\
\hline set/99 & 55 & 4,67 & 0 & 0 & 0 & 0 & 0 \\
\hline out/99 & 142 & 16,27 & 62 & 7,11 & 72 & 43,66 & 10,13 \\
\hline nov/99 & 97 & 11,9 & 0 & 0 & 0 & 0 & 0 \\
\hline $\mathrm{dez} / 99$ & 107 & 12,06 & 16 & 1,80 & 37 & 14,95 & 20,56 \\
\hline $\mathrm{jan} / 00$ & 97 & 9,8 & 50 & 5,05 & 233 & 51,55 & 46,14 \\
\hline $\mathrm{fev} / 00$ & 39 & 3,57 & 21 & 1,92 & 54 & 53,85 & 28,13 \\
\hline $\mathrm{mar} / 00$ & 35 & 4,56 & 20 & 2,60 & 193 & 57,14 & 74,23 \\
\hline abr/00 & 59 & 7,5 & 48 & 6,10 & 419 & 81,36 & 68,69 \\
\hline mai/00 & 57 & 7,2 & 52 & 6,57 & 727 & 91,23 & 110,65 \\
\hline jun/00 & 81 & 13,13 & 75 & 12,16 & 753 & 92,59 & 61,92 \\
\hline $\mathrm{jul} / 00$ & 89 & 12,05 & 71 & 9,61 & 662 & 79,78 & 68,89 \\
\hline ago/00 & 82 & 8,27 & 61 & 6,16 & 641 & 74,39 & 104,06 \\
\hline set/00 & 90 & 7,65 & 79 & 6,71 & 718 & 87,78 & 107,00 \\
\hline out/00 & 37 & 4,24 & 28 & 3,21 & 273 & 75,68 & 85,05 \\
\hline nov/00 & 24 & 2,95 & 9 & 1,10 & 17 & 37,50 & 15,45 \\
\hline $\mathrm{dez} / 00$ & 123 & 13,86 & 76 & 8,57 & 381 & 61,79 & 44,46 \\
\hline jan/01 & 25 & 2,53 & 19 & 1,92 & 78 & 76,00 & 40,63 \\
\hline $\mathrm{fev} / 01$ & 14 & 1,28 & 11 & 1,01 & 86 & 78,57 & 85,15 \\
\hline
\end{tabular}


APÊNDICE 1. Quantidade e peso de goiabas coletadas e infestadas, número de pupários de moscas-das-frutas e índices de infestação no pomar de Jaíba, MG. (maio/1999 a abril/2001 e maio/2002 a agosto/2003)

\begin{tabular}{lrrrrrrr}
\hline \multirow{2}{*}{ Mês/ano } & \multicolumn{2}{c}{ Frutos coletados } & \multicolumn{2}{c}{ Frutos infestados } & \multirow{2}{*}{ Pupários } & \multicolumn{2}{c}{ Índices de Infestação } \\
\cline { 2 - 4 } & Número & Peso (kg) & Número & Peso (kg) & & F.I. (\%) ${ }^{1}$ & I.I. $^{2}$ \\
\hline mar/01 & 38 & 4,95 & 26 & 3,39 & 43 & 68,42 & 12,68 \\
abr/01 & 68 & 8,65 & 38 & 4,83 & 58 & 55,88 & 12,01 \\
mai/02 & 97 & 12,43 & 19 & 2,55 & 91 & 19,59 & 35,70 \\
jun/02 & 71 & 11,51 & 28 & 4,32 & 45 & 39,44 & 10,42 \\
jul/02 & 95 & 12,86 & 11 & 1,71 & 55 & 11,58 & 32,19 \\
ago/02 & 51 & 5,15 & 9 & 1,10 & 45 & 17,65 & 40,88 \\
set/02 & 110 & 9,35 & 15 & 1,31 & 47 & 13,64 & 35,76 \\
out/02 & 109 & 12,49 & 48 & 5,93 & 132 & 44,04 & 22,28 \\
nov/02 & 91 & 11,17 & 41 & 5,36 & 129 & 45,05 & 24,05 \\
dez/02 & 52 & 5,86 & 8 & 1,40 & 100 & 15,38 & 71,33 \\
jan/03 & 98 & 9,90 & 33 & 4,50 & 104 & 33,67 & 23,10 \\
fev/03 & 93 & 8,52 & 15 & 1,23 & 28 & 16,13 & 22,81 \\
mar/03 & 98 & 12,76 & 40 & 5,02 & 113 & 40,82 & 22,50 \\
abr/03 & 118 & 15,00 & 65 & 8,58 & 240 & 55,08 & 27,97 \\
mai/03 & 99 & 17,12 & 50 & 8,61 & 163 & 50,51 & 18,92 \\
jun/03 & 89 & 13,57 & 65 & 9,95 & 394 & 73,03 & 39,61 \\
jul/03 & 103 & 9,64 & 55 & 7,21 & 244 & 53,40 & 33,85 \\
ago/03 & 38 & 1,71 & 4 & 0,40 & 7 & 10,53 & 17,34 \\
\hline 1 & & & & & &
\end{tabular}

${ }^{1}$ Frutos infestados

${ }^{2}$ Intensidade de infestação 
APÊNDICE 2. Quantidade e peso de goiabas coletadas e infestadas, número de pupários de moscas-das-frutas e índices de infestação no pomar de Nova Porteirinha, MG. (maio/1999 a abril/2001 e maio/2002 a agosto/2003)

\begin{tabular}{|c|c|c|c|c|c|c|c|}
\hline \multirow{2}{*}{ Mês/ano } & \multicolumn{2}{|c|}{ Frutos coletados } & \multicolumn{2}{|c|}{ Frutos infestados } & \multirow{2}{*}{ Pupários } & \multicolumn{2}{|c|}{ Índices de Infestação } \\
\hline & Número & Peso (kg) & Número & $\overline{\text { Peso }(\mathrm{kg})}$ & & F.I. $(\%)^{1}$ & I.I. $^{2}$ \\
\hline mai/99 & 42 & 6,92 & 25 & 4,12 & 85 & 59,52 & 20,63 \\
\hline jun/99 & 20 & 3,20 & 12 & 1,92 & 71 & 60,00 & 36,98 \\
\hline jul/99 & 20 & 3,50 & 9 & 1,59 & 33 & 45,00 & 20,75 \\
\hline ago/99 & 35 & 4,80 & 6 & 0,82 & 26 & 17,14 & 31,71 \\
\hline set/99 & 87 & 16,06 & 9 & 1,66 & 27 & 10,34 & 16,27 \\
\hline out/99 & 32 & 4,96 & 10 & 1,55 & 50 & 31,25 & 32,26 \\
\hline nov/99 & 27 & 4,24 & 4 & 0,63 & 7 & 14,81 & 11,11 \\
\hline dez/99 & 4 & 0,66 & 4 & 0,66 & 15 & 100,00 & 22,73 \\
\hline $\mathrm{jan} / 00$ & 3 & 0,16 & 0 & 0 & 0 & 0 & 0 \\
\hline fev/00 & 3 & 0,27 & 0 & 0 & 0 & 0 & 0 \\
\hline $\mathrm{mar} / 00$ & 32 & 4,44 & 17 & 2,36 & 43 & 53,13 & 18,22 \\
\hline $\mathrm{abr} / 00$ & 84 & 13,64 & 54 & 8,77 & 327 & 64,29 & 37,29 \\
\hline mai/00 & 48 & 7,91 & 32 & 5,27 & 148 & 66,67 & 28,08 \\
\hline jun/00 & 16 & 2,56 & 9 & 1,44 & 76 & 56,25 & 52,78 \\
\hline $\mathrm{jul} / 00$ & 9 & 1,59 & 5 & 0,89 & 18 & 55,56 & 20,22 \\
\hline ago/00 & 13 & 1,78 & 6 & 0,82 & 10 & 46,15 & 12,20 \\
\hline set/00 & 26 & 4,80 & 16 & 2,95 & 44 & 61,54 & 14,92 \\
\hline out/00 & 2 & 0,31 & 0 & 0 & 0 & 0 & 0 \\
\hline nov/00 & 20 & 3,14 & 17 & 2,67 & 105 & 85,00 & 39,33 \\
\hline $\mathrm{dez} / 00$ & 27 & 4,46 & 15 & 2,48 & 260 & 55,56 & 104,84 \\
\hline jan/01 & 58 & 3,11 & 27 & 1,45 & 224 & 46,55 & 154,48 \\
\hline fev/01 & 24 & 2,13 & 12 & 1,07 & 64 & 50,00 & 59,81 \\
\hline
\end{tabular}


APÊNDICE 2. Quantidade e peso de goiabas coletadas e infestadas, número de pupários de moscas-das-frutas e índices de infestação no pomar de Nova Porteirinha, MG. (maio/1999 a abril/2001 e maio/2002 a agosto/2003)

\begin{tabular}{|c|c|c|c|c|c|c|c|}
\hline \multirow{2}{*}{ Mês/ano } & \multicolumn{2}{|c|}{ Frutos coletados } & \multicolumn{2}{|c|}{ Frutos infestados } & \multirow{2}{*}{ Pupários } & \multicolumn{2}{|c|}{ Índices de Infestação } \\
\hline & Número & Peso (kg) & Número & Peso (kg) & & F.I $(\%)^{1}$ & I.I. $^{2}$ \\
\hline $\begin{array}{l}\mathrm{mar} / 01 \\
\end{array}$ & 29 & 4,42 & 16 & 2,44 & 59 & 55,17 & 24,18 \\
\hline $\mathrm{abr} / 01$ & 81 & 13,16 & 52 & 8,45 & 249 & 64,20 & 29,47 \\
\hline mai/02 & 0 & 0 & 0 & 0 & 0 & 0 & 0 \\
\hline jun/02 & 0 & 0 & 0 & 0 & 0 & 0 & 0 \\
\hline jul/02 & 83 & 14,7 & 4 & 0,54 & 5 & 4,82 & 9,26 \\
\hline ago/02 & 90 & 12,33 & 3 & 0,32 & 5 & 3,33 & 15,63 \\
\hline set/02 & 110 & 20,30 & 7 & 1,29 & 18 & 6,36 & 13,95 \\
\hline out/02 & 120 & 18,58 & 28 & 6,61 & 91 & 23,33 & 13,77 \\
\hline nov/02 & 119 & 18,71 & 32 & 5,82 & 56 & 26,89 & 9,62 \\
\hline $\mathrm{dez} / 02$ & 137 & 22,62 & 51 & 9,02 & 241 & 37,23 & 26,72 \\
\hline $\mathrm{jan} / 03$ & 89 & 4,77 & 17 & 1,03 & 34 & 19,10 & 33,01 \\
\hline $\mathrm{fev} / 03$ & 25 & 2,22 & 0 & 0 & 0 & 0 & 0 \\
\hline mar/03 & 113 & 15,67 & 45 & 7,50 & 277 & 39,82 & 36,93 \\
\hline $\mathrm{abr} / 03$ & 120 & 19,48 & 49 & 9,33 & 254 & 40,83 & 27,22 \\
\hline mai/03 & 99 & 16,32 & 22 & 3,53 & 36 & 22,22 & 10,20 \\
\hline jun/03 & 90 & 14,42 & 36 & 5,61 & 87 & 40,00 & 15,51 \\
\hline jul/03 & 105 & 15,38 & 43 & 7,00 & 129 & 40,95 & 18,43 \\
\hline ago/03 & 17 & 1,87 & 2 & 0,22 & 3 & 11,76 & 13,64 \\
\hline
\end{tabular}

${ }^{1}$ Frutos infestados

${ }^{2}$ Intensidade de infestação 